$\frac{355}{5.12}-9 ? 9.5 .0$

Ehergy Technology Division ANL-96/18

Energy Technology Division Energy Technology Division Energy Technology Division Energy Technology Division Energy Technology Division Energy Technology Division Energy Technology Division Energy Technology Division Energy Technology Division Energy Technology Division Energy Technology Division Energy Technology Division Energy Technology Division Energy Technology Division Energy Technology Division Energy Technology Division Energy Technology Division Energy Technology Division Energy Technology Division Energy Technology Division Energy Technology Division Energy Technology Division Energy Technology Division Energy Technology Division Energy Technology Division Energy Technology Division Energy Technology Division Energy Technology Division Energy Technology Division Energy Technology Division Energy Technology Division Energy Technology Division Energy Technology Division

\title{
Dynamic Stability of Repulsive-Force Maglev Suspension Systems
}

\author{
by Y. Cai, D. M. Rote, T. M. Mulcahy, \\ Z. Wang, S. S. Chen, and S. Zhu
}

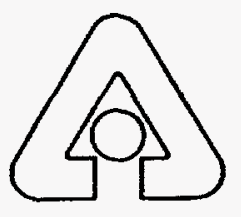

Argonne National Laboratory, Argonne, Illinois 60439 operated by The University of Chicago

for the United States Department of Energy under Contract W-31-109-Eng-38

Energy Tachnology Division Energy Technology Division Energy Technology Division Energy Technology Division Energy Technology Division Energy Technology Division Energy Technology Division Energy Technology Division 
Argonne National Laboratory, with facilities in the states of Illinois and Idaho, is owned by the United States government, and operated by The University of Chicago under the provisions of a contract with the Department of Energy.

\section{DISCLAIMER}

This report was prepared as an account of work sponsored by an agency of the Lnited States Government. Neither the United States Government nor any agency thereof, nor any of their employees, makes any warranty, express or implied, or assumes any legal liability or responsibility for the accuracy, completeness, or usefulness of any information, apparatus, product, or process disclosed, or represents that its use would not infringe privately owned rights. Reference herein to any specific commercial product, process, or service by trade name, trademark, manufacturer, or otherwise, does not necessarily constitute or imply its endorsement, recommendation, or favoring by the United States Government or any agency thereof. The views and opinions of authors expressed herein do not necessarily state or reflect those of the United States Government or any agency thereof.

Reproduced from the best available copy.

Available to DOE and DOE contractors from the

Office of Scientific and Technical Information

P.O. Box 62

Oak Ridge, TN 37831

Prices available from (423) 576-8401

Available to the public from the

National Technical Information Service

U.S. Department of Commerce

5285 Port Royal Road

Springfield. VA 22161 


\section{Dynamic Stability of Repulsive-Force Maglev Suspension Systems}

by

Y. Cai, D. M. Rote, ${ }^{*}$ T. M. Mulcahy, Z. Wang,* S. S. Chen, and S. Zhu

Energy Technology Division

November 1996

Work supported by U. S. Army Corps of Engineers and the Federal Railroad Administration through interagency agreements E8691R001 and DTFR53-91-X00018, respectively, with the U.S. Department of Energy, and by Argonne National Laboratory

${ }^{*}$ Center for Transportation Research

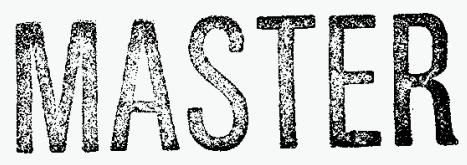





\section{DISCLAMMER}

Portions of this document may be illegible in electronic image products. Images are produced from the best available original document. 


\section{Contents}

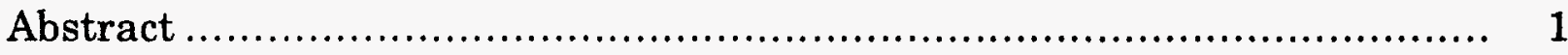

1 Introduction ........................................................................ 1

1.1 Tests of Dynamics of Large-Scale Vehicles on Linear Test Tracks...... 2

1.2 Analytical and Laboratory-Scale Investigations of Stability and Dynamics of Magnetically Suspended Systems.............................. 5

1.3 Nature of the Magnetic Forces and Vehicle Dynamics Work at ANL ... 10

2 Measurement of Magnetic Forces ........................................... 13

2.1 Experimental Setup for Measuring Magnetic Forces ................... 13

2.2 Results and Discussion of Measured Magnetic Forces.................. 16

2.3 Magnetic Force Computations ............................................. 20

2.4 Measuring Magnetic Forces of Guidance Magnets..................... 30

3 Dynamic Stability Experiments........................................... 31

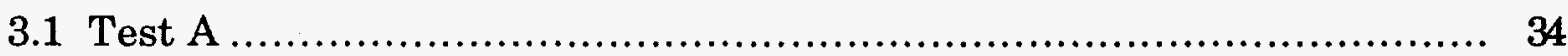

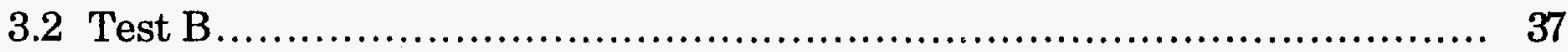

4 Numerical Simulation of Maglev Vehicles with Five DOF .................. 42

4.1 Theoretical Aspects ....................................................... 43

4.2 Computer Code for Maglev Systems.................................... 46

4.3 Numerical Simulation of Test A and Comparison with Experimental Results.................................................................... 47

4.4 Numerical Simulation of Test B and Comparison with Experimental Results

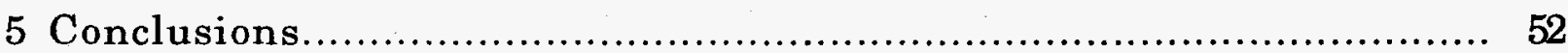

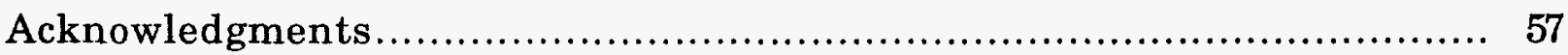

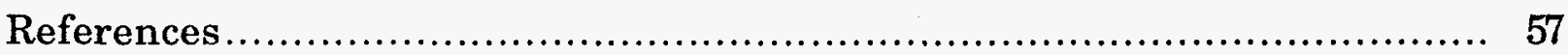

Appendix: Magnetic Force Data from Experimental Measurements........... 63 


\section{Figures}

1 Experimental setup of rotating wheel with aluminum L-shaped ring mounted on top

2 Experimental apparatus for measuring magnetic force 15

3 Schematic diagram of apparatus used to measure magnetic forces on L-shaped aluminum sheet guideway

4 Measured lift magnetic force, for various wheel surface velocities $V$, as a function of lift height and gap $\mathrm{Y}^{*}$

5 Measured guidance magnetic force, for various wheel surface velocities $\mathrm{V}$, as a function of lift height and gap $\mathrm{Y}^{*}$

6 Measured drag magnetic force, for various wheel surface velocities $V$, as a function of lift height and gap $\mathrm{Y}^{*}$

7 Measured lift magnetic force, for various values of $\mathrm{h}$ and $\mathrm{Y}^{*}$, as a function of velocity

8 Measured guidance magnetic force, for various values of $h$ and $\mathrm{Y}^{*}$, as a function of velocity

9 Measured drag magnetic force, for various values of $h$ and $\mathrm{Y}^{*}$, as a function of velocity

10 Magnet and equivalent coil

11 Measured and MAGFORCE-calculated lift forces when $\mathrm{Y}^{*}=12.7 \mathrm{~mm}$

12 Measured and MAGFORCE-calculated guidance forces when $\mathrm{Y}^{*}=12.7 \mathrm{~mm}$

13 Measured and MAGFORCE-calculated drag forces when $\mathrm{Y}^{*}=12.7 \mathrm{~mm}$

14 Measured and MAGFORCE-calculated lift forces when $\mathrm{Y}^{*}=5 \mathrm{~mm} \ldots \ldots 24$ 
15 Measured and MAGFORCE-calculated drag forces when $\mathrm{Y}^{*}=5 \mathrm{~mm} \ldots$

16 Alternative magnet and equivalent coil

17 Measured and MAGFORCE-calculated lift forces when $\mathrm{Y}^{*}=12.7 \mathrm{~mm}$

18 Measured and MAGFORCE-calculated guidance forces when $\mathrm{Y}^{*}=12.7 \mathrm{~mm}$ 26

19 Measured and MAGFORCE-calculated drag forces when $\mathrm{Y}^{*}=12.7 \mathrm{~mm}$

20 Measured and ELEKTRA-calculated lift, guidance, and drag forces when $\mathrm{Y}^{*}=12.7 \mathrm{~mm}$ 27

21 Measured and ELEKTRA-calculated lift forces when $\mathrm{Y}^{*}=5 \mathrm{~mm}$. 28

22 Measured and ELEKTRA-calculated guidance forces when $\mathrm{Y}^{*}=5 \mathrm{~mm}$

23 Measured and ELEKTRA-calculated drag forces when $\mathrm{Y}^{*}=5 \mathrm{~mm} \ldots \ldots$. 28

24 Measured and ELEKTRA-calculated lift forces when $\mathrm{h}=7 \mathrm{~mm}$ 29

25 Measured and ELEKTRA-calculated guidance forces when $\mathrm{h}=7 \mathrm{~mm}$

26 Measured and ELEKTRA-calculated drag forces when $\mathrm{h}=7 \mathrm{~mm}$

27 Guidance magnet on aluminum sheet guideway. 30

28 Measured lift and drag magnetic forces of guidance magnet as a function of velocity

29 Schematic diagram of experimental apparatus for testing maglev dynamic stability 32

30 Vehicle model with four levitation magnets for Test $\mathrm{A}$ 33 


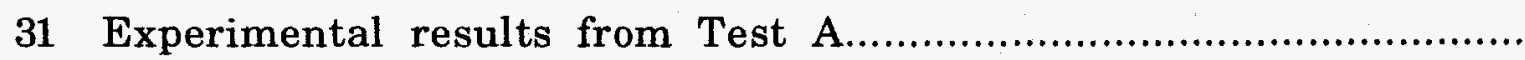

32 Vehicle model with four levitation and four guidance magnets

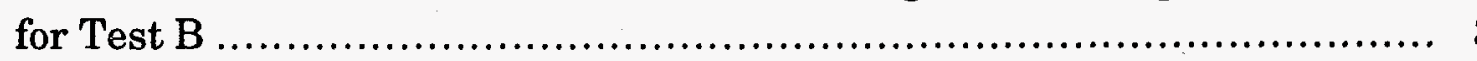

33 Accelerometer arrangement for vehicle model in Test B.................... 39

34 Experimental results from Test B ..................................... 41

35 Displacement components of a maglev system ......................... 43

36 Experimental results from Case 1 in Test A............................ 47

37 Simulation results of lateral and vertical mass center displacement in Test $A$ at various vehicle speeds

38 Simulated time histories of lateral and vertical displacement of vehicle that contacts side wall of guideway.

39 Simulation results of displacement and rotation in Test A when vehicle speed $=20 \mathrm{~m} / \mathrm{s}$.

40 Experimental results when guidance magnet gap $=13.5 \mathrm{~mm}$ in Test B

41 Simulation results of displacement and rotation in Test $B$ when vehicle speed $=15 \mathrm{~m} / \mathrm{s}$.

42 Simulation results of displacement and rotation in Test B when vehicle speed $=20 \mathrm{~m} / \mathrm{s}$.

43 Simulation results of displacement and rotation in Test B when vehicle speed $=25 \mathrm{~m} / \mathrm{s}$.

44 Simulation results of displacement and rotation in Test B when vehicle speed $=30 \mathrm{~m} / \mathrm{s}$.

45 Comparison of vehicle guidance and drag forces as a function of velocity

46 Comparison of vertical gap and drag force as a function of velocity when vehicle is at equilibrium 


\section{Tables}

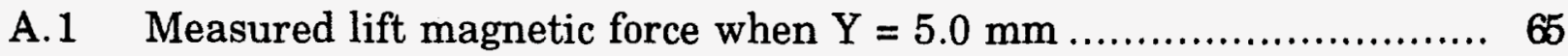

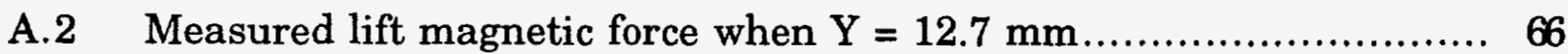

A.3 Measured lift magnetic force when $\mathrm{h}=7.0 \mathrm{~mm} \ldots \ldots \ldots \ldots \ldots \ldots \ldots \ldots \ldots \ldots$

A.4 Measured lift magnetic force when $\mathrm{h}=12.7 \mathrm{~mm} \ldots \ldots \ldots \ldots \ldots \ldots \ldots \ldots 68$

A.5 Measured guidance magnetic force when $\mathrm{Y}=5.0 \mathrm{~mm} \ldots \ldots \ldots \ldots \ldots \ldots$

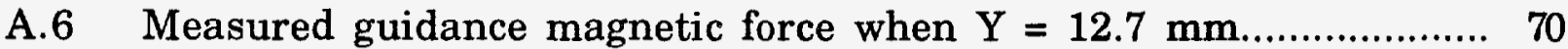

A.7 Measured guidance magnetic force when $\mathrm{h}=7.0 \mathrm{~mm} \ldots \ldots \ldots \ldots \ldots \ldots . \ldots 1$

A.8 Measured guidance magnetic force when $\mathrm{h}=12.7 \mathrm{~mm} \ldots \ldots \ldots \ldots \ldots .73$

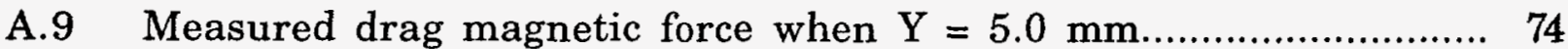

A.10 Measured drag magnetic force when $\mathrm{Y}=12.7 \mathrm{~mm} \ldots \ldots \ldots \ldots \ldots \ldots \ldots . \ldots \ldots$

A.11 Measured drag magnetic force when $\mathrm{h}=7.0 \mathrm{~mm} \ldots \ldots \ldots \ldots \ldots \ldots \ldots \ldots$

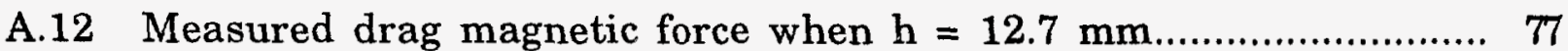

A.13 Measured lift and drag magnetic force for guidance magnet .......... 78 


\section{Dynamic Stability of Repulsive-Force Maglev Suspension Systems}

by

Y. Cai, D. M. Rote, T. M. Mulcahy, Z. Wang, S. S. Chen, and S. Zhu

\section{Abstract}

This report summarizes the research performed on maglev vehicle dynamic stability at Argonne National Laboratory during the past few years. It also documents both measured and calculated magnetic-force data. Because dynamic instability is not acceptable for any commercial maglev system, it is important to consider this phenomenon in the development of all maglev systems. This report presents dynamic stability experiments on maglev systems and compares the results with predictions calculated by a nonlinear-dynamics computer code. Instabilities of an electrodynamic-suspension system type vehicle model were obtained by experimental observation and computer simulation of a five-degree-offreedom maglev vehicle moving on a guideway that consists of a pair of L-shaped aluminum conductors attached to a rotating wheel. The experimental and theoretical analyses developed in this study identify basic stability characteristics and future research needs of maglev systems.

\section{Introduction}

The subject of vehicle dynamics and the need to satisfy ride quality requirements have long been recognized as crucial to the commercial success of passenger-carrying transportation systems. Design concepts for maglev systems are no exception. Early maglev investigators and designers were well aware of the importance of ride quality and took care to ensure that their designs would meet acceptable ride quality standards. More recently, the System Concept Definition program sponsored under the auspices of the U.S. National Maglev Initiative, required concept designers to meet a detailed set of ride quality specifications (Coltman 1992).

In contrast, the subject of dynamic stability of electrodynamic suspension (EDS) systems (i.e., those that use repulsive forces between magnets and induced eddy currents), which has obvious implications for system safety and cost, has not 
received nearly as much attention. This may be due in part to the difficulty of conducting sufficiently accurate computer simulations, or to not having the capability to sort out the many complex factors that influence the dynamics of magnetically suspended vehicles on test tracks. In lieu of conducting complete theoretical and/or experimental studies, there has been a tendency to adopt the pragmatic design approach of adding either active or passive mechanisms to damp out or suppress undesirable motion, including any instabilities that might arise. (This is not an unreasonable approach because many suspension system designs require some degree of added motion control to achieve the desired ride quality.) Not surprisingly, the consistency of the conclusions reached by various investigators regarding the dynamic stability of EDS systems has not always been obvious.

\subsection{Tests of Dynamics of Large-Scale Vehicles on Linear Test Tracks}

Early tests of EDS-type maglev systems that employed either continuoussheet (see e.g., Coffey et al. 1972, 1973, 1974a, 1974b, 1974c; Iwahana et al. 1980) or discrete-coil guideways (references cited below) demonstrated stable performance. The tests performed by Coffey et al., used a vehicle of $\approx 500 \mathrm{~kg}$ that was magnetically supported and guided by four superconducting magnets (SCMs) that interacted with a guideway consisting of two parallel continuous aluminum sheets with L-shaped cross sections. The vehicle was towed up to speeds of $\approx 15 \mathrm{~m} / \mathrm{s}$ (approximately three times lift-off speed) by a continuous cable attached to a power winch. Passive damping was provided for all tests by SCM cryostat walls and damping coils that were placed in the liquid-nitrogen baths of each cryostat between the lift coils and the guideway surfaces. Active damping was added for some tests by mounting normal-conducting coils under the magnet cryostats. The excitation of these coils was controlled by a feedback circuit that contained accelerometers that sensed the vertical acceleration. Response of the vehicle to planned guideway irregularities showed the system to be robustly stable over the tested speed range. Neither the tests nor analytical calculations exhibited instabilities for the tested speed range. During their initial tests, Coffey et al. $(1972,1973,1974 \mathrm{a}, 1974 \mathrm{~b}, 1974 \mathrm{c})$ found that the electrical discontinuities between the sections of continuous aluminum sheet in the guideway caused large periodic vehicle oscillations that tended to mask the effects of planned guideway irregularities that they wanted to investigate. Consequently, to reduce the amplitude of the observed oscillations, they found it desirable to electrically connect the sections of aluminum sheet. 
Iwahana et al. (1980) later performed a series of tests that also used a continuous-sheet guideway. For convenience, they used the same vehicle but with a modified version of the inverted-T-cross-section test track that was originally used to pretest the system installed at Miyazaki in the late 1970s (see below). The test vehicle contained four SCMs for lift and four for propulsion and null-flux guidance. Two rows of horizontally mounted ground coils were replaced with two rows of flat aluminum sheet sections placed end to end. The sheet sections (5397 $\times$ $500 \times 20 \mathrm{~mm}$ ) were not electrically connected. The vertically mounted coils, used for propulsion and null-flux guidance in their earlier pre-Miyazaki design tests, were also used for the "continuous-sheet" guideway tests. The test protocol consisted of acceleration to a running speed, running at constant speed, then deceleration to rest. Lift-off and the drag peak occurred at $\approx 30 \mathrm{~m} / \mathrm{s}$. Three running speeds were reported: 38,50 , and $58 \mathrm{~m} / \mathrm{s}$. No instabilities were reported for these running speeds. However, a coincidental resonance occurred between the length of aluminum-sheet-section and the natural heave motion of the suspension system at $\approx 35 \mathrm{~m} / \mathrm{s}$. This coincidental resonance caused the vehicle vibrations near that speed to be larger (for acceleration, deceleration, and running) than at all other values. There were no reported efforts to remove the electrical discontinuities between the aluminum sheet sections.

Using discrete-coil guideway systems, the Japanese ran tests on various EDS-type systems at the Miyazaki test track starting in the late 1970s. The first configuration was an inverted T-shaped guideway that consisted of horizontally mounted ground or lift coils and vertically mounted propulsion and null-flux guidance coils. This structure was straddled by a 10 -metric-ton (mt) vehicle (MLU-500) that carried separate lift and propulsion SCMs mounted on an inverted-U-shaped support structure. Data on vehicle dynamics were reported in the range of $\approx 21 \mathrm{~m} / \mathrm{s}$ (presumably the lift-off speed) to $83 \mathrm{~m} / \mathrm{s}$ (Yamashita 1978). The amplitudes of all modes decreased with increasing speed throughout the reported speed range and no instabilities were evident. The only passive damping present was the result of eddy currents induced in the guideway coils, the superconducting coils, and cryostat walls (stainless steel inner vessel, $2 \mathrm{~mm}$ thick; aluminum radiation shield, $2 \mathrm{~mm}$ thick; and aluminum outer vessel, $5 \mathrm{~mm}$ thick). In December 1979, that configuration achieved a record speed of 144 $\mathrm{m} / \mathrm{s}$. Vehicle dynamics data were not given in the English language literature, although it was subsequently noted that, due to excessive lateral vibration, the inverted-U-shaped superconducting magnet support structure was broken (Tanaka 1991). 
In the $1980 \mathrm{~s}$, the Miyazaki system was changed to a U-shaped guideway, with horizontally mounted lift coils and sidewall-mounted propulsion and guidance coils. The three-vehicle set (designated MLU-001) fitted inside the U-shaped guideway and carried SCMs mounted vertically so that they faced the sidewall-mounted guideway coils. The guideway coils, the superconducting container walls, and additional damping plates provided passive damping. In addition, because it was intended that these vehicles carry passengers, a secondary suspension system, with passive springs and dampers, was added. Although extensive testing of this vehicle set was carried out, relatively little vehicle dynamics data have been reported in the English language literature. One paper (Tanaka 1982), which contained some results of test runs of the threevehicle set, showed that, although there was no indication of instability in the velocity range of $50-79 \mathrm{~m} / \mathrm{s}$, the vertical and lateral peak-to-peak amplitude varied from $\approx 10$ to $20 \mathrm{~mm}$. Angular rotations remained below $0.6^{\circ}$. An interesting series of tests, reported by Sato et al. (1985), demonstrated the dynamic response of a twovehicle set to deliberately placed guideway discontinuities. The reported tests were carried out at $83 \mathrm{~m} / \mathrm{s}$, which was determined to be near a coincidental resonance between the spacing of the vehicle magnet and the structural natural frequency of the guideway sidewall. The vehicle recovered from responses to the discontinuities within a couple of cycles and did not touch the guideway, and thus proved that, in spite of the resonant condition, the suspension system was robustly stable. Acceleration measured at the top of the sidewall structure, over the speed range of $56-83 \mathrm{~m} / \mathrm{s}$, showed a rapid increase in the sidewall acceleration as the resonance condition was approached at $83 \mathrm{~m} / \mathrm{s}$. The lift-off speed of the vehicles was evidently near $56 \mathrm{~m} / \mathrm{s}$.

In 1987, a new 17-mt vehicle configuration (MLU-002) came on line at Miyazaki that had the suspension magnets placed at the front and rear of the vehicle as opposed to being distributed along its length as was the case for the MLU-001 series. The MLU-002, with a lift-off speed of $\approx 49 \mathrm{~m} / \mathrm{s}$, was tested to speeds of $\approx 106 \mathrm{~m} / \mathrm{s}$ (Fujie 1989). No instabilities have been reported for that vehicle although other problems were experienced, including noticeable yaw motion above the lift-off speed (Rote 1989) and magnet quenches near the maximum speed, caused by excessive heat generated by combined mechanical and electromagnetic resonance. In 1993, a modified vehicle, the MLU-002N, was introduced that alleviated the magnet quench problem and permitted testing up to $\approx 120 \mathrm{~m} / \mathrm{s}$ (near the maximum possible speed for the $7.1-\mathrm{km}$ test track and installed power) (Masada 1993, 1995; Nakashima et al. 1993). In this modified vehicle, the guideway lift conductors were changed from horizontally mounted 
single-coil type to sidewall-mounted null-flux type. Again, no instabilities were reported.

\subsection{Analytical and Laboratory-Scale Investigations of Stability and Dynamics of Magnetically Suspended Systems}

We now turn to the early results of analytical studies of idealized systems and experiments with small-scale models. Somewhat in contrast to the successful field tests of relatively large-scale vehicles on linear test tracks described above, these investigations demonstrated that magnetically levitated and guided systems were intrinsically underdamped against perturbations and formed unstable equilibrium states (Davis and Wilkie 1971; Fink and Hobrecht 1971; Moon 1977; Kolm and Thornton 1973; Borcherts 1982). The term "underdamped" means that, in the absence of enhanced active or passive damping mechanisms, a damping force can be generated only by the "intrinsic magnetic damping" that arises from ohmic losses associated with the eddy currents induced in the guideway conductors and, to a much lesser extent, in the field source windings themselves (see, e.g., Yamaguchi and Fujiwara 1993).

It is well known that the induced eddy currents that produce the levitating force also give rise to the electromagnetic (EM) drag force that must be overcome by a propulsion motor. Inasmuch as this drag force decreases with speed above the peak of the EM drag force, it is natural to expect that the intrinsic magnetic damping would also decrease with speed and, as a consequence, result in underdamped motion or instability (Davis and Wilkie 1971; Fink and Hobrecht 1971). (What is generally regarded as the EM drag force that resists the forward motion of a vehicle is measured under steady-state, i.e., constant-speed, conditions, whereas intrinsic damping pertains to non-steady-state conditions or departures from an equilibrium condition, e.g., sudden position and velocity perturbations in any direction. Therefore, it is not immediately obvious that intrinsic damping should behave in precisely the same way as the EM drag force.)

Ohno et al. (1973) studied the pulsating lift forces in a linear synchronous motor (LSM) and found that these lift forces may cause parametric and combination resonances in addition to heaving and pitching oscillations. Experiments on the Massachusetts Institute of Technology (MIT) magneplane model system (Kolm and Thornton 1973) showed obvious evidence of dynamic instability that was recorded on film in the early 1970s. Pitch-heave and other combinations of modes were observed. The magneplane system model consisted 
of an array of pancake-shaped SCM coils mounted in a cylindrically shaped vehicle that was magnetically levitated, guided, and propelled over an aluminum trough-shaped guideway that contained propulsion windings. They found that the amplitude of oscillations could be reduced by an order of magnitude through feed-back control of the LSM phase relative to the position of the poles of the vehicle's magnets. Unfortunately, little detailed documentation is available and dynamic stability was not discussed in detail.

Much later, in a memorandum, Kolm (1993) commented that "EDS suspensions are inherently stable, but they are also inherently underdamped, and are susceptible to catastrophic oscillations, particularly in rectangular trough configurations." He noted that, in the first series of tests at the Francis Bitter Laboratory at MIT, a $1 / 25$ th-scale magnetically suspended vehicle was towed through various guideways. In the case of a rectangular guideway, the vehicle "...often reached a limiting velocity and then fishtailed along the remaining guideway. Occasionally, the oscillations increased to catastrophic amplitude, causing wall-scraping and even derailment." He explained that the largeamplitude motions were the result of a drag-force-induced yaw instability. When a vehicle approaches a side wall because of some disturbance, a presumed increase in EM drag force will occur and will induce a yaw motion that will proceed until it is overcome by an elastic restoring or guidance force. The latter force will cause the vehicle to rebound in the opposite yaw direction, and if insufficiently damped, will lead to a growing yaw motion until the guideway is contacted.

The foregoing comments by Kolm appear to be in direct conflict with the reported results (see discussion above) of tests on large-scale vehicles on linear guideways. Presumably, Kolm's comments are based largely on his experiments at MIT. Those experiments may have been confined to relatively low speeds, where the EM drag force has a dominant influence (especially for small-scale systems), and also to models with very little enhanced passive damping, i.e., intrinsic magnetic damping may have been the predominant component of the damping force. Hence, it is reasonable to assume that he was working in the region of the parameter space where negative intrinsic magnetic damping could manifest itself. (See following discussion regarding negative intrinsic magnetic damping.)

If this is in fact the case, then it is plausible that the drag-force-induced instability that Kolm spoke of would not be seen in the large-scale vehicle tests. This follows from the fact the test vehicles included a substantial amount of 
enhanced passive damping (the tests were performed mostly above the drag peak) and it follows especially if they also were subject to strong, nonlinear guidance forces that could effectively limit the lateral motion. This line of reasoning is consistent with the observation that the lift-off speed of the Japanese test vehicles at Miyazaki is surprisingly high $(\cong 50 \mathrm{~m} / \mathrm{s})$. It was reported to one of the authors of this report that the reason for this high lift-off speed was insufficient guidance force at lower speeds (Rote 1993).

In 1974, Moon observed that an experimental vehicle model with three degrees of freedom (DOF), floating above a large rotating wheel with a "V"-shaped aluminum rim, exhibited a lateral-roll-yaw instability. Later, Moon (1978) noted that "While full-scale tests have yet to report such instabilities, laboratory model tests of fully levitated and guided models have shown that they can occur under a broad range of guidance track configurations and magnet and vehicle geometries." He and other authors noted that intrinsic magnetic damping has been shown to decrease with speed and can become negative, leading to selfexcited vehicle oscillations (Moon 1977; Davis and Wilkie 1971; Iwamoto et al. 1974; Yamada et al. 1974).

Davis and Wilkie (1971) showed, analytically, that in the absence of other damping mechanisms and coupling to other modes, this negative intrinsic magnetic damping gives rise to an unstable lift force between a moving currentcarrying wire and a conductor sheet. However, the rate of growth of amplitude in the vertical direction was found to be quite slow (on the order of minutes). They cautioned that the only reason intrinsic magnetic damping was significant was because it was the only source of damping being considered. They found that, if aerodynamic damping was included, it could easily satisfy their derived condition for horizontal but not vertical stability. Consequently, they concluded that, even with aerodynamic damping, active damping would be required to achieve vertical stability. They did not consider enhanced passive damping devices such as conductors placed between the field source and the guideway conductor.

Subsequently, the Ford Motor Co. team (Davis et al. 1972) conducted further analytical studies of damping and examined passive damping mechanisms as well. Later, these studies were refined and laboratory experiments on the effects of passive and active damping were carried out by Reitz et al. (1973). Davis et al. (1972) and Reitz et al. (1973) concluded that placing passive conducting plates or tuned coils between the lift magnets (fixed to the magnets) and a sheet guideway did not provide sufficient damping to give acceptable ride quality for the expected guideway roughness. Therefore, it was concluded that either a secondary 
suspension system or some form of active control was needed. In their final report (Philco-Ford Corp. 1975), the Ford team concluded that "for realistic guideway roughness levels, the suspension is not sufficiently soft to meet the ride quality standards without damping, and since there is very little inherent damping in the system, some form of external damping must be provided." After considering various options for active control, they concluded that the preferred baseline control concept for their particular conceptual system design was a combination of positive position (relative to the guideway) feedback with filtered absolute damping (relative to an inertial reference frame).

Fink and Hobrecht (1971) analyzed the case of an infinitely long current loop moving parallel to a conductor sheet with a velocity perpendicular to the length of the loop. They found that all equilibrium positions of the loop were unstable under linear and angular perturbations.

Yamada et al. (1974) were apparently the first investigators to demonstrate the phenomenon of negative intrinsic damping experimentally. They used a pendulum that consisted of a small magnet array supported by a string. The magnet array was free to move normal to the surface of a rotating aluminum cylinder. They reported that, after accounting for aerodynamic and mechanical drag, the remaining drag force was positive at very low rotor speeds $(v<w$, where $\mathrm{w}$ is the characteristic speed defined by $2 / \mu_{\mathrm{o}} \sigma \mathrm{T}$, where $\mu_{\mathrm{o}}$ is the permeability of free space $\left[=4 \pi \times 10^{-7}\right.$ webers per ampere.meter], $\sigma$ is the conductivity in siemens per meter, and $\mathrm{T}$ is the smaller of the cylinder wall thickness and the skin depth) and was negative for high rotor speeds $(\mathrm{v}>\mathrm{w})$.

Moon (1977) reported on a similar experiment, in which he attempted to minimize the air gap changes by using a stiff cantilever beam (natural frequency $\cong 22 \mathrm{~Hz}$ ) to support the magnet. The magnet was replaced by a dummy load to measure the aerodynamic and mechanical damping forces. He also found that the intrinsic negative damping occurred at speeds higher than a critical velocity.

It should be understood that it is quite difficult to measure the negative intrinsic damping force because of the confounding effects of other damping sources, such as aerodynamic and mechanical structural damping and, in the case of superconducting magnets, eddy-current damping in container walls placed between the windings and the guideway conductors. Changes in the air gap can also lead to difficulties of interpretation. 
In his 1978 paper, Moon reported on a laboratory experiment in which he simulated, with a rotating-wheel apparatus, the inverted-T-shaped guideway used at Miyazaki in the late 1970s. Two parallel rows of short aluminum segments with L-shaped cross sections were mounted around the rim of the wheel. Eight lift and eight guidance permanent magnets were mounted on the small model vehicle. Yaw lateral flutter-limit-cycle oscillations and pitch-yaw limit-cycle flutter were observed to occur in vehicles with certain inertial geometries. (Limit cycles arise when growing-amplitude motions are limited by nonlinear forces.) Moon (1978) appears to have been the first investigator to identify these complex limit-cycle oscillations in magnetically suspended systems. It is tempting to speculate that to the extent that nonlinear magnetic forces act to limit response of real vehicles to perturbations, they could help account for the failure to observe conditions under which the vehicles actually hit the guideway in the large-scale vehicle tests described above. It must be remembered, however, that, in all of those tests, both aerodynamic and passive eddy-current damping mechanisms were in place and, together with the large clearance air gaps, probably bore the dominant responsibility for preventing guideway contact.

Fujiwara (1980) reported the results of calculations and an experimental study of magnetic damping in which a pair of superconducting magnets was suspended from the ends of a beam that was free to rock in the vertical plane normal to the surface of a turntable upon which was mounted a ring of 18 ground coils. He also studied the effects of adding damper coils in the liquid nitrogen baths that were above the SCMs and damper plates attached below the SCM cryostats. Both his analytical and experimental results showed that, as the velocity increased, the net magnetic damping force first decreased to a minimum but positive value (in the range of $11-17 \mathrm{~km} / \mathrm{h}$ ) and then increased. When the damping plate was removed, the velocity dependence of the net damping force remained the same, but was reduced by a factor of approximately 2 . It was further reduced when the damper coils were removed. Under the latter conditions (no enhanced passive damping with the possible exception of that from the cryostat walls and SCM windings), a difference was observed between the cases where the two SCMs moved in the same and in opposite phase. For the outof-phase case, the net damping force actually became negative in the calculations but not in the experimental results, presumably indicating residual damping contributions from the cryostat walls and perhaps AC losses in the SCM windings or some other damping source that was not taken into account.

More recently, Fujiwara and Hariyama (1983) conducted additional tests, with a modified rotating apparatus in which they suspended four SCMs in a 
cryostat above a turntable that contained track coils. They investigated the relative contributions to damping of the guideway coils, a damper sheet, and a thermal shield plate. Without the damper sheet and with alternating polarity, they observed that the net damping force increased from a small negative value at $\approx 11 \mathrm{~m} / \mathrm{s}$ to increasing positive values for speeds $>17 \mathrm{~m} / \mathrm{s}$. With the damper plate and alternating magnet polarity, they found that the damping force was always positive and increased significantly throughout the tested velocity range $(11-28 \mathrm{~m} / \mathrm{s})$; it increased still further when the damper plate was used with only two magnets of the same polarity and twice the excitation.

Andriollo et al. (1995a, 1995b) investigated the transient stability of EDS systems both analytically and numerically. They concluded that in EDS systems, the transient stability is affected by the electrical and geometrical parameters of both the on-ground levitation coils and the on-board excitation coils, as well as by the mechanical parameters of both the vehicle and the suspensions between the bogies and the vehicle. Under certain conditions, transient oscillations due to a motion perturbation could increase and lead the vehicle to instability.

\subsection{Nature of the Magnetic Forces and Vehicle Dynamics Work at ANL}

We hope that it is evident from the foregoing historical review that despite what appears to be an abundance of published information, certain important issues related to magnetically suspended systems remain somewhat unresolved. For example, although there is little doubt that negative intrinsic magnetic damping occurs, it cannot easily be observed experimentally, nor are its nature and consequences for vehicle dynamics fully understood. Although the importance of negative intrinsic magnetic damping to large-scale vehicle dynamics is probably small when other damping mechanisms are present, some uncertainties remain, especially near the lift-off velocity and at velocities where natural resonances of the guideway and/or vehicle suspension or propulsion systems occur. The extent to which large-amplitude limit-cycle oscillations actually occur in the dynamics of large-scale vehicle tests has not been addressed. The dynamic, as opposed to static, properties of the magnetic forces have not been addressed in detail and the extent to which those forces can dynamically couple modes that are statically uncoupled is not well known. To develop a clear and consistent picture of all of these issues from information in the literature, careful attention to the details is required. For a number of reasons, however, the necessary details are often not available. 
In general, little attention has been given to the problem of delineating the roles of the various sources of damping present in a large-scale system as a function of velocity and frequency. Consequently, it is not easy to predict whether and for what region of the design parameter space a maglev system will be dynamically stable.

Therefore, the objective of the R\&D program on dynamic stability of maglev systems at Argonne National Laboratory (ANL) since 1991 (Coffey et al. 1991; Chen et al. 1992; Cai et al. 1992a, 1992b, 1992c, 1993a, 1993b, 1993c; Chen et al. 1993; He et al. 1994; Zhu et al. 1994; Cai and Chen 1995, 1996) has been to develop a general approach for investigating and predicting the occurrence of instabilities in maglev suspension systems and to provide a better understanding of the conditions (design features and parameter values) that can lead to dynamic instabilities.

At ANL, Cai et al. (1993a; 1993b) and Cai and Chen (1995) analyzed the dynamic instabilities of an EDS-type maglev system with three- and five-DOF vehicles traveling on a double-L-shaped pair of continuous-sheet guideway conductors. Both analytical and numerical approaches were used, and various magnetic suspension forces, compiled from experimental data, were incorporated into the theoretical models. Divergence and flutter were obtained from analytical and numerical solutions for the coupled vibration of a three-DOF maglev vehicle model (Cai et al. 1993a, 1993b; Cai and Chen 1995). A computer code for numerically simulating dynamic stability of the five-DOF vehicle model was developed, and extensive computations with various parameters were performed to determine the stability characteristics of EDS-type maglev systems. Instabilities of five directions of motion (heave, slip, roll, pitch, and yaw) of the dynamic vehicle model were predicted and it was demonstrated that system parameters, such as system damping, vehicle geometry, and coupling effects among five different motions, play very important roles in the occurrence of dynamic instability in maglev systems (Cai et al. 1993a; Cai and Chen 1995).

Magnetic forces are basically position dependent at a fixed speed, and they are also speed dependent. In general, they may also be dependent on accelerations in all three directions. These motion-dependent magnetic forces can induce various types of instability. In addition, a periodicity of the motiondependent magnetic forces may, in some cases, also induce parametric and combination resonances (Cai et al. 1992b). 
Magnetic forces are obtained mainly from experimental measurements. At ANL, two different experiments to measure forces were performed. In the first experiment, a quasistatic method was applied to measure magnetic forces in which a permanent magnet was held next to an aluminum L-shaped continuous ring mounted on the top surface of a $1.2-\mathrm{m}$-diameter rotating wheel. The forces were measured as a function of position at a given steady speed (Cai et al. 1992b). In the second experiment, dynamic (motion-dependent) magnetic force measurements were based on an unsteady-motion theory. A direct method was used to measure magnetic damping and stiffness, and to investigate the effect of various parameters, such as conductivity, gap, excitation frequency, and oscillation amplitude (Chen et al. 1993; Zhu et al. 1994). Experimental results indicated that negative intrinsic magnetic damping will develop once the characteristic speed is exceeded. In the maglev system, instability is expected to occur if the total damping value becomes small or negative. A computer model simulation of intrinsic magnetic damping forces in a maglev system that consisted of a discrete coil guideway confirmed the existence of the negative damping phenomenon above a critical speed (He et al. 1994).

However, in this report, we compile only the experimental data of the magnetic force for a continuous conductor guideway, measured by the quasistatic method (i.e., forces measured at fixed speeds). In recent years, experiments were conducted at ANL to measure those magnetic forces. We summarize those magnetic forces in this report because those data, obtained from steady-state experiments, play a very important role in the numerical simulation of dynamic stability analysis of maglev vehicles. All of the experimental data have been incorporated into an existing computer program for nonlinear-dynamics simulation of maglev vehicles. We also believe that documentation of magnetic force data that have never been published will provide potential references for future maglev programs.

The main purpose of this report is to present an overview of the recent experimental investigation of the dynamic stability of maglev systems at ANL. Two series of tests were performed with a vehicle that was magnetically suspended over a double L-shaped continuous-aluminum guideway mounted on the top of a rotating wheel. In Test 1 , a vehicle model was supported by four permanent magnets on four corners, whereas, in Test 2, four magnets for levitation and four magnets for guidance were attached to the vehicle. In both tests, the vehicle, constrained in its longitudinal direction by a metal tether attached at various positions, was free to move in up to five modes (vertical heave, lateral slip, pitch, yaw, and roll). Several accelerometers and a force transducer 
(only for drag direction) were placed on the vehicle. The vehicle's motion in five directions was measured by double analog integration. When the rotating speed of the wheel varied, stable and unstable motions of the maglev vehicle were observed and recorded.

A computer program was developed at ANL to simulate the dynamic response of maglev systems (Coffey et al. 1991; Cai and Chen 1995). The program can simulate the nonlinear dynamic response of maglev systems with six DOF when the user inputs vehicle and track configurations; it was employed in this study to calculate the dynamic response and onset of instability in a maglev vehicle model with five DOF. The simulations and predictions were compared with results obtained from dynamic stability experiments.

\section{Measurement of Magnetic Forces}

Magnetic forces are needed for any analysis of vehicle dynamics, design of guideway structures and fastening, and prediction of ride quality. These force components are considered here from the standpoint of vehicle stability. As a significant part of ANL's maglev R\&D program, magnetic forces of a permanent magnet moving over an L-shaped aluminum sheet guideway were measured experimentally with a quasistatic method; this report provides an overview of that effort. Details of the experimental setup and measured force data are presented in this section. The measured magnetic forces are compared with magnetic forces calculated by various computer codes, including MAGFORCE and ELEKTRA.

We included the experimentally determined magnetic forces in this report because data yielded by experiments play a very important role in the analysis of numerical simulations of dynamic stability of maglev vehicles.

\subsection{Experimental Setup for Measuring Magnetic Forces}

An experiment was conducted at ANL to investigate the lift, drag, and guidance magnetic forces that act on an $\mathrm{NdFeB}$ permanent magnet that is moving over an aluminum (6061-T6) L-shaped ring mounted on the top surface of a 1.2-m-diameter rotating wheel (shown in Figs. 1 and 2). For a given rotating speed of the wheel (ranging from 0 to $600 \mathrm{r} / \mathrm{min}, 0$ to $37.7 \mathrm{~m} / \mathrm{s}$ ), the lift, guidance, and drag magnetic forces were measured while the guidance gap $\mathrm{Y}^{*}$ and lift height $h$ were varied. A schematic diagram of the measurement approach is shown in Fig. 3 (Cai et al. 1992). 


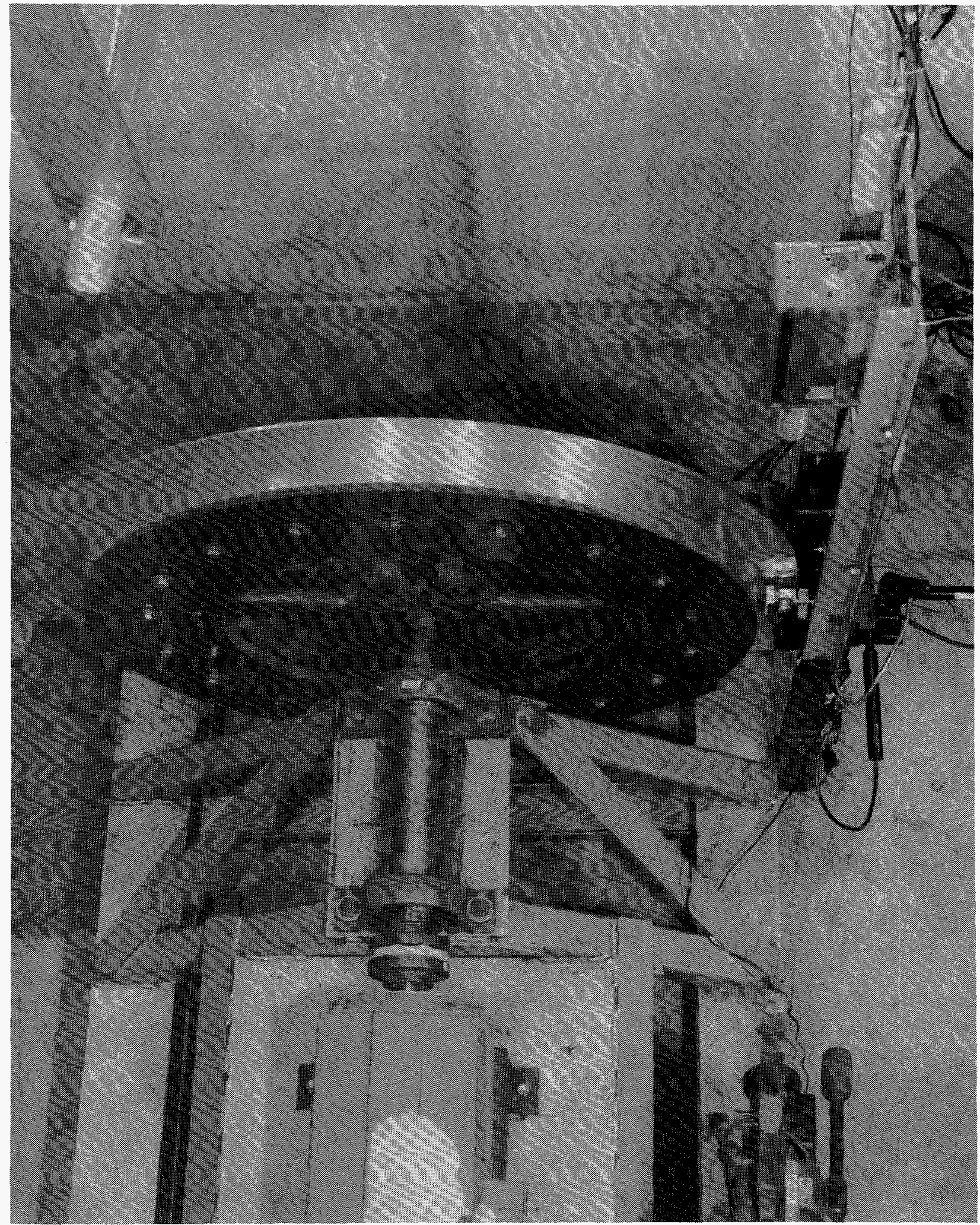

Fig. 1. Experimental setup of rotating wheel with aluminum L-shaped ring mounted on top 
Comap?n:s

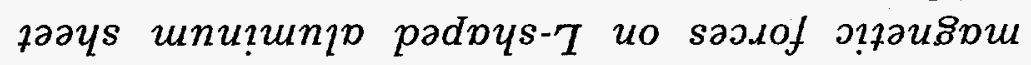

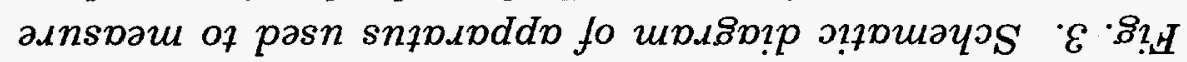

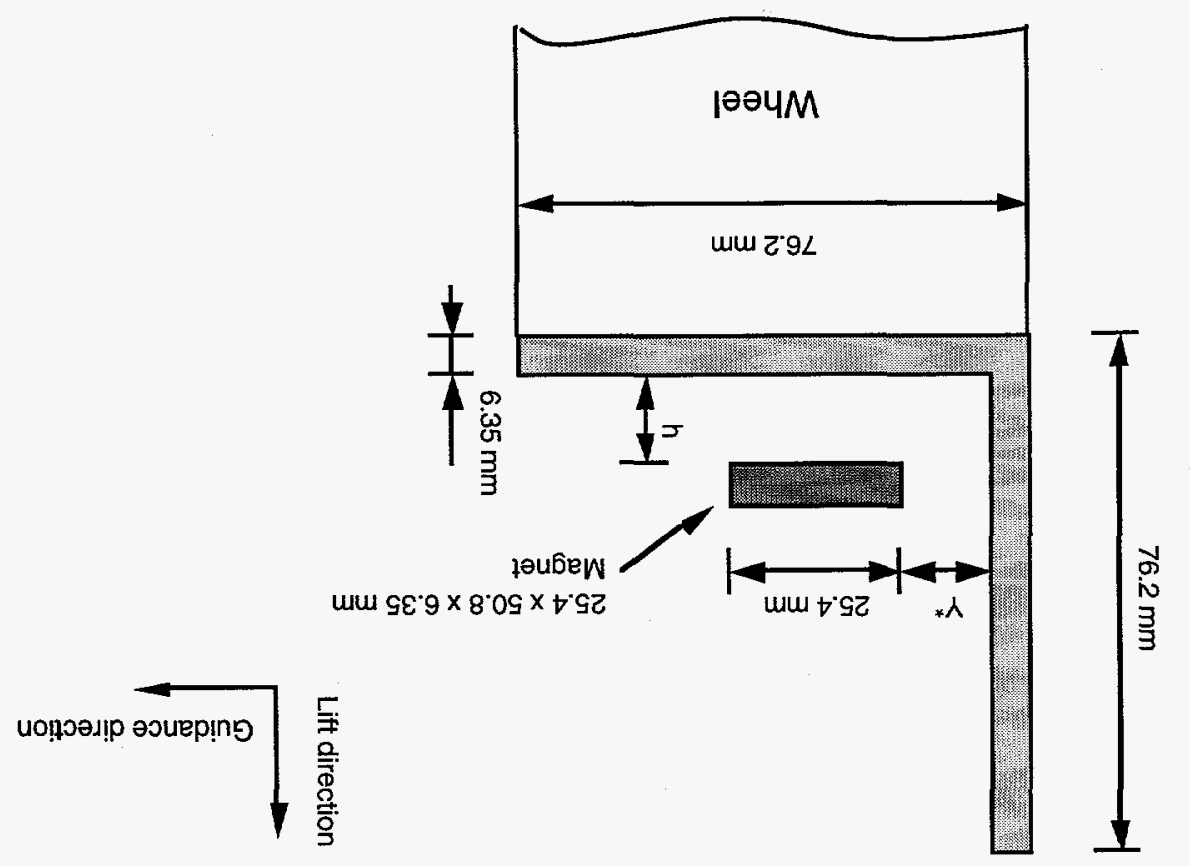

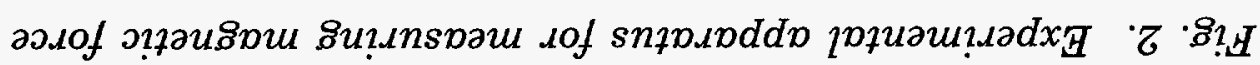

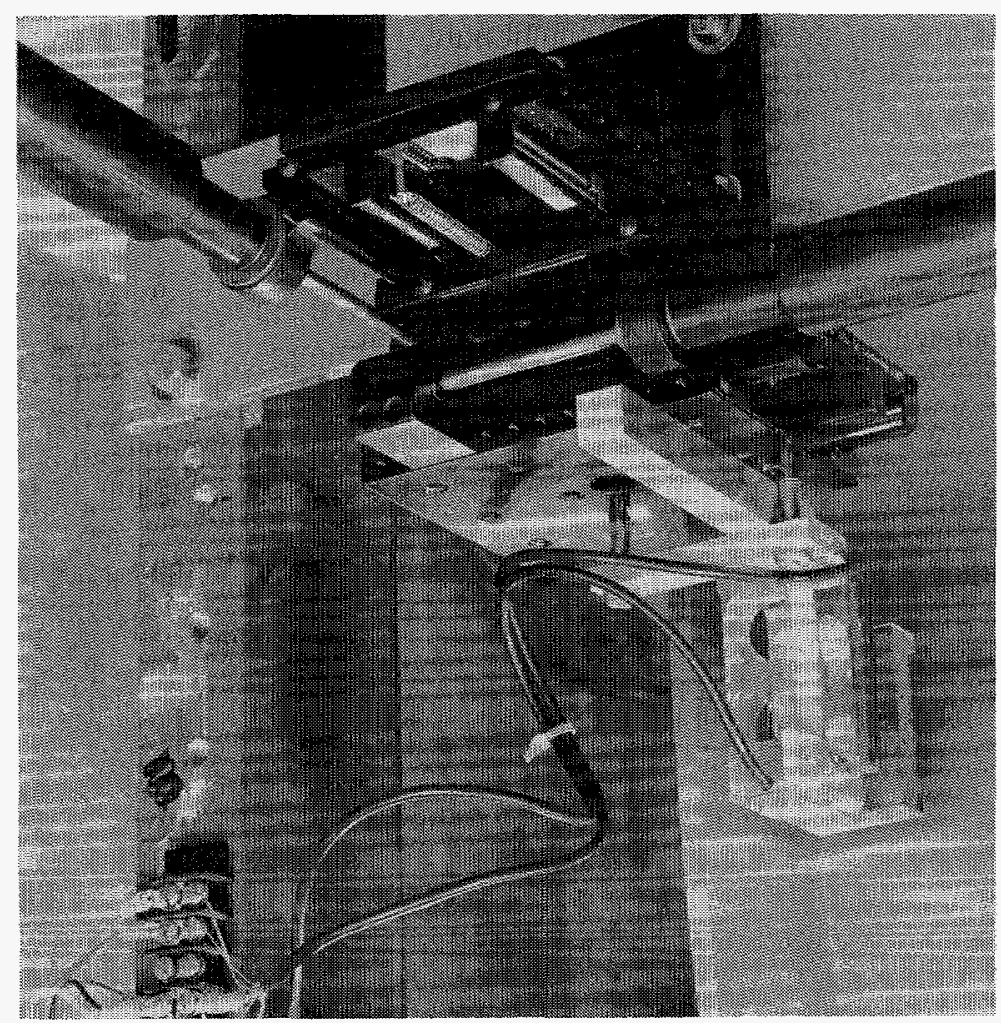


During testing, the long side of the $25.4 \times 50.8 \times 6.35-\mathrm{mm}$ rectangular magnet was oriented parallel to the direction of motion of the L-shaped guideway and was held stationary by a two-component force transducer that comprised two BLH C2G1 load cells connected in series to measure lift and guidance forces simultaneously. Laboratory weights were used to calibrate the transducer and to assess crosstalk (which was found to be $<2 \%$ ). The base of the load cell assembly was mounted on motorized stages that provided accurate positioning $( \pm 0.05 \mathrm{~mm})$. Out-of-roundness of the L-shaped guideway ring varied, but was always $< \pm 0.15 \mathrm{~mm}$ for the lateral leg and $\pm 0.35 \mathrm{~mm}$ for the vertical leg. Ability to exactly position the magnet with respect to the guideway dominated our experimental error, which was estimated as $\pm 5 \%$.

Lift, guidance, and drag forces were measured as a function of $h$, with $\mathrm{Y}^{*}$ fixed at 5 and $12.7 \mathrm{~mm}$, or as a function of $\mathrm{Y}^{*}$ with $\mathrm{h}$ fixed at 7 and $12.7 \mathrm{~mm}$ while the surface velocity of the lateral leg of the guideway varied from $4.55 \mathrm{~m} / \mathrm{s}$ to $36.1 \mathrm{~m} / \mathrm{s}$.

\subsection{Results and Discussion of Measured Magnetic Forces}

Measured lift, guidance, and drag forces are plotted in Figs. 4, 5, and 6, respectively, as a function of $h$, with $\mathrm{Y}^{*}$ fixed, or as a function of $\mathrm{Y}^{*}$, with $\mathrm{h}$ fixed, and with the wheel surface velocity $=4.55,7.89,10.62,13.32,18.20,24.15,30.10$, and $36.10 \mathrm{~m} / \mathrm{s}$.

The following characteristics of measured lift, guidance, and drag forces were noted from Figs. 4-6.

- The qualitative trends in the lift, guidance, and drag force data for the L-shaped guideway are the same for all tested velocities.

- With fixed gap $\mathrm{Y}^{*}$, the lift force decreases as height increases (Figs. $4 \mathrm{a}$ and $4 \mathrm{~b}$ ); with fixed height, the lift force remains almost the same when gap $\mathrm{Y}^{*}$ varies (Figs. $4 \mathrm{c}$ and $4 \mathrm{~d}$ ). With fixed gap, the guidance force depends weakly on the height, especially for large $\mathrm{Y}^{*}$ and V (Figs. 5a and 5b), whereas with fixed height, the guidance force decreases strongly as the gap increases (Figs. $5 \mathrm{c}$ and $5 \mathrm{~d}$ ). The relatively small dependence of the lift force on $\mathrm{Y}^{*}$ and that of the guidance force on $\mathrm{h}$ implies that motions in the horizontal and vertical directions are only weakly coupled. The drag force decreases as either gap or height increases (Fig. 6). 


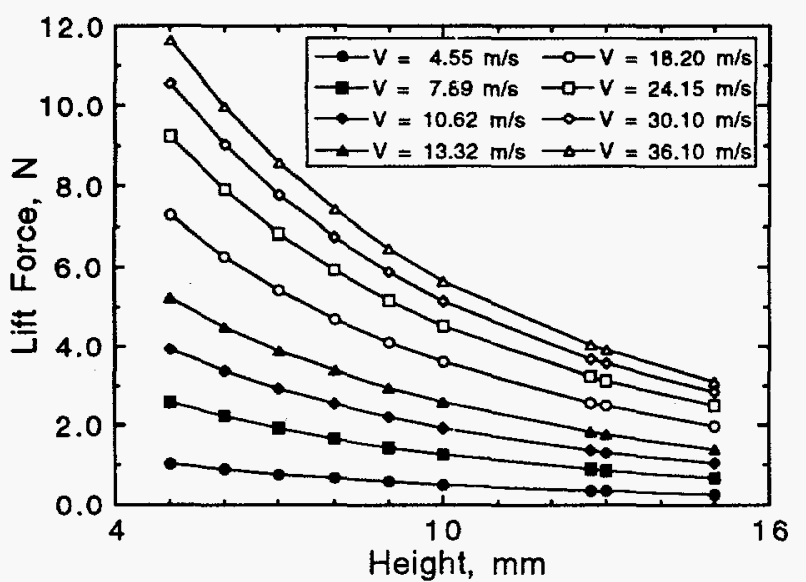

(a)

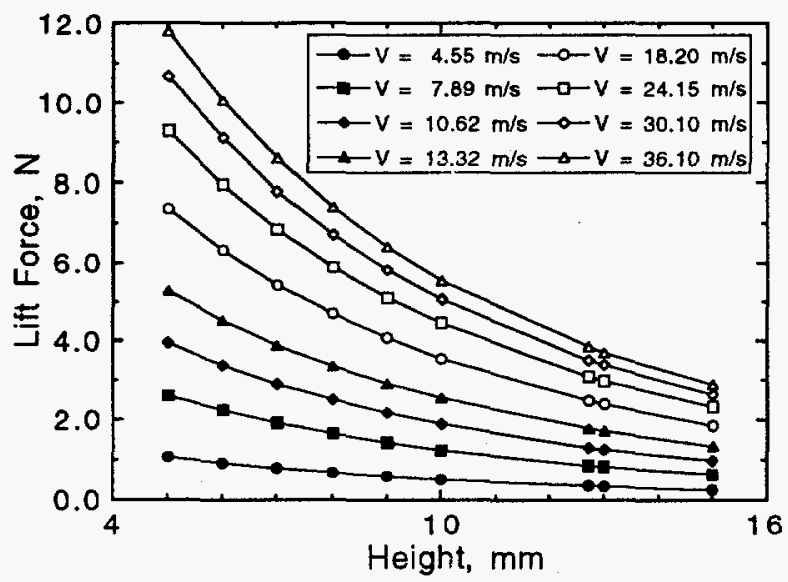

(b)

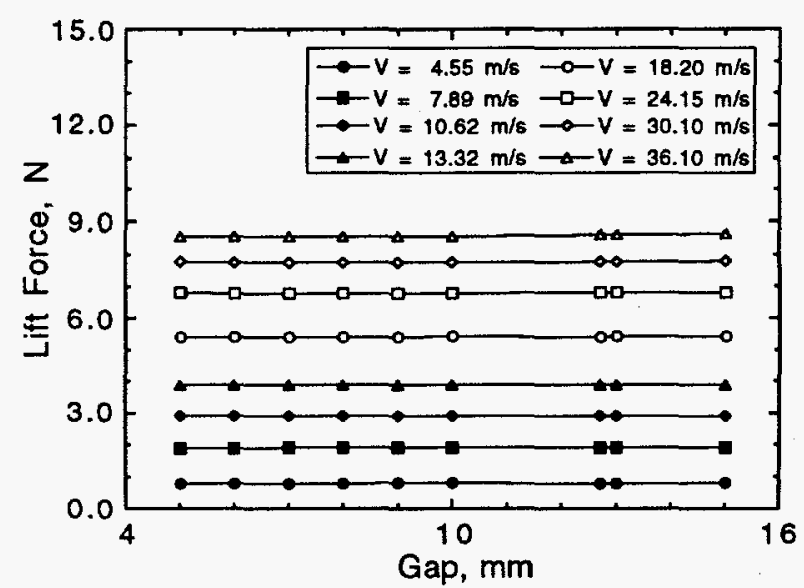

(c)

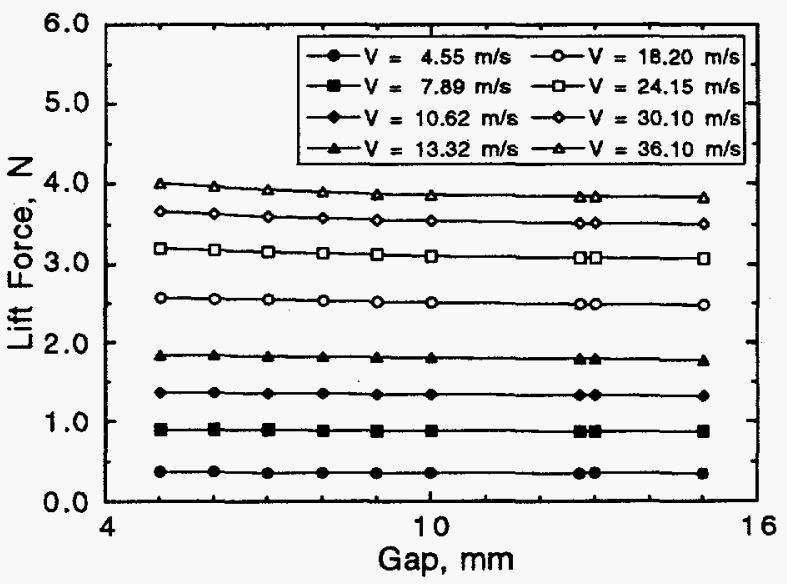

(d)

Fig. 4. Measured lift magnetic force, for various wheel surface velocities $V$, as a function of lift height when (a) $Y^{*}=5.0 \mathrm{~mm}$ and (b) $Y^{*}=12.7 \mathrm{~mm}$, and as a function of gap $Y^{*}$ when (c) $h=7.0 \mathrm{~mm}$ and (d) $h=12.7 \mathrm{~mm}$

- When compared with the lift and drag forces, the value of the guidance force is relatively small.

- Two features of guidance force are evident. First, a maximum occurs in the variation of guidance force with respect to height at a fixed gap (as shown in Figs. 5a and 5b), a phenomenon that is caused by the corner region of the guideway. Second, a minimum occurs in the variation of guidance force with respect to gap variations at a fixed height (as shown in Figs. 5c and 5d). This minimum is caused by the outer edge of the lateral leg of the guideway. As shown in the authors' previous publications (Cai et al. 1992a, 1992b), the first feature is associated with a flutter and the second with a divergence instability of a maglev vehicle model with three DOF. 


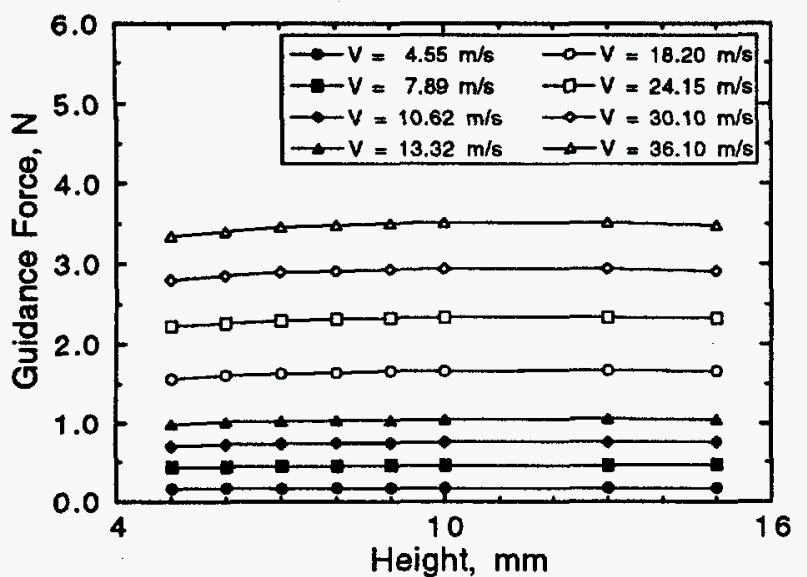

(a)

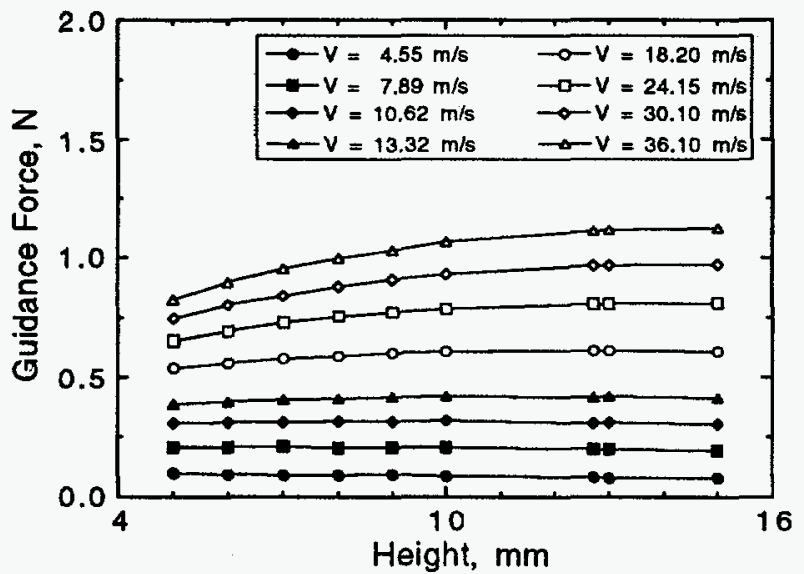

(b)

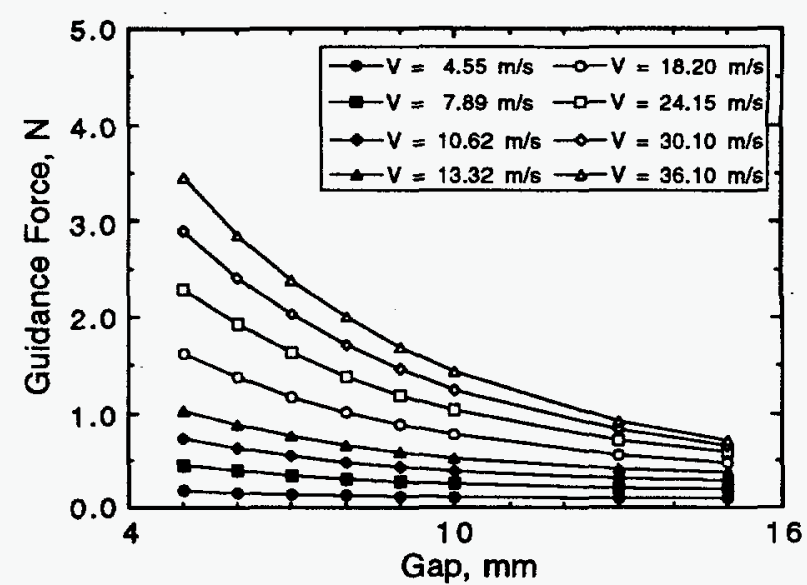

(c)

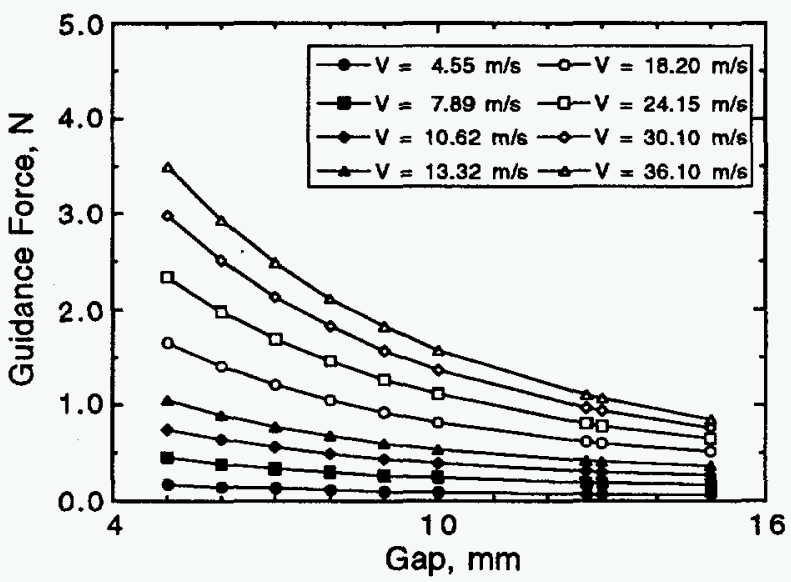

(d)

Fig. 5. Measured guidance magnetic force, for various wheel surface velocities $V$, as a function of lift height when (a) $Y^{*}=5.0 \mathrm{~mm}$ and (b) $Y^{*}=12.7 \mathrm{~mm}$, and as a function of gap $Y^{*}$ when (c) $h=7.0 \mathrm{~mm}$ and (d) $h=12.7 \mathrm{~mm}$

The measured lift, guidance, and drag forces are replotted in Figs. 7-9, respectively, as a function of velocity, with $\mathrm{Y}^{*}$ or $\mathrm{h}$ fixed. Characteristics of the lift, guidance, and drag forces from Figs. 7-9 can be summarized as follows:

- When velocity increases, the lift and guidance forces overall increase (Figs. 7 and 8), whereas drag force increases in the lower velocity range and decreases in the higher velocity range (Fig. 9). The broad maximum in the drag force-vs.-velocity curve is characteristic of small-scale permanent magnets interacting with continuous aluminum sheets. 


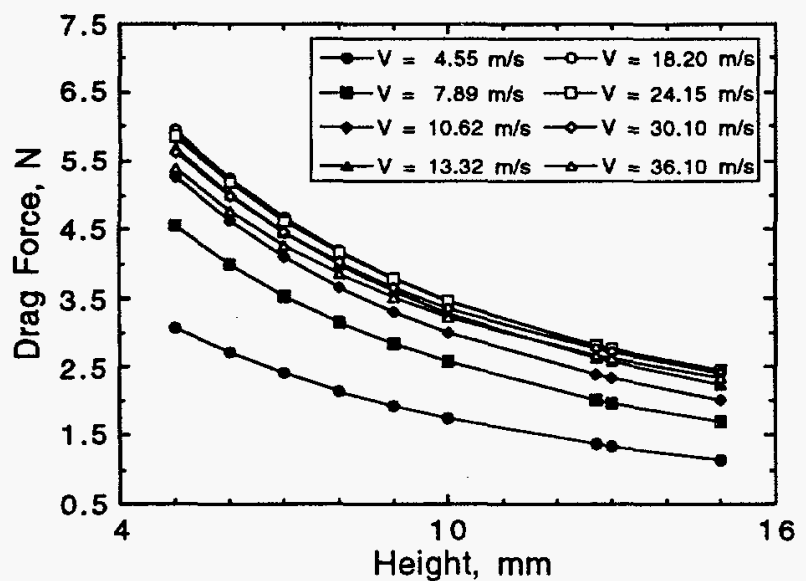

(a)

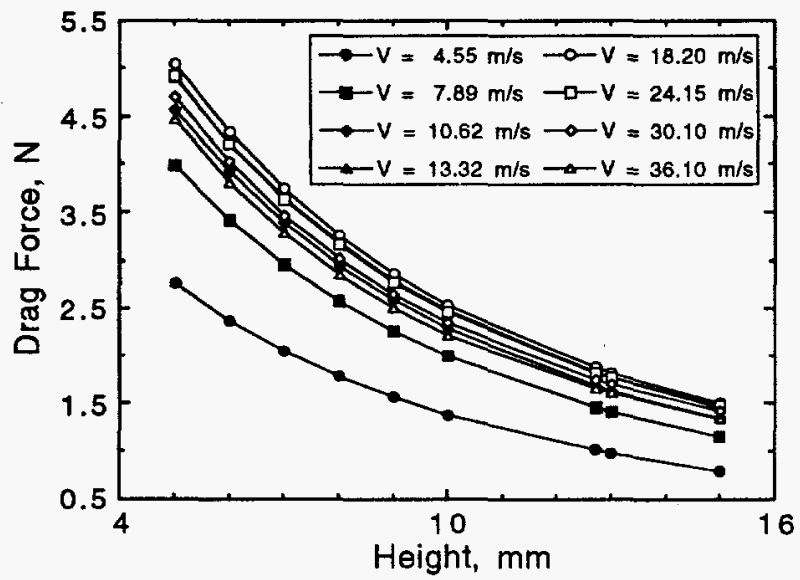

(b)

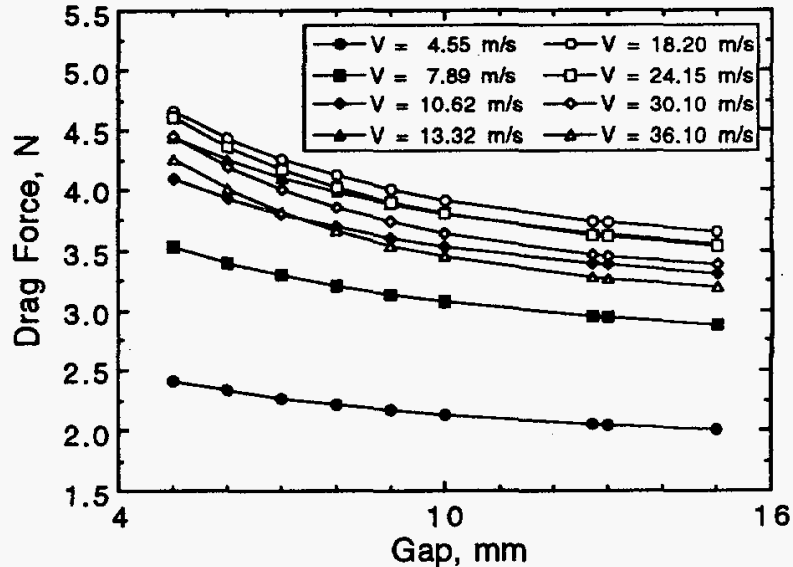

(c)

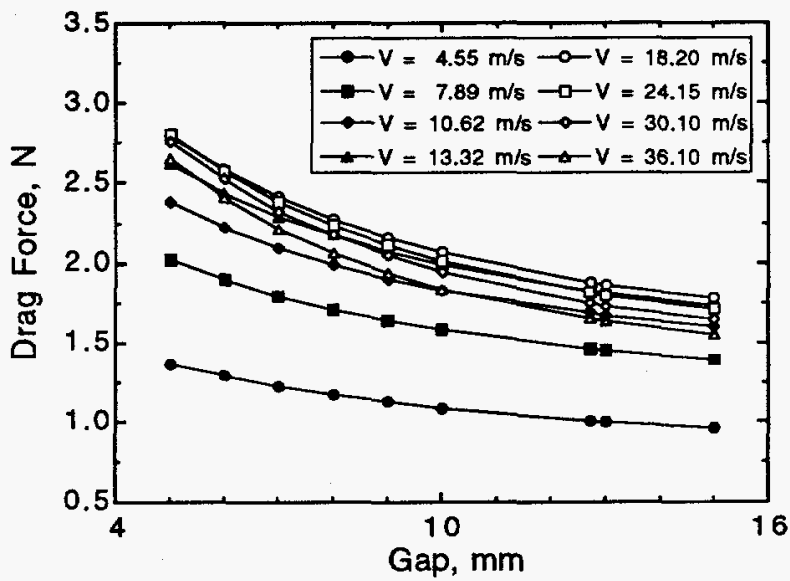

(d)

Fig. 6. Measured drag magnetic force, for various wheel surface velocities $V$, as a function of lift height when (a) $Y^{*}=5.0 \mathrm{~mm}$ and (b) $Y^{*}=12.7 \mathrm{~mm}$, and as a function of gap $Y^{*}$ when (c) $h=7.0 \mathrm{~mm}$ and (d) $h=12.7 \mathrm{~mm}$

- In the lower velocity range, the drag force is quite large when compared with lift and guidance forces. Depending upon vehicle geometry, particularly the length-to-width ratio, destabilizing torques caused by the drag force may exceed the restoring torques due to guidance forces at low speed.

The magnetic force data from experimental measurements are included in the Appendix of this report. Polynomial expressions were fitted to the magneticforce curves of Figs. 4-9 and were used in the computer code to simulate the dynamic response of a maglev vehicle. 


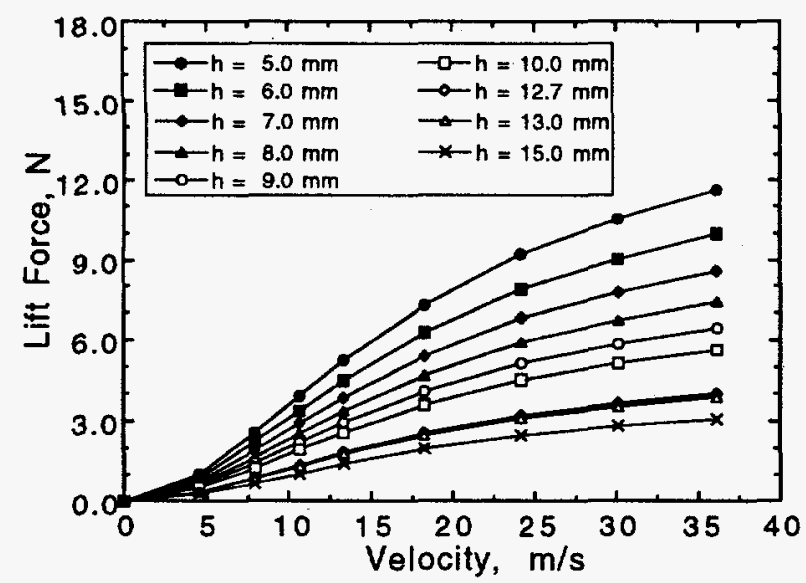

(a)

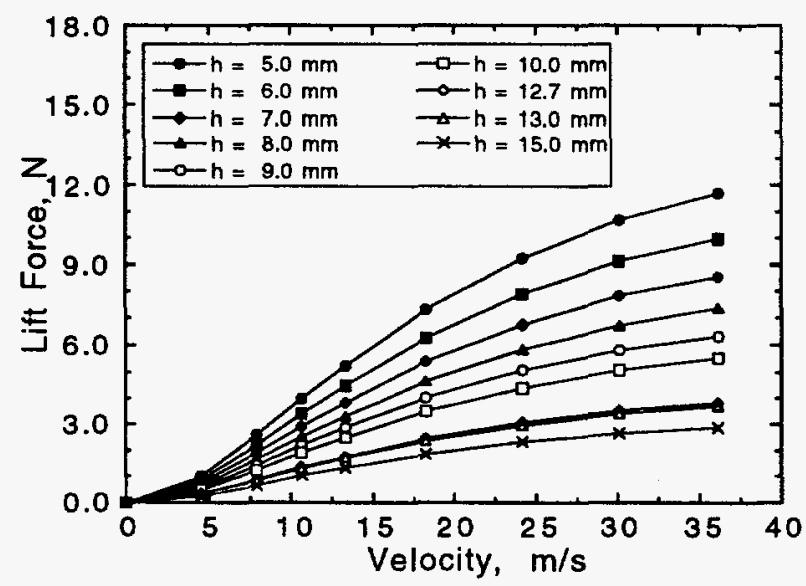

(b)

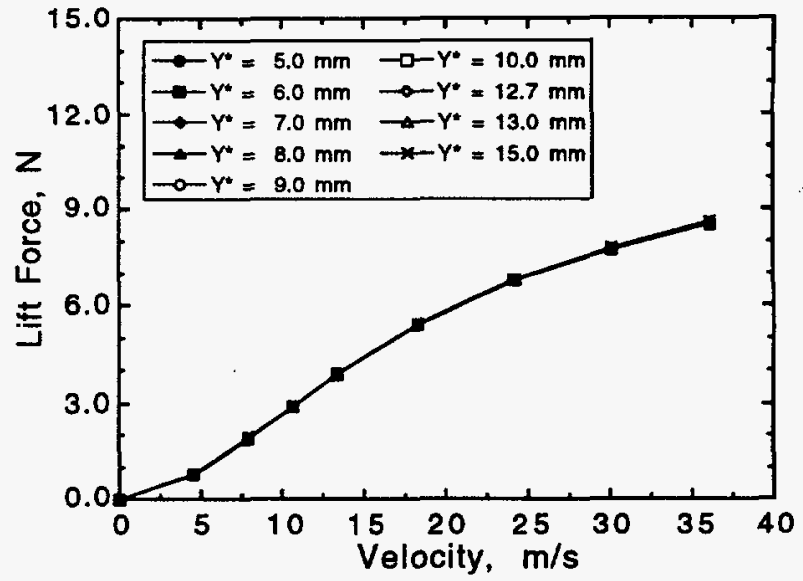

(c)

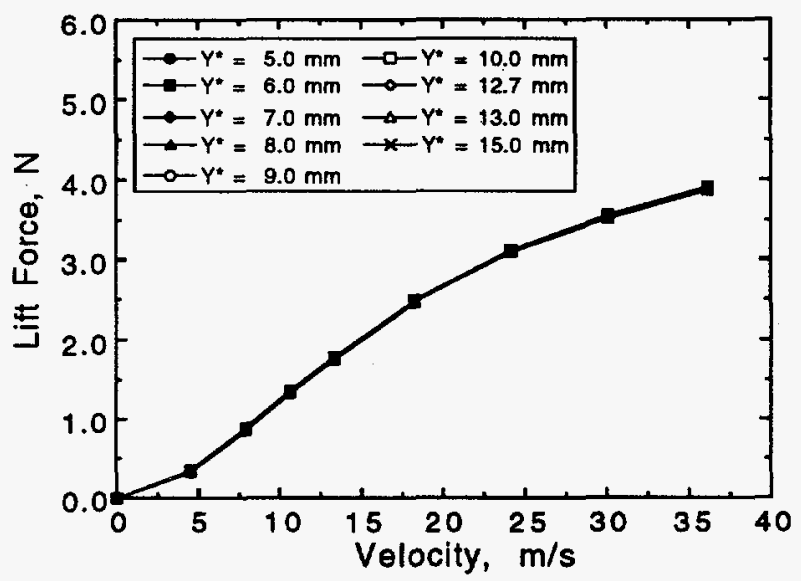

(d)

Fig. 7. Measured lift magnetic force, for various values of $h$ and $Y^{*}$, as a function of velocity when (a) $Y^{*}=5.0 \mathrm{~mm}$, (b) $Y^{*}=12.7 \mathrm{~mm}$, (c) $h=$ $7.0 \mathrm{~mm}$, and $(d) h=12.7 \mathrm{~mm}$

\subsection{Magnetic Force Computations}

A series of computations was carried out for a permanent magnet held near a moving L-shaped continuous guideway; the results were compared with experimental magnetic force data. The reason for conducting force computations was not only to verify experimental data, but also to fill in the gaps in the experimental data. The force computations were conducted with various computer codes, including MAGFORCE (Coffey et al. 1972) and ELEKTRA (a commercial code leased from Vector Fields, Inc.), with the configuration and dimensions of the magnet and L-shaped guideway as shown in Fig. 3. 


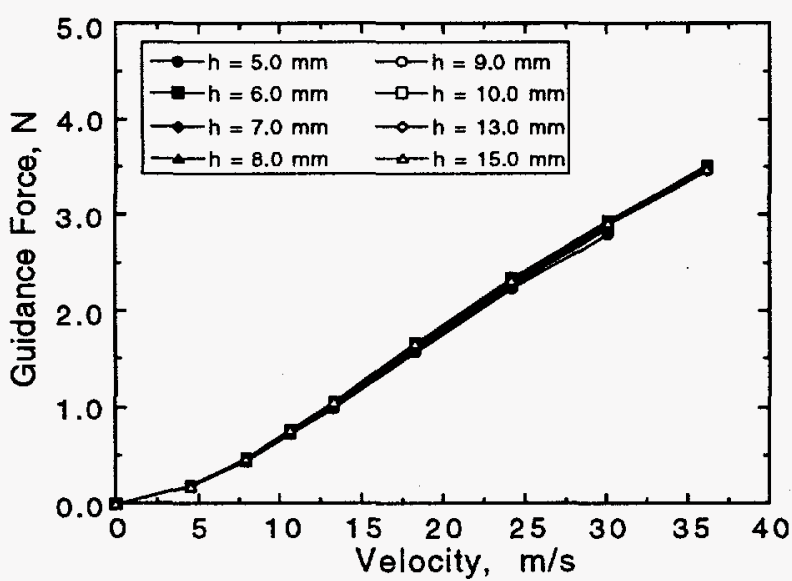

(a)

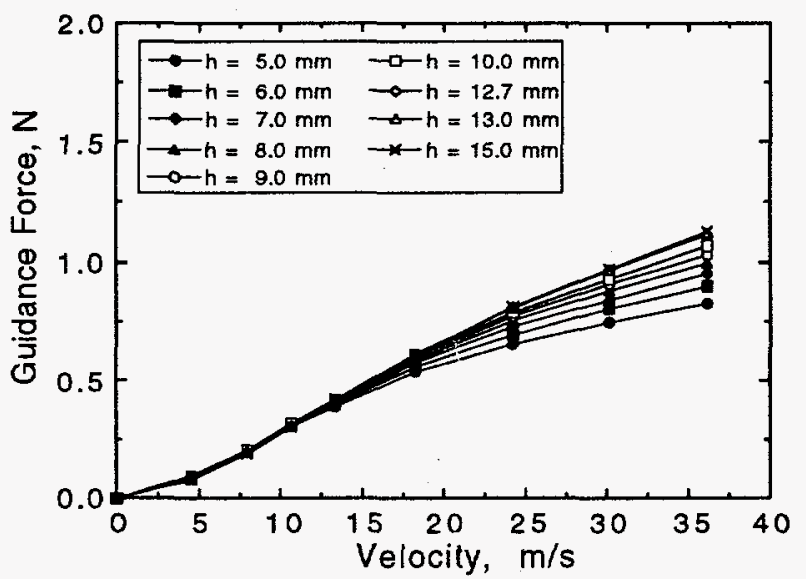

(b)

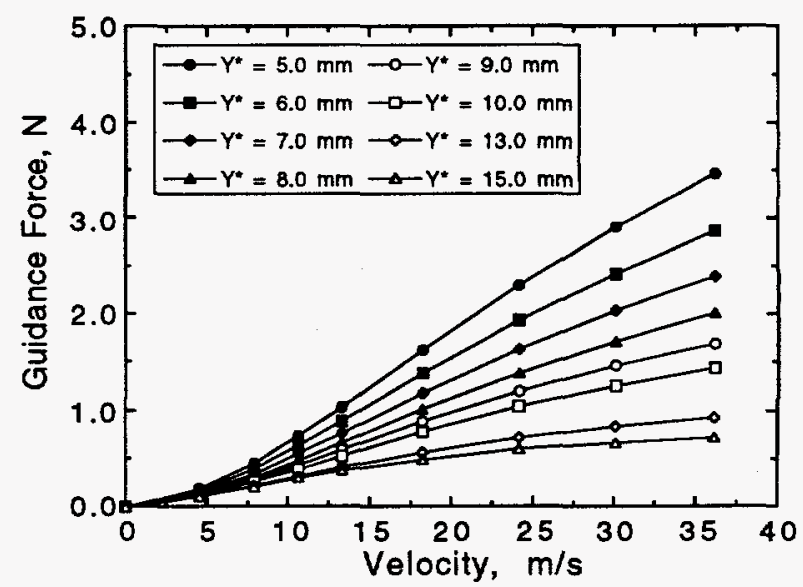

(c)

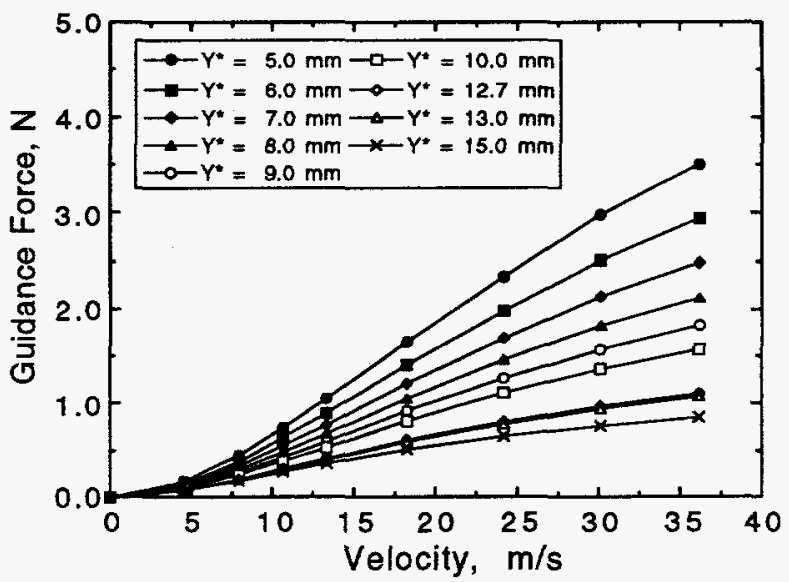

(d)

Fig. 8. Measured guidance magnetic force, for various values of $h$ and $Y^{*}$, as a function of velocity when (a) $Y^{*}=5.0 \mathrm{~mm}$, (b) $Y^{*}=12.7 \mathrm{~mm}$, (c) $h=$ $7.0 \mathrm{~mm}$, and $(d) h=12.7 \mathrm{~mm}$

\subsubsection{MAGFORCE}

MAGFORCE was recoded at ANL by $\mathrm{H}$. Coffey and is based on a published Fourier transformation formulation (Coffey et al. 1972). For a finite-thickness, flat-plate guideway of infinite width, MAGFORCE works very well. An option built into the MAGFORCE code also allows it to be applied to an L-shaped guideway whose vertical and lateral surfaces extend to infinity. Care must be taken if edge effects are important. 


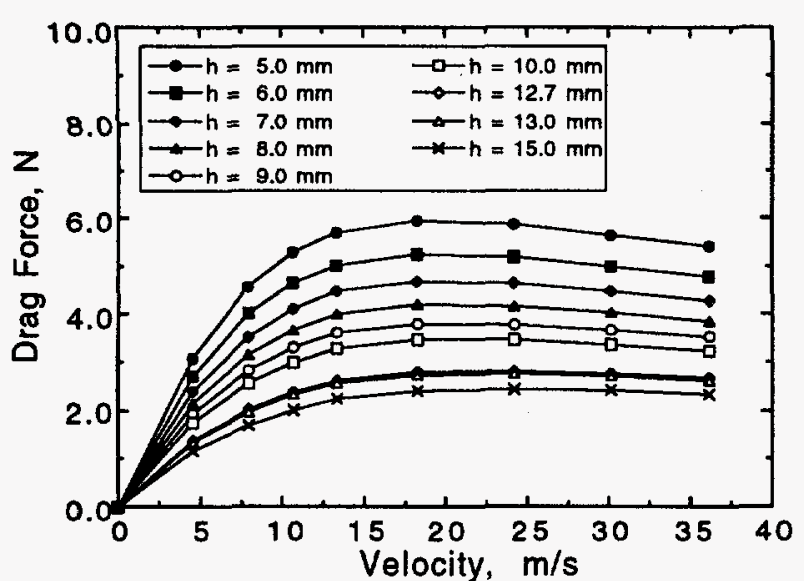

(a)

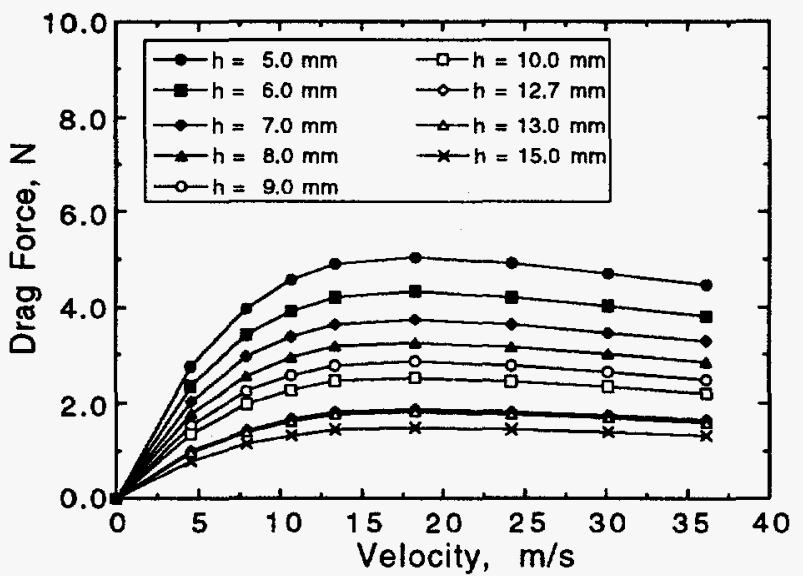

(b)

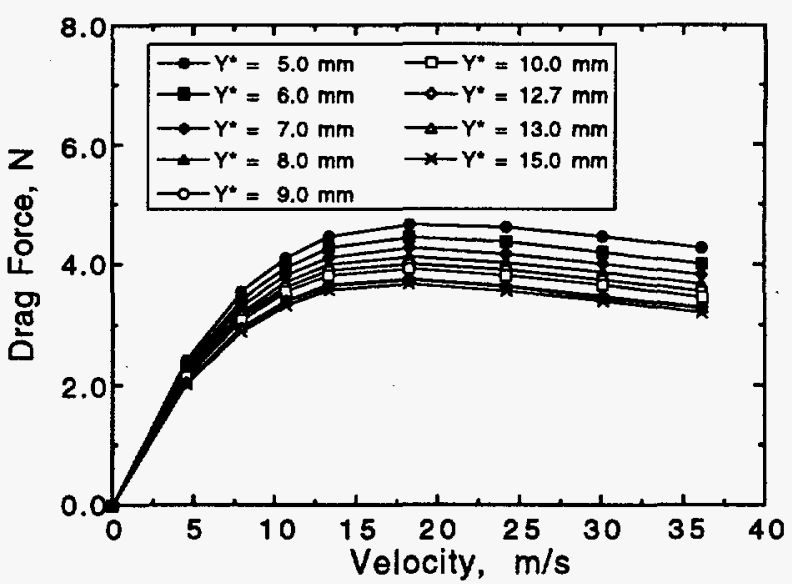

(c)

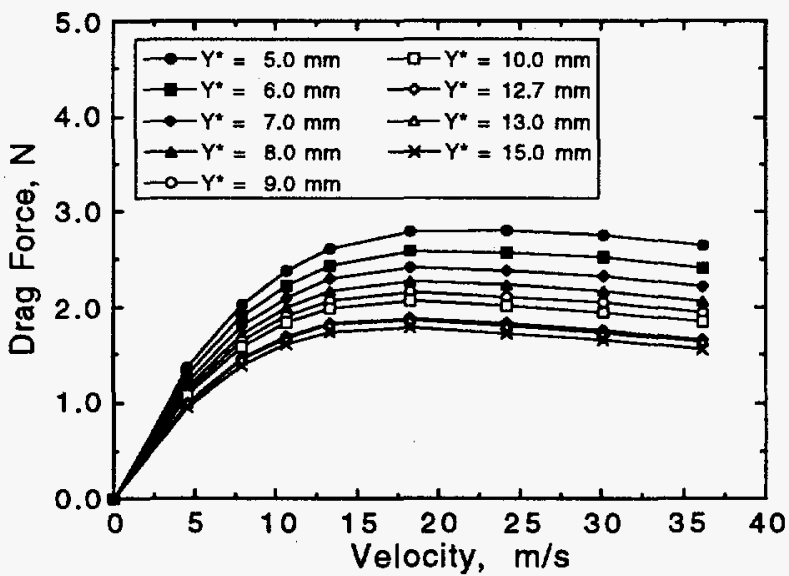

(d)

Fig. 9. Measured drag magnetic force, for various values of $h$ and $Y^{*}$, as a function of velocity when (a) $Y^{*}=5.0 \mathrm{~mm}$, (b) $Y^{*}=12.7 \mathrm{~mm}$, (c) $h=$ $7.0 \mathrm{~mm}$, and (d) $h=12.7 \mathrm{~mm}$

In our experiments, we fixed a permanent magnet to a force transducer near a moving L-shaped guideway. Because MAGFORCE does not simulate a permanent magnet directly, an equivalent coil must be used to simulate the permanent magnet. We assumed that the dimensions of the coil are the same as those of the magnet $(5.08 \times 2.54 \mathrm{~cm})$, and placed the coil in the middle of the magnet, as shown in Fig. 10. This kind of coil model was used in flat-plate guideway problems, and it worked very well. However, for L-shaped guideway problems, large errors were encountered, especially for drag and guidance forces. Figures 11-15 show the force results, which indicate that lift forces match experimental data reasonably well; however, discrepancies up to $50 \%$ were noted for drag and guidance forces. 


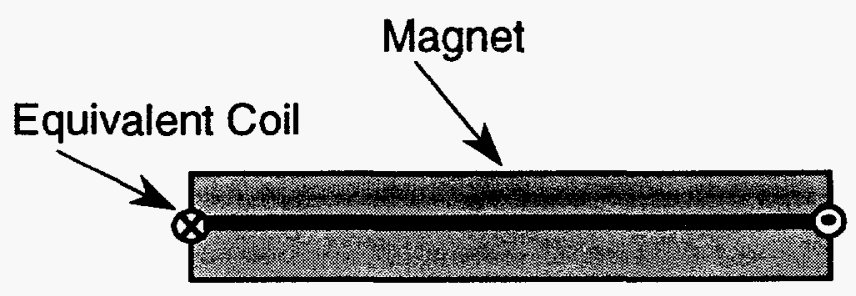

Fig. 10. Magnet and equivalent coil

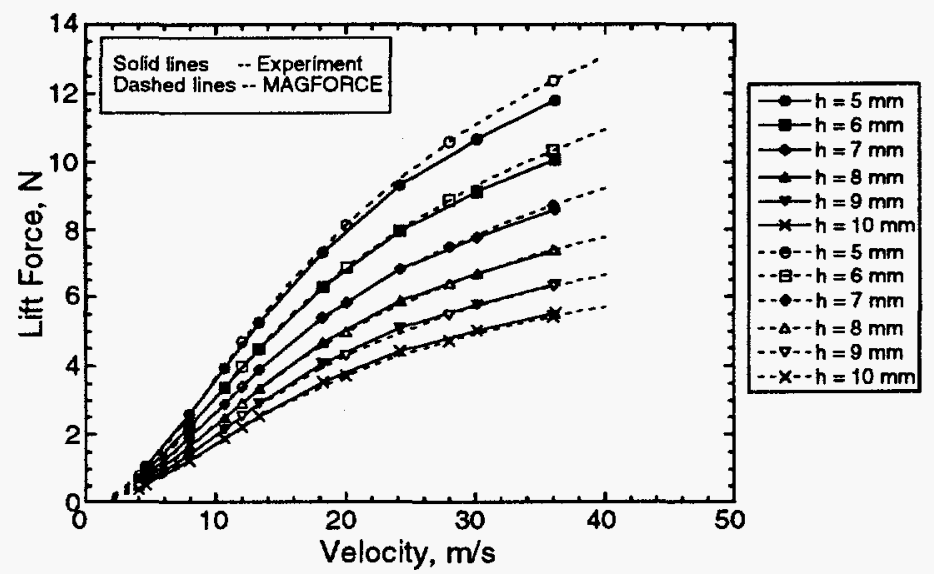

Fig. 11. Measured and MAGFORCE-calculated lift forces when $Y^{*}=12.7 \mathrm{~mm}$

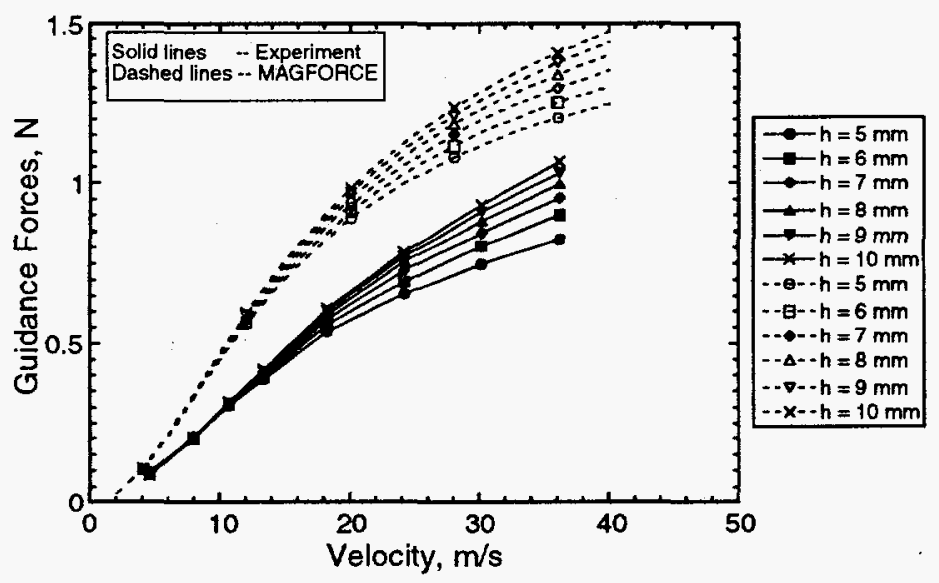

Fig. 12. Measured and MAGFORCE-calculated guidance forces when $Y^{*}=12.7 \mathrm{~mm}$ 


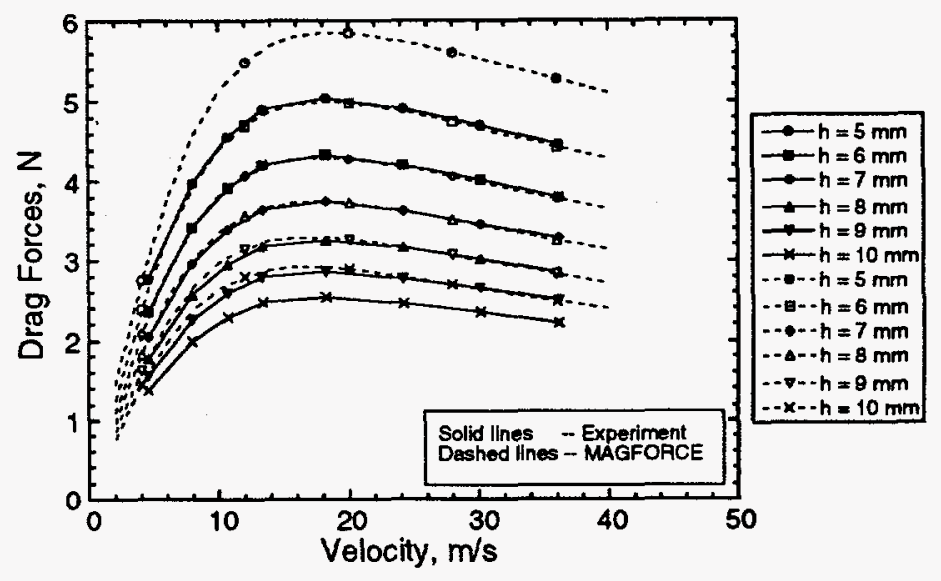

Fig. 13. Measured and MAGFORCE-calculated drag forces when $Y^{*}=12.7 \mathrm{~mm}$

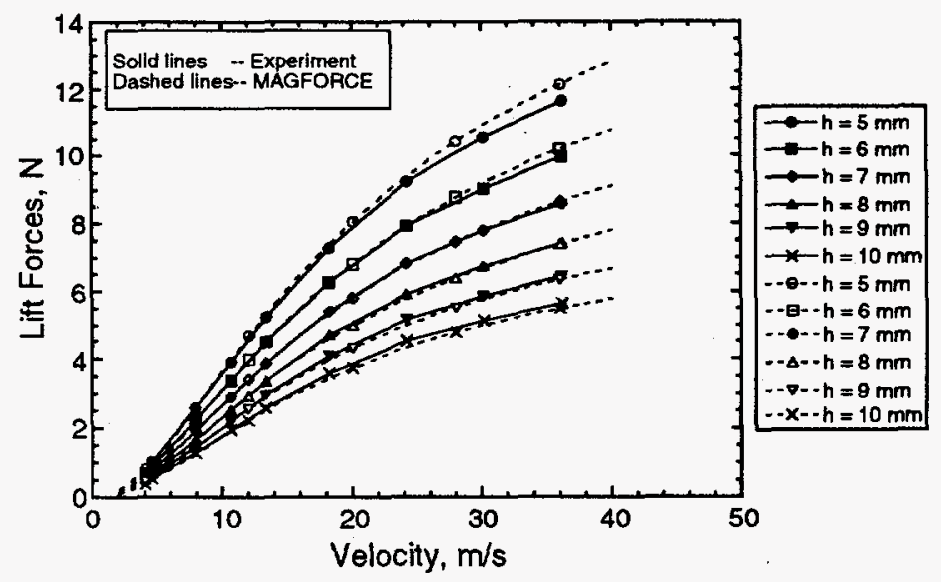

Fig. 14. Measured and MAGFORCE-calculated lift forces when $Y^{*}=5 \mathrm{~mm}$

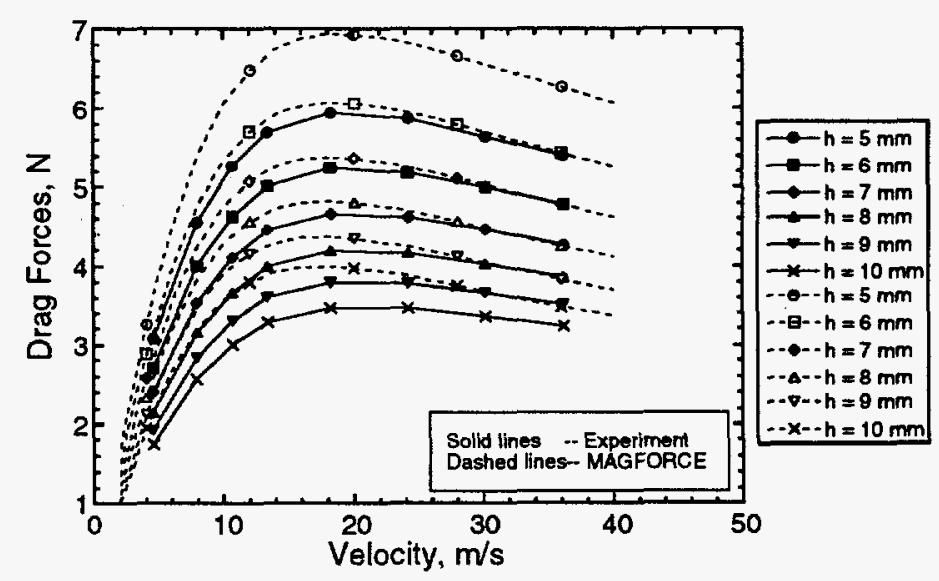

Fig. 15. Measured and MAGFORCE-calculated drag forces when $Y^{*}=5 \mathrm{~mm}$ 
A possible reason for the discrepancies is that the equivalent coil was inappropriately located in the middle plane of the magnet. An alternative was proposed that it should also be located elsewhere but not on the surface that faced the guidance plate (Fig. 16). Because the thickness of the magnet is $6.35 \mathrm{~mm}$, the cross-sectional dimensions of equivalent coil turns are assumed to be $4.45 \times$ $1.91 \mathrm{~cm}$. MAGFORCE results obtained with this alternative equivalent coil are shown in Figs. 17-19. Discrepancies are smaller than those of the previous model, but the shapes of the guidance force curves obtained from MAGFORCE differ from those that were obtained from experiments.

For design purposes, MAGFORCE is useful because it will give us an approximation of the steady-state capabilities for levitation, guidance, and propulsion. However, it does not model a permanent magnet and L-shaped guideway accurately enough to be used to calculate the forces and force gradients that are needed to predict dynamic effects.

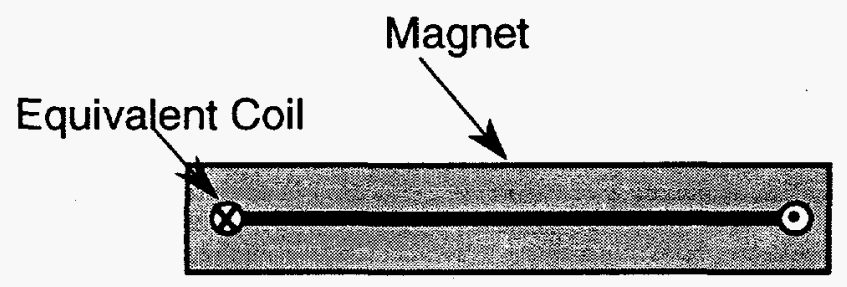

Fig. 16. Alternative magnet and equivalent coil

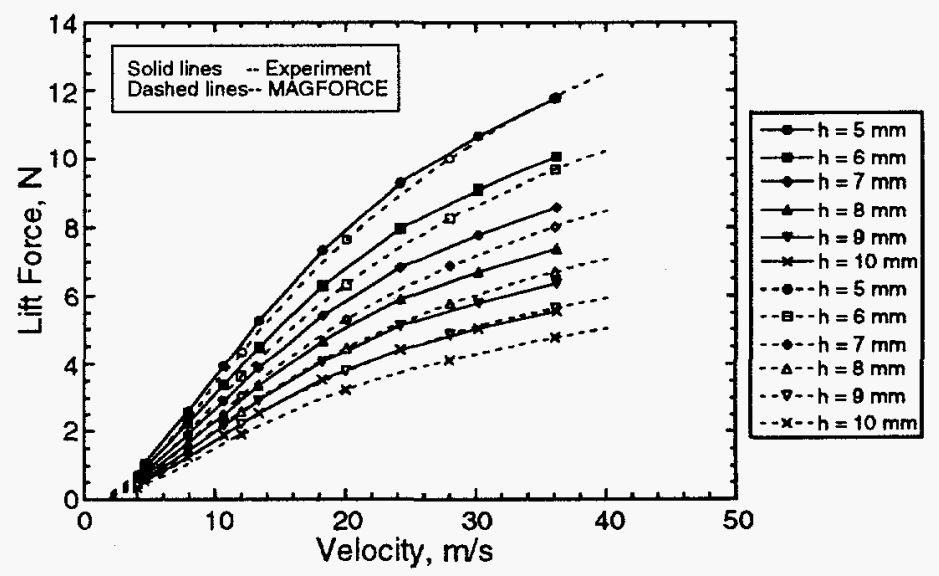

Fig. 17. Measured and MAGFORCE-calculated lift forces when $Y^{*}=12.7 \mathrm{~mm}$ 


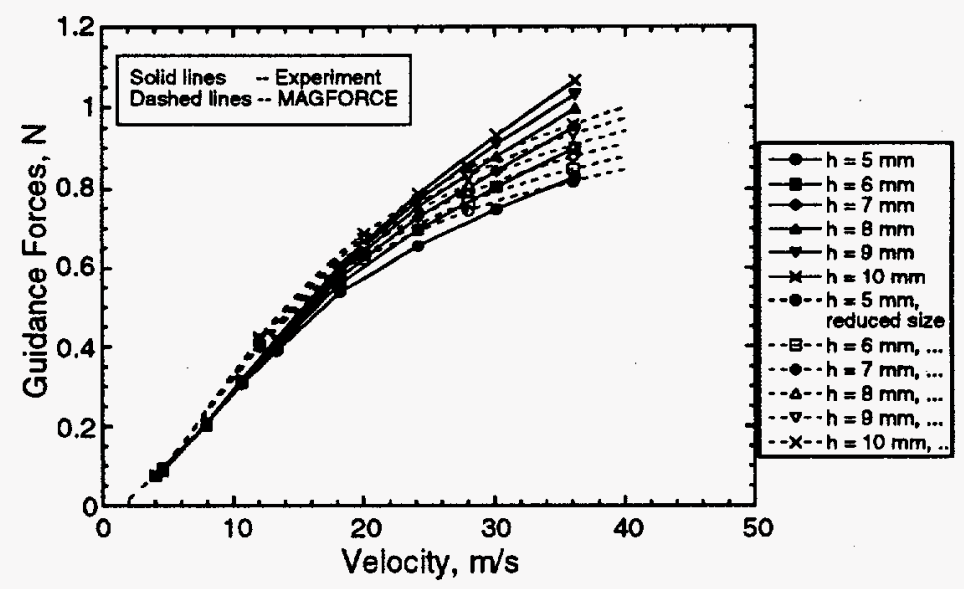

Fig. 18. Measured and MAGFORCE-calculated guidance forces when $Y^{*}=12.7 \mathrm{~mm}$

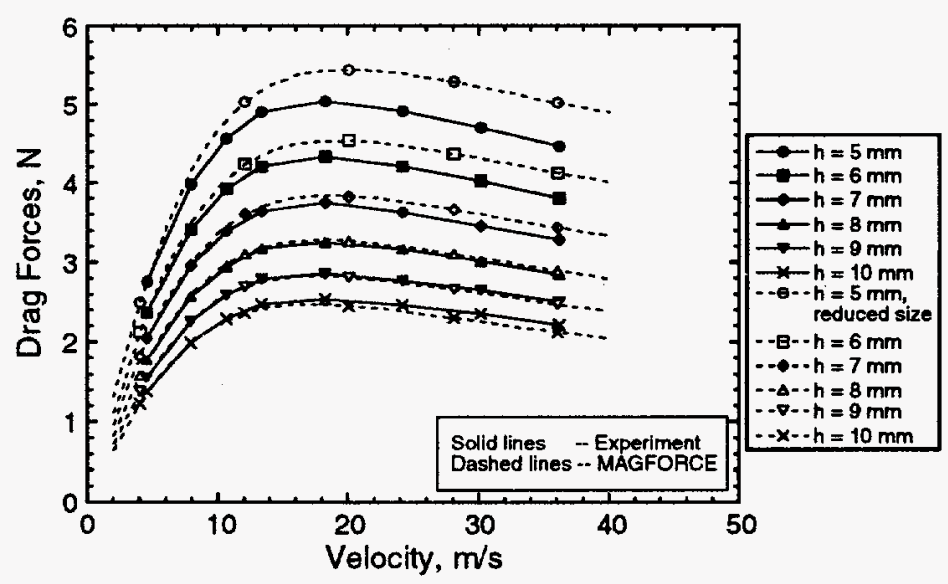

Fig. 19. Measured and MAGFORCE-calculated drag forces when $Y^{*}=12.7 \mathrm{~mm}$

\subsubsection{ELEKTRA}

The velocity version of ELEKTRA is a finite-element computer code developed by Vector Fields, Ltd.; it is capable of solving three-dimensional eddy-current problems that contain a moving conductor. Theoretically, ELEKTRA can be used to analyze any kind of eddy current problems with complex geometries. It has been successfully used to analyze flat-plate guideway and edge effect problems. Here, we use it to analyze the L-shaped guideway problem.

Because ELEKTRA does not simulate a permanent magnet directly, an equivalent coil must be used to simulate the permanent magnet. Therefore, 
equivalent ampere turns (A-T) of the coil must be determined. One way to determine the ampere turns is to compare the amplitude and shape of the magnetic field in the gap between the magnet (coil) and the conductor sheet. When this technique is used, a coil equivalent to the magnet used in the experiments would have 5,994 A-T. The outer dimensions of the coil used in ELEKTRA correspond exactly to the outer dimensions of the permanent magnet used in the experiment, and the coil cross section is $1 \mathrm{~mm}$ wide by $6.35 \mathrm{~mm}$ high.

During construction of the mesh, one should make the mesh distribution around and inside the coil as fine as possible to obtain more accurate force computations. The total number of nodes for our case is $\approx 13,000-16,000$, and computational time for one velocity is $\approx 2-8 \mathrm{~h}$, depending on the velocity.

Figure 20 shows lift, drag, and guidance forces vs. velocity calculated for $\mathrm{h}=$ $12.7 \mathrm{~mm}$ and $\mathrm{Y}^{*}=12.7 \mathrm{~mm}$. ELEKTRA results agree well with experimental data. However, ELEKTRA is too time-consuming; it sometimes required 6-8 h (2000-3000 iterations) at a SUN work station to obtain converged solutions.

Figures 21-23 illustrate forces vs. velocity for $\mathrm{Y}^{*}=5 \mathrm{~mm}$. Figures $24-26$ show forces vs. velocity for $\mathrm{h}=7 \mathrm{~mm}$. All ELEKTRA results are in good agreement with experimental data. However, ELEKTRA has two shortcomings: it is too timeconsuming, as mentioned above, and it sometimes has difficulty in achieving convergence, even though the velocity is not high, e.g., $25 \mathrm{~m} / \mathrm{s}$. In addition,

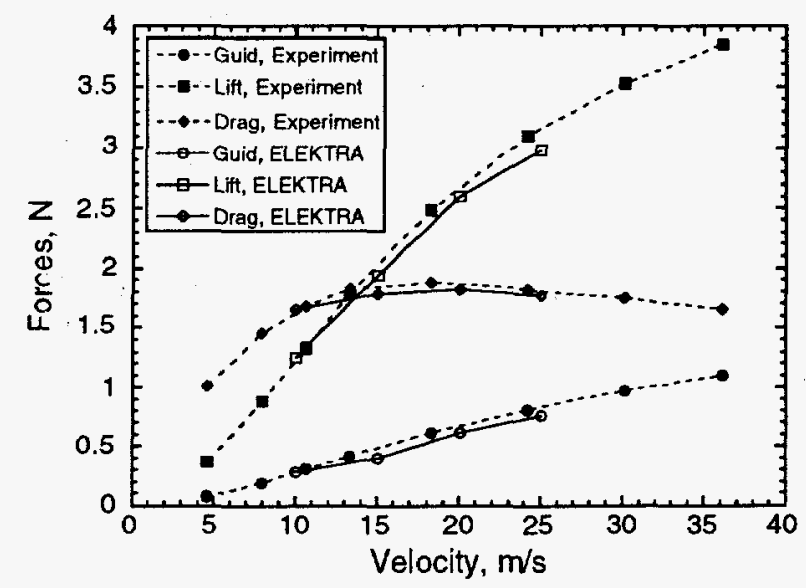

Fig. 20. Measured and ELEKTRA-calculated lift, guidance, and drag forces when $Y^{*}=12.7 \mathrm{~mm}$ 


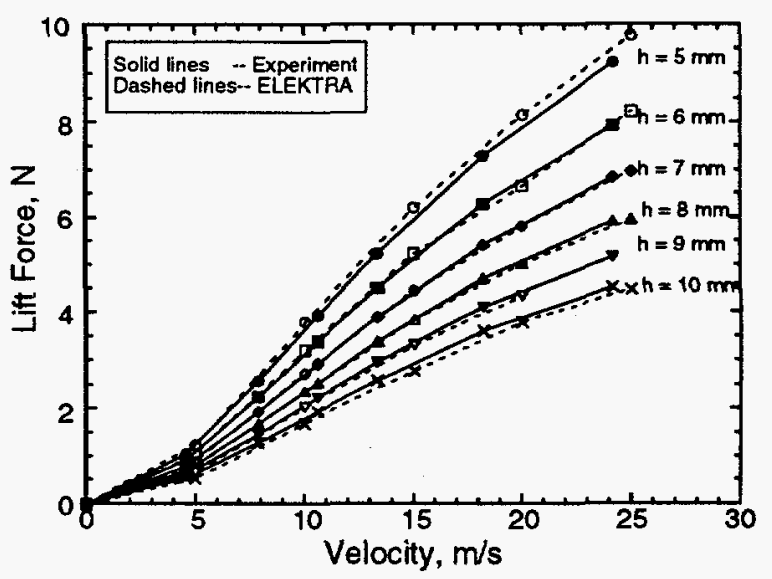

Fig. 21. Measured and ELEKTRA-calculated lift forces when $Y^{*}=5 \mathrm{~mm}$

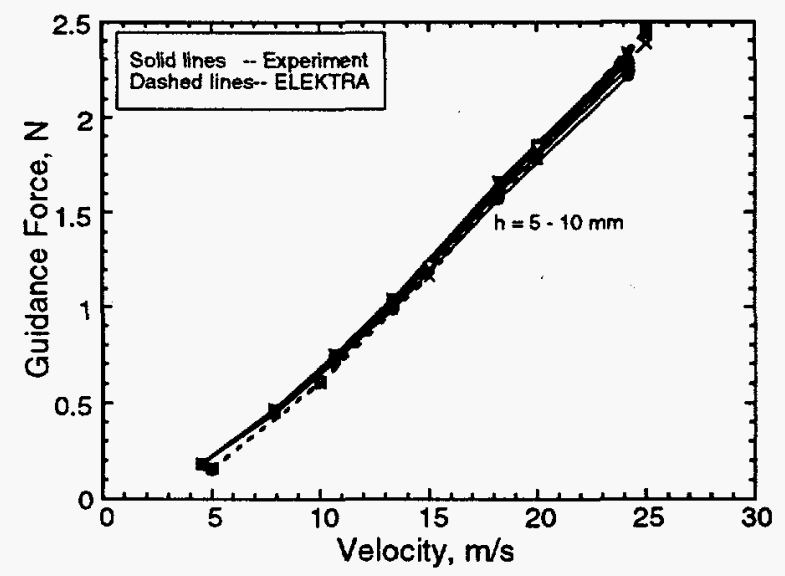

Fig. 22. Measured and ELEKTRA-calculated guidance forces when $Y^{*}=5 \mathrm{~mm}$

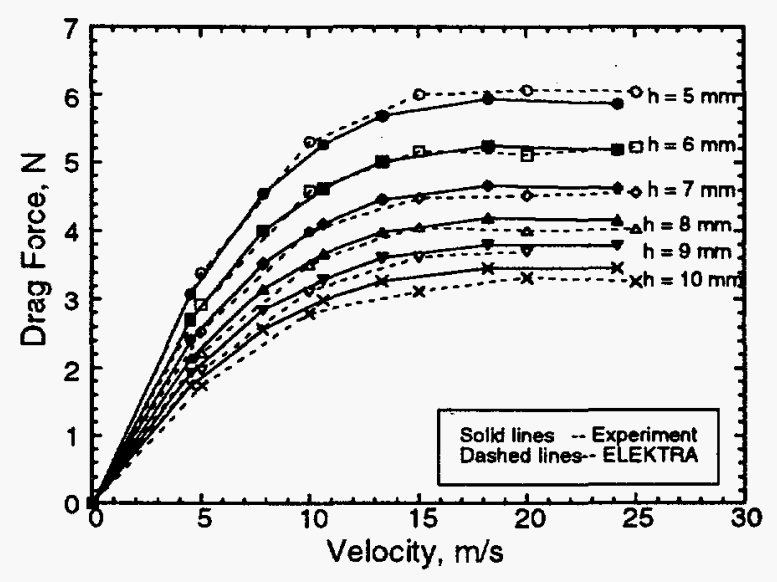

Fig. 23. Measured and ELEKTRA-calculated drag forces when $Y^{*}=5 \mathrm{~mm}$ 


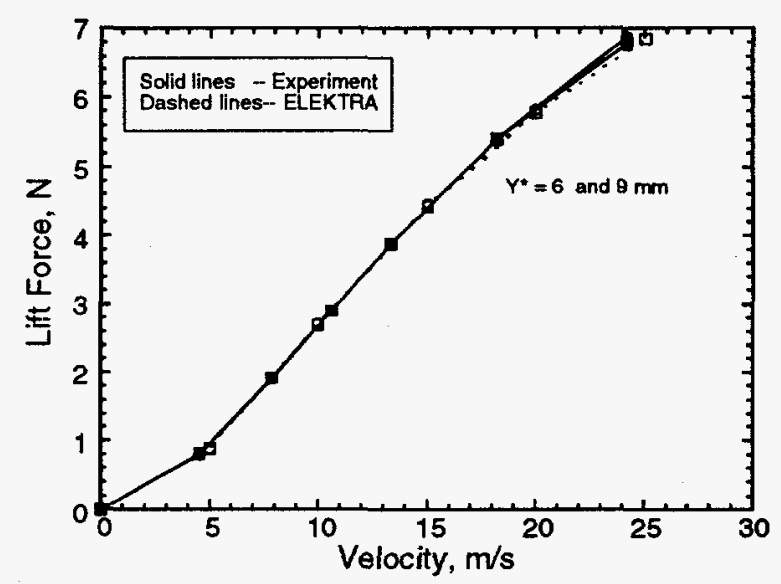

Fig. 24. Measured and ELEKTRA-calculated lift forces when $h=7 \mathrm{~mm}$

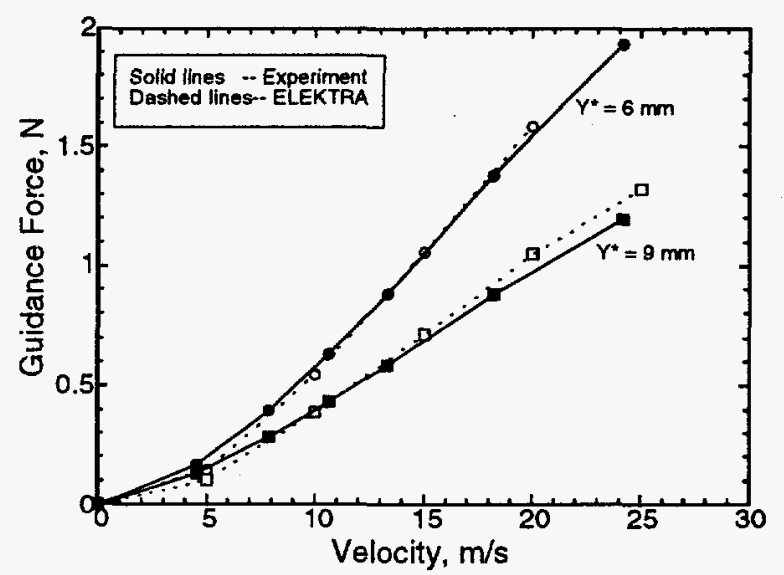

Fig. 25. Measured and ELEKTRA-calculated guidance forces when $h=7 \mathrm{~mm}$

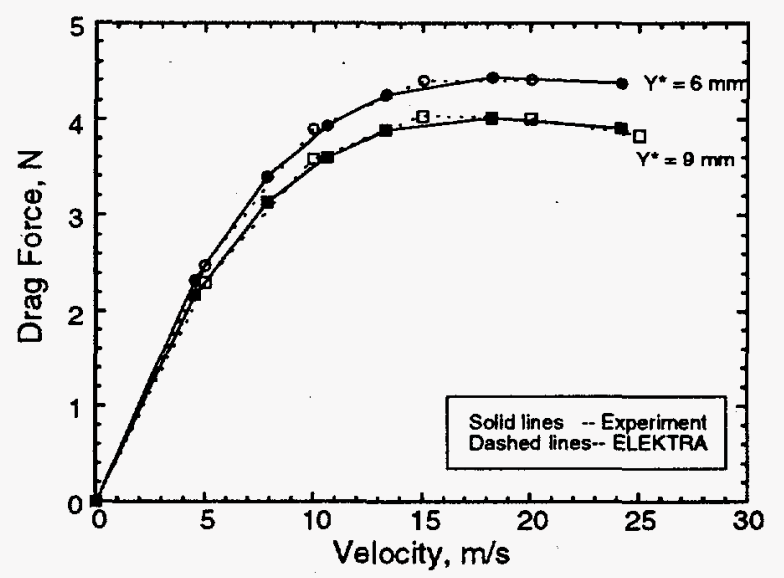

Fig. 26. Measured and ELEKTRA-calculated drag forces when $h=7 \mathrm{~mm}$ 
ELEKTRA has been verified as a means of calculating steady-state magnetic forces, but dynamic forces (of damping) must still be measured because ELEKTRA can treat motion in only one direction.

\subsection{Measuring Magnetic Forces of Guidance Magnets}

As will be discussed later, the $25.4 \times 50.8 \times 6.35-\mathrm{mm}$ rectangular magnet shown in Fig. 3 could not provide sufficient guidance force for a maglev vehicle moving on an L-shaped aluminum guideway. Consequently, additional guidance magnets are needed to increase the guidance force and vehicle stability. A rectangular $12.7 \times 50.8 \times 6.35-\mathrm{mm}$ magnet was selected as a guidance magnet. The measurement of lift and drag forces was conducted by affixing the magnet to a force transducer near the surface of a rotating drum covered with a 14.61-cmwide, $6.35-\mathrm{mm}$-thick aluminum sheet rolled to a diameter of $26.99 \mathrm{~cm}$. The rotating speed can be varied from 0 to $3500 \mathrm{r} / \mathrm{min}$; therefore, the speed of the wheel is $0-50 \mathrm{~m} / \mathrm{s}$ (the detailed experimental setup can be found in Chen et al. 1993). The configuration of the guidance magnet is shown in Fig. 27, where the distance between the magnet and the aluminum sheet is $h$.

The measured lift and drag forces of the guidance magnet as a function of velocity are plotted in Fig. 28, with h fixed at 8.5, 13.5, and $18.5 \mathrm{~mm}$. Lift and drag force data are included in the Appendix. The curve fits to magnetic forces in Fig. 28 were derived from polynomial expressions and incorporated into a computer code for dynamic simulation of a maglev vehicle.

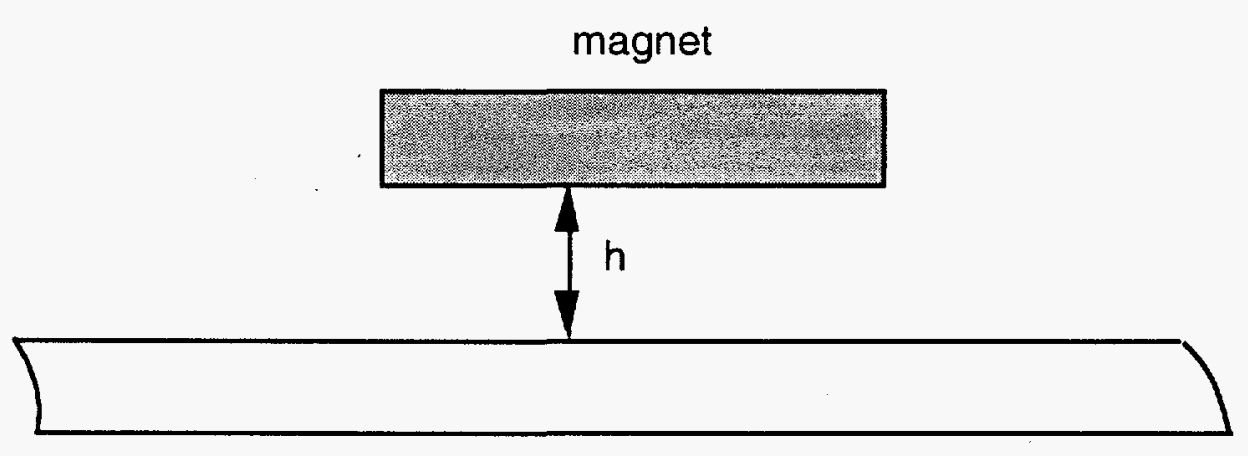

Fig. 27. Guidance magnet on aluminum sheet guideway 


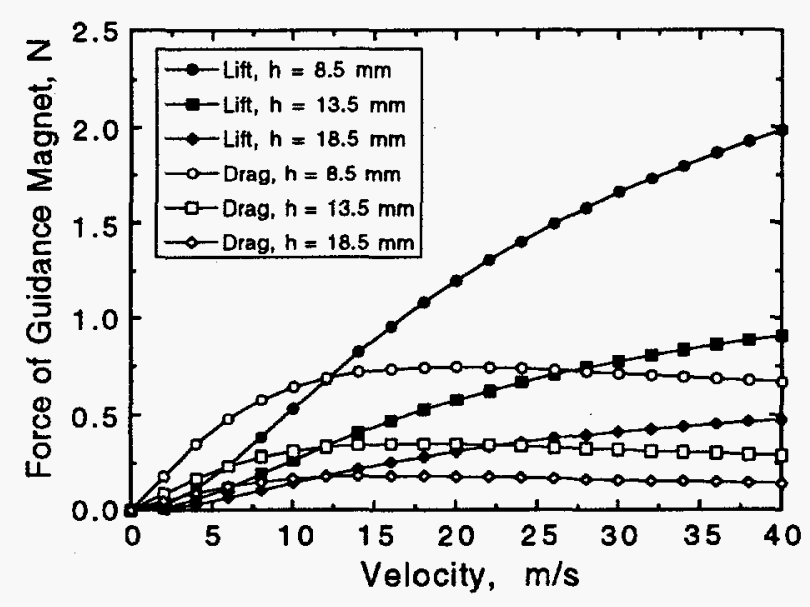

Fig. 28. Measured lift and drag magnetic forces of guidance magnet as a function of velocity

\section{Dynamic Stability Experiments}

The experimental apparatus for the maglev dynamic stability investigation is shown in Fig. 29. Two L-shaped aluminum tracks, like an inverted T, are mounted over a rotating wheel. The maglev vehicle is magnetically levitated over the aluminum track when the wheel rotates with constant but adjustable speed. The vehicle, constrained in its longitudinal direction by a metal tether attached to a shaft whose position can be adjusted (see Fig. 30), is free to move in up to five modes (vertical heave, lateral slip, pitch, yaw, and roll). The rotating speed of the 1.2-m-diameter wheel can be adjusted from 0 to $600 \mathrm{r} / \mathrm{min}(0$ to $37.7 \mathrm{~m} / \mathrm{s})$ on the surface of the wheel.

A force transducer is attached between the tether and support frame; therefore, the drag force applied to the vehicle can be measured. Several small accelerometers are installed on the vehicle body to measure vehicle motion by double analog integration. Displacement and force signals are first filtered by band-pass filters to eliminate low- and high-frequency noises, and then digitized and stored in the analyzer. These signals are then analyzed to obtain frequencies and displacements of vehicle motion as a function of wheel speed. 


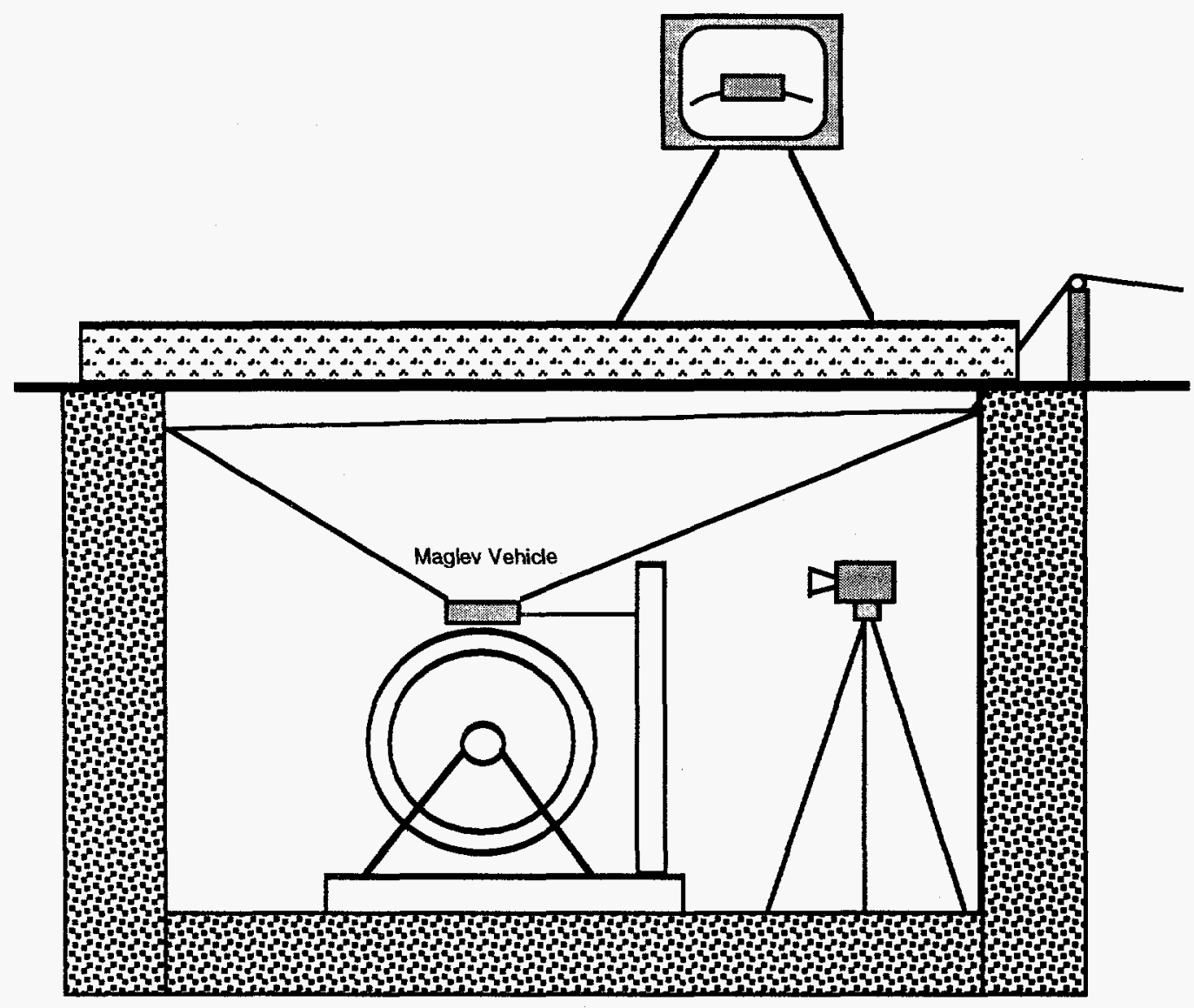

Fig. 29. Schematic diagram of experimental apparatus for testing maglev dynamic stability

For safety, the experimental apparatus is placed in an underground room with heavy concrete covers. A video camera is set beside the wheel. The tests can be observed on a TV set and recorded by a VCR aboveground.

A fishing line is attached to each of the vehicle's four corners to control the position of the vehicle (like moving a puppet). When the vehicle is levitated, the fishing lines are loose; if instability occurs, the vehicle must be pulled out of the track to prevent damage to the vehicle and magnets; when the experiments are finished, the vehicle is hung over the wheel.

The object of this experiment was to investigate the existence of instability in maglev systems. The term instability refers to motions that depart from equilibrium state and are distinguished from random oscillations due to track irregularities and from resonance-driven oscillations associated with the circular nature of the rotating guideway (Chu and Moon 1983). 

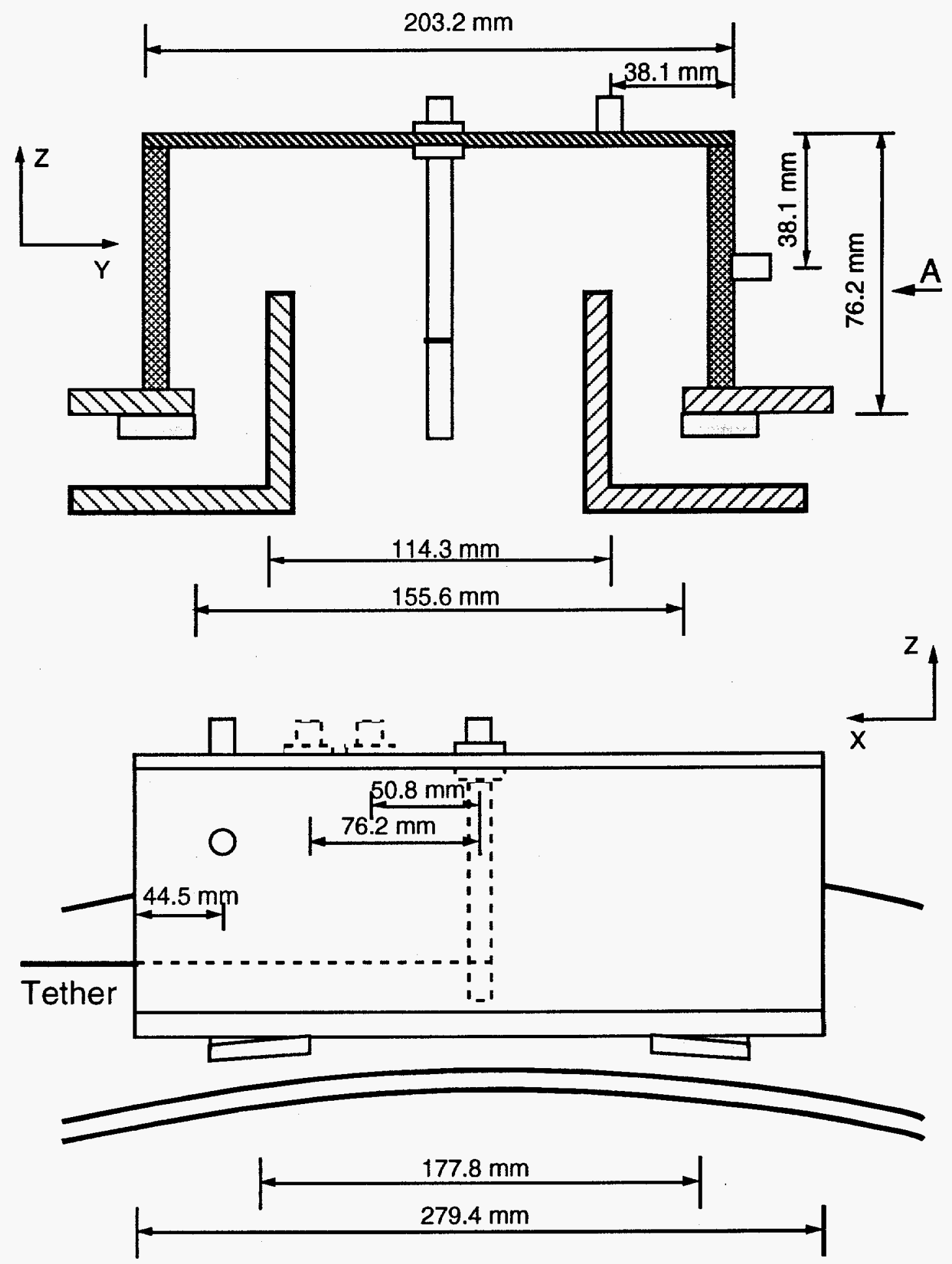

A

Fig. 30. Vehicle model with four levitation magnets for Test $A$ 
Two series of tests (A and B) were performed with a free vehicle moving on a double L-shaped aluminum guideway mounted on the top of the rotating wheel. In Test A, a vehicle model was supported by four permanent magnets on four corners, whereas in Test B, four magnets for levitation and an additional four magnets for guidance were attached to the vehicle. The vehicle's motion in five directions was measured by double analog integration. When the rotating speed of the wheel was varied, stable and unstable motion of the maglev vehicle was observed and recorded.

\subsection{Test A}

The vehicle model, with four $25.4 \times 50.8 \times 6.35-\mathrm{mm}$ rectangular levitation magnets, is shown in Fig. 30. The vehicle body was made of fiberglass/epoxy (G-10) sheet. Dimensions of the vehicle are indicated in Fig. 30. A shaft, to which a tether is attached, can move back and forth along the longitudinal centerline of the vehicle; it constrains the longitudinal DOF of the vehicle. Two accelerometers are installed on the vehicle to measure vertical and lateral motion.

To identify the regions of stability of the vehicle model, several runs were performed under various vehicle conditions, such as, changing lateral gaps to vary guidance forces, adding mass to vary vertical gaps and lift forces, and centering or offsetting the shaft. Dynamic instability was observed under most of the vehicle conditions.

Figure 31 shows typical experimental results. In this test, the total mass of the vehicle was $2.12 \mathrm{~kg}$. The lateral gap was set at $155.6 \mathrm{~mm}$ (see Fig. 30). The test was run from a high speed of $595 \mathrm{r} / \mathrm{min}$ to a low speed of $128 \mathrm{r} / \mathrm{min}$ (if the speed is too low, the lift forces cannot levitate the vehicle). Vertical and lateral displacements were measured with accelerometers by analog integration. Drag force was measured by a force transducer between the tether and the frame. Three cases, with the shaft in the center, and offset 50.8 and $76.2 \mathrm{~mm}$, were plotted in Fig. 31, in terms of RMS vertical and lateral displacements and RMS drag force as function of wheel speed. At least four speed regions were found by both measurement and observation. For example, consider the case with the shaft in the center (Case 1). (1) When the speed is $<132 \mathrm{r} / \mathrm{min}$, the vehicle is unstable, with high-frequency flutter. (2) When the speed is between 132 and $245 \mathrm{r} / \mathrm{min}$, the vehicle is stable, amplitudes of displacement and force are relatively small, and the power spectral densities (PSDs) show clear harmonic 

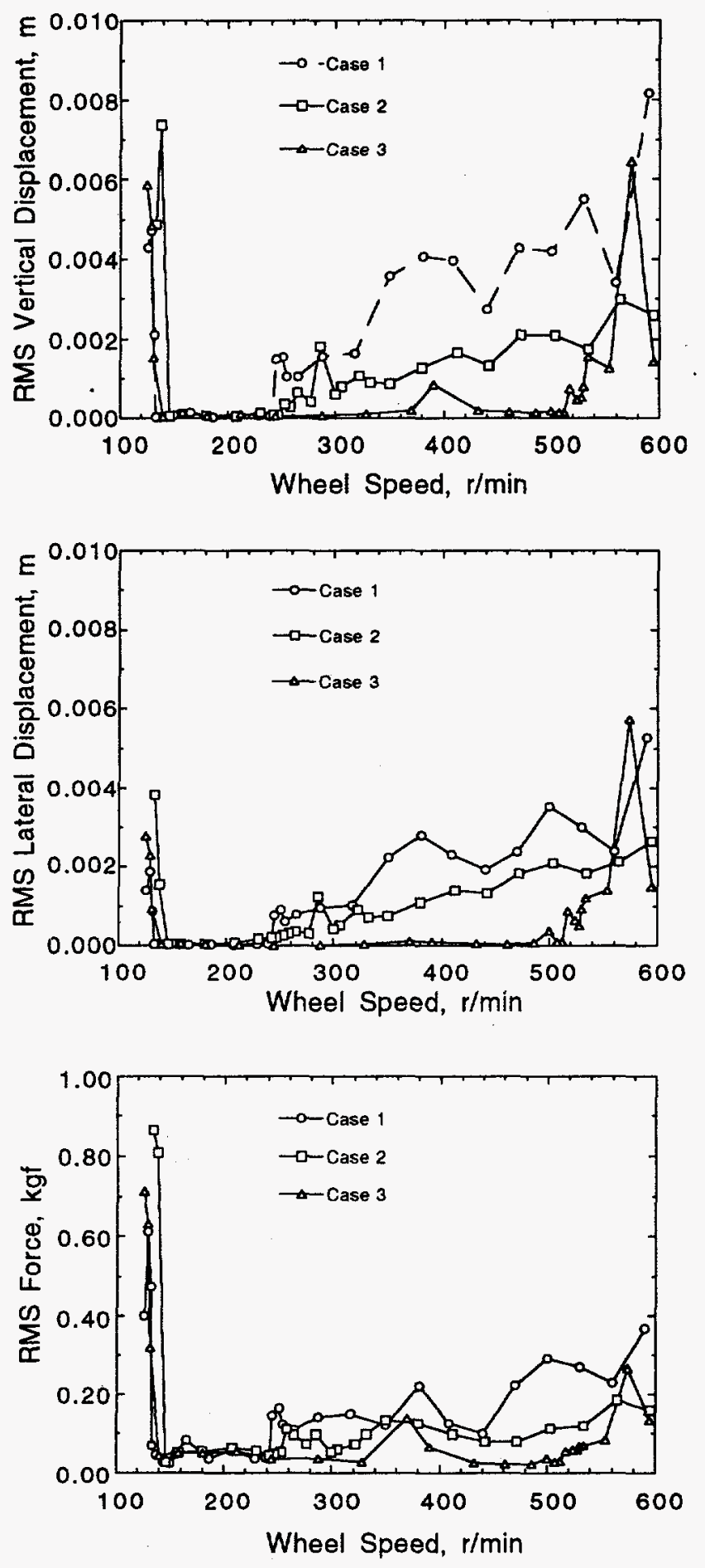

Fig. 31. Experimental results from Test A; Case 1 = shaft centered, Case 2 = shaft offset $50.8 \mathrm{~mm}$, Case 3 = shaft offset $76.2 \mathrm{~mm}$ 
peaks. (3) When the speed is between 245 and $471 \mathrm{r} / \mathrm{min}$, the vehicle is unstable and dominated by slide and yaw instability (divergence), and the oscillating frequency is quite low. (4) When the speed is $>471 \mathrm{r} / \mathrm{min}$, the vehicle is unstable in almost every direction and the oscillation amplitudes in five directions increase significantly. Cases 2 and 3 show the same trends for four speed regions except that the offset from the center of mass in Cases 2 and 3 is accompanied by smaller amplitude motions and drag force fluctuations.

Using the expression for the characteristic velocity $\left(\mathrm{V}_{\mathrm{c}}=2 / \mu_{\mathrm{o}} \sigma \mathrm{T}\right)$ mentioned in the introduction, and the conductivity of aluminum $\left(2.74 \times 10^{7}\right)(\mathrm{S} / \mathrm{m})$, we obtain the value $V_{c} \cong 9 \mathrm{~m} / \mathrm{s} \equiv 143 \mathrm{r} / \mathrm{min}$ (wheel radius $=0.6 \mathrm{~m}$ ). Our previous work with flat-cross-section guideways (Zhu et al. 1994), and that of other investigators cited earlier, show that the intrinsic magnetic damping tends to become negative in the vicinity of this criticai velocity and, depending on other conditions, may reach a maximum negative value at somewhat higher velocities, and then approach zero or positive values with further increases in velocity.

For the moment, we shall assume that, as was the case for flat-cross-section guideway measurements, intrinsic magnetic damping is the dominant source of damping in this experiment. Furthermore, although lift-off velocity $\left(V_{\ell}\right)$ was not mentioned, (the vehicle was highly unstable in this velocity range), extrapolation of the available data indicates that $\mathrm{V}_{\ell} \cong 118 \pm 8 \mathrm{r} / \mathrm{min}$. In addition, the velocity $\left(V_{p}\right)$, which corresponds to the peak in the drag force, is in the range of $15-20 \mathrm{~m} / \mathrm{s}$ (239-318 r/min). The drag force exceeds the guidance force for all parameter values of interest and all velocities, and exceeds the lift force for $\mathrm{V} \leq 15 \mathrm{~m} / \mathrm{s}$. These considerations suggest that, not only is the drag force dominant up to $\approx 240 \mathrm{r} / \mathrm{min}$, but the intrinsic magnetic damping is near zero or negative for speeds near or $>\approx 140 \mathrm{r} / \mathrm{min}$. This would account for the highly unstable nature of the vehicle motion near $\mathrm{V}_{\ell}$, but it would also lead one to expect the vehicle to be unstable at all speeds up to at least $240 \mathrm{r} / \mathrm{min}$.

The experimental results, however, show that the vehicle is, in fact, stable between 140 and $240 \mathrm{r} / \mathrm{min}$. This clear discrepancy suggests that the expectation of unstable operation, based on the considerations given above, is in error. Either the intrinsic magnetic damping phenomenon for the L-shaped guideway is different from that for the flat guideway, or sufficient additional sources of damping are present in the experimental setup. Discussion, to follow, of the results of computer code calculations indicates that this velocity region can be made stable by the addition of a small amount of passive damping. 
Drag force can be thought of as contributing to this test configuration in two ways (in reality the picture is somewhat more complex). One way in which drag force contributes is via eddy currents induced in the lateral leg of the L-shaped guideway conductor. These same eddy currents also produce the lift force. Another way in which drag force contributes is via the eddy currents induced in the vertical leg, which also generates the guidance force. The relative magnitudes of these two contributions changes substantially as the velocity and the height $h$ increase ( $Y^{*}$ fixed). For $0<V \leq V_{\ell}, h=0$, and the drag force contribution from the lateral leg dominates. As $\mathrm{V}$ increases beyond $\mathrm{V}_{\ell}, \mathrm{h}$ must increase, and the relative contribution of the eddy currents in the lateral leg to the drag force decreases. This means that, as $V$ (and therefore $h$ ) increases, the vertical motion of the vehicle is less influenced by the component of the drag force coming from the lateral leg. That component tends to enhance pitching movement and couples rolling into yawing motion. Unfortunately, the contribution of drag force coming from the vertical leg changes very little with $h$. Consequently, the latter component of the drag force continues to have a strong influence on the lateral and yaw motions of the vehicle up to relatively high velocities. The situation is exacerbated by the relatively weak guidance force and lack of damping. It should be noted that both components of the drag force couple to the longitudinal motion of the vehicle, which accounts for the close resemblance of the traces of the horizontal, vertical, and tether forces shown in Fig. 31.

A rough idea of the relative magnitudes of these two contributions to the drag force can be obtained by examining Figs. $6 \mathrm{c}$ and $6 \mathrm{~d}$. In Fig. $6 \mathrm{c}, \mathrm{h}$ is small and the variation of the drag force with $\mathrm{Y}^{*}$ is small. In Fig. $6 \mathrm{~d}, \mathrm{~h}$ is larger and the relative variation of the drag force with $\mathrm{Y}^{*}$ is correspondingly larger. Comparison of Figs. $6 \mathrm{a}$ with $6 \mathrm{c}$, or $6 \mathrm{~b}$ with $6 \mathrm{~d}$, shows that the drag force is three times more sensitive to $\mathrm{h}$ than to $\mathrm{Y}^{*}$.

From observation and analysis, the vehicle model with four magnets (see Fig. 30) is likely to develop a divergence instability because the guidance force provided by the magnet on the L-shaped guideway is quite small when compared with lift and drag forces (see Section 2). Therefore, a new vehicle with additional guidance magnets was assembled and tested in Test $B$.

\subsection{Test B}

The vehicle model, with four $25.4 \times 50.8 \times 6.35-\mathrm{mm}$ levitation magnets and four $12.7 \times 50.8 \times 6.35-\mathrm{mm}$ guidance magnets, is schematically shown in Fig. 32 . 


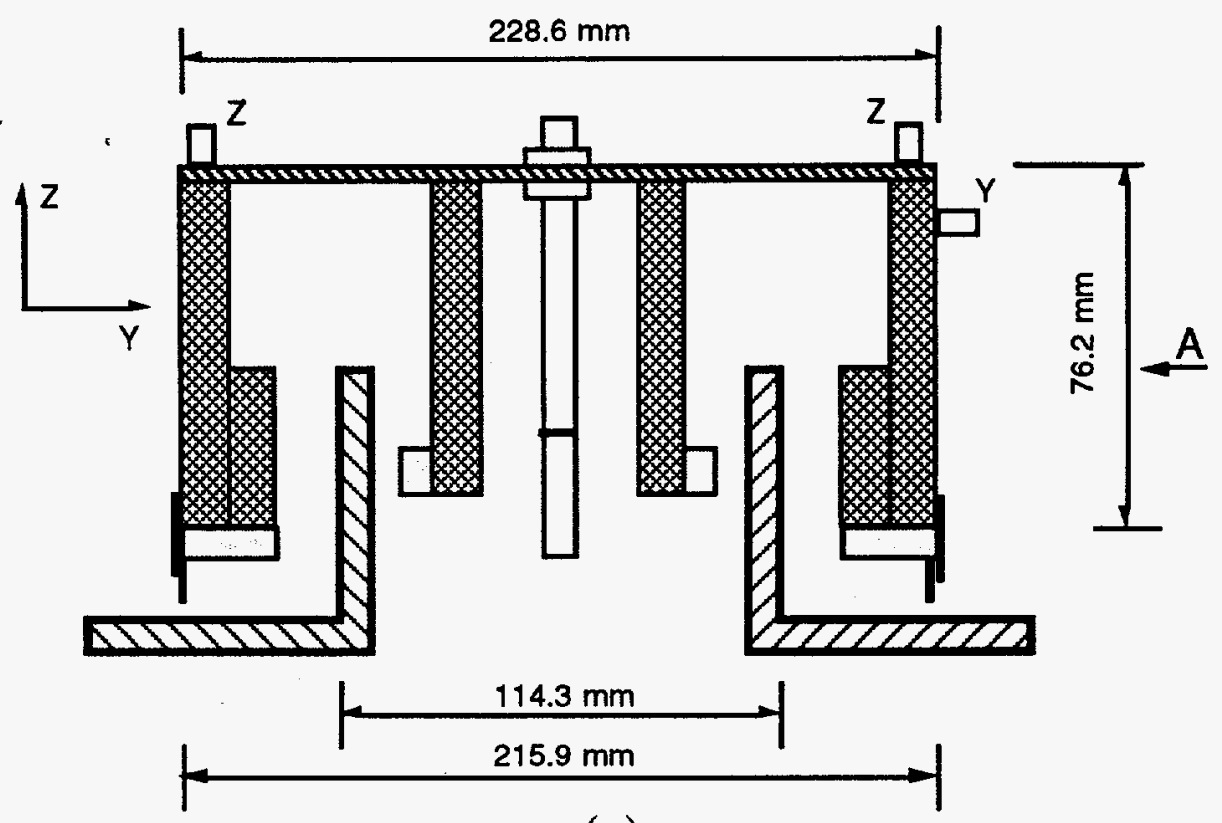

(a)
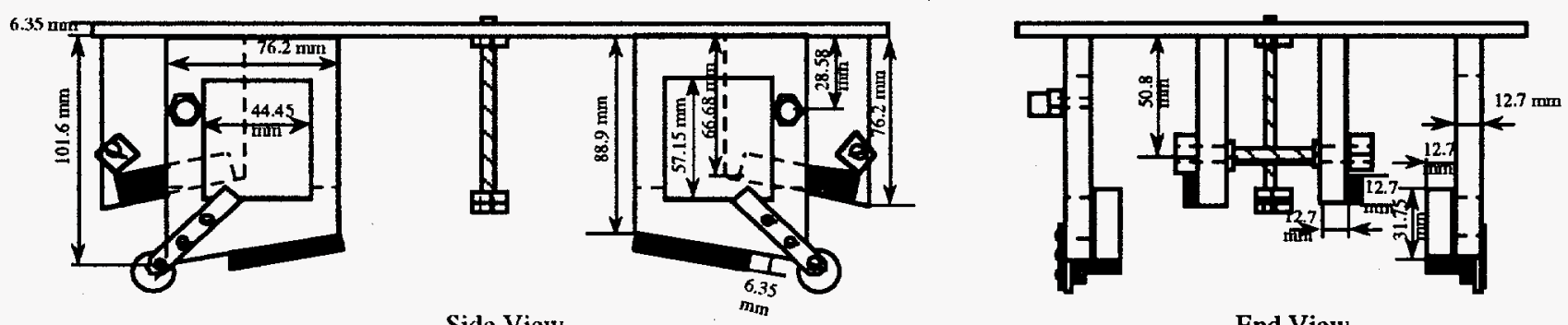

End View

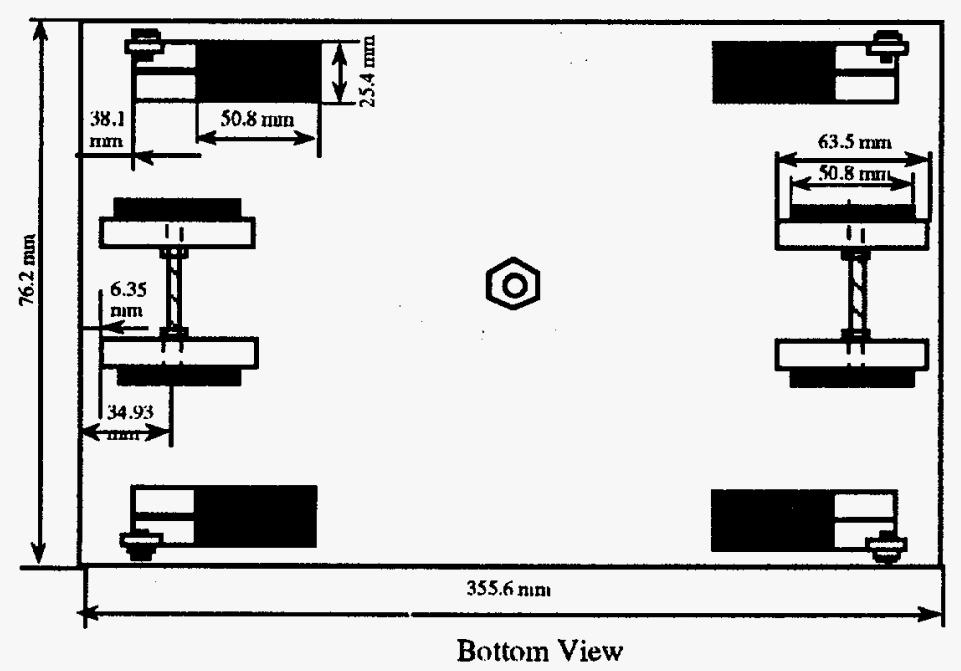

(b)

Fig. 32. Vehicle model with four levitation and four guidance magnets for Test B: (a) schematic diagram, (b) detailed vehicle drawing 
The clearances between the sheet guideway and guidance and levitation magnets can be set at several values. Four small wheels are attached to the vehicle to prevent damage from dynamic instability. The vehicle weight is $2.502 \mathrm{~kg}$ or $24.52 \mathrm{~N}$. Moments of inertia from measurement are $0.4389,0.2840$, and $0.1920 \mathrm{kgm}^{2}$ for $\mathrm{x}, \mathrm{y}$, and $\mathrm{z}$ axes, respectively.

In addition to the force transducer connected to the tether, six accelerometers were placed on the vehicle (Fig. 33): four (Z1, Z2, Z3, and Z4) at the four corners of the vehicle in the vertical direction and two (Y1 and $\mathrm{Y} 2)$ at two corners of one side of the vehicle, in the lateral direction. Accelerations were doubly integrated to obtain displacement. Therefore, vehicle motion, including vertical heave, lateral slide, pitch, yaw, and roll can be calculated from measured displacements as follows:

$$
\begin{aligned}
& \text { Heave }(t)=\left[Z_{1}(t)+Z_{2}(t)+Z_{3}(t)+Z_{4}(t)\right] / 4 \\
& \text { Slide }(t)=\left[Y_{1}(t)+Y_{2}(t)\right] / 2
\end{aligned}
$$

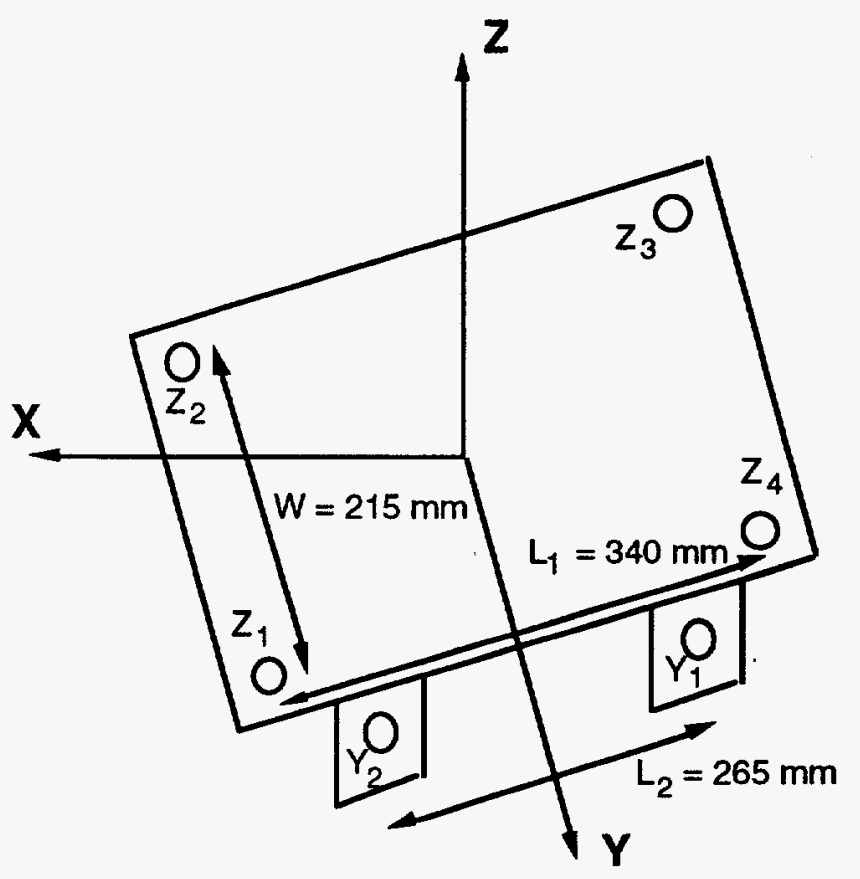

Fig. 33. Accelerometer arrangement for vehicle model in Test $B$ 


$$
\begin{aligned}
& \operatorname{Pitch}(t)=\left[Z_{3}(t)+Z_{4}(t)-Z_{1}(t)-Z_{2}(t)\right] /\left(2 L_{1}\right) \\
& \text { Yaw }(t)=\left[Y_{2}(t)-Y_{1}(t)\right] / L_{2} \\
& \text { Roll }(t)=\left[Z_{1}(t)+Z_{4}(t)-Z_{2}(t)-Z_{3}(t)\right] /(2 W)
\end{aligned}
$$

Vehicle response and stability were tested as a function of speed for a specific configuration of levitation and guidance magnets. When the flywheel was running at speeds from 300 to $600 \mathrm{r} / \mathrm{min}$, two dynamic instability regions were noted. Two video tapes that show the dynamic response of the vehicle at different speeds are available.

A test was conducted to see if the vehicle can be operated in a stable position without the four guidance magnets. The result showed that, in this setup, the vehicle was always unstable. Of course, in this configuration, the lift magnets were deliberately placed far away from the vertical leg of the L-shaped guideway to minimize interaction with that leg.

Several series of tests were performed to investigate the effect of the clearance between the sheet guideway and the magnets. The gap between the sheet guideway and the levitation magnets was set at 1.27 and $2.54 \mathrm{~mm}$, while the gap between the sheet guideway and the guidance magnets was set at $8.5,13.5$, and $18.5 \mathrm{~mm}$. The response characteristics depend on the gaps between the guideway surfaces and the levitation and guidance magnets. However, some general characteristics were noted.

- For speeds $>450 \mathrm{r} / \mathrm{min}$, the motion of the vehicle was small.

- For speeds between 350 and $450 \mathrm{r} / \mathrm{min}$, the motion of the vehicle was fairly large, and one wheel frequently touched the guideway.

- For speeds between 300 and $350 \mathrm{r} / \mathrm{min}$, the motion of the vehicle was again relatively small.

- For speeds $<300 \mathrm{r} / \mathrm{min}$, the vehicle was not yet completely levitated.

Figure 34 shows results of a detailed test performed for the following gaps: $2.54 \mathrm{~cm}$ between the vertical part of the guideway $\mathrm{L}$ and the edge of the levitation magnets; $1.35 \mathrm{~cm}$ beiween the vertical part of the guideway $\mathrm{L}$ and guidance 


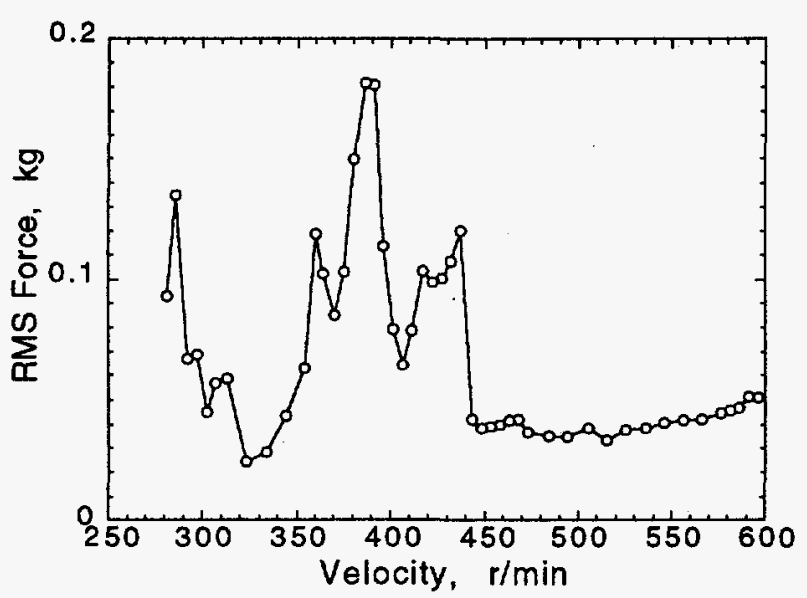

(a)

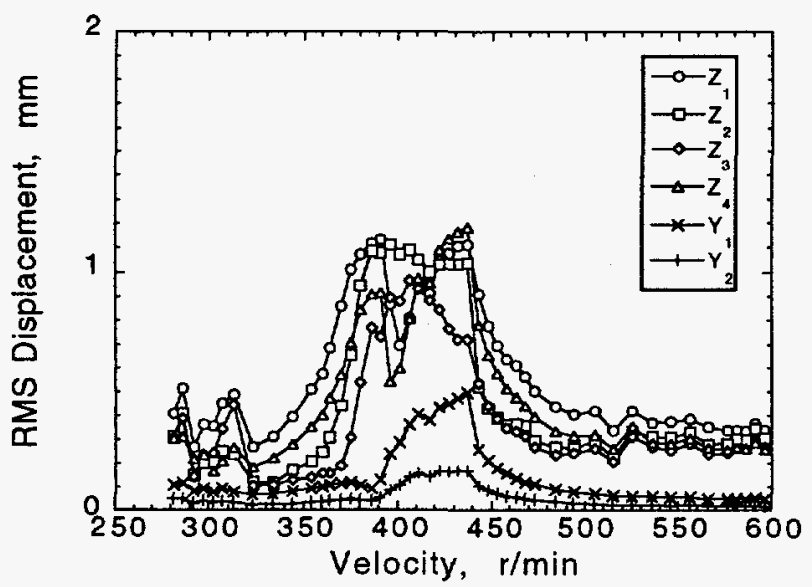

(b)

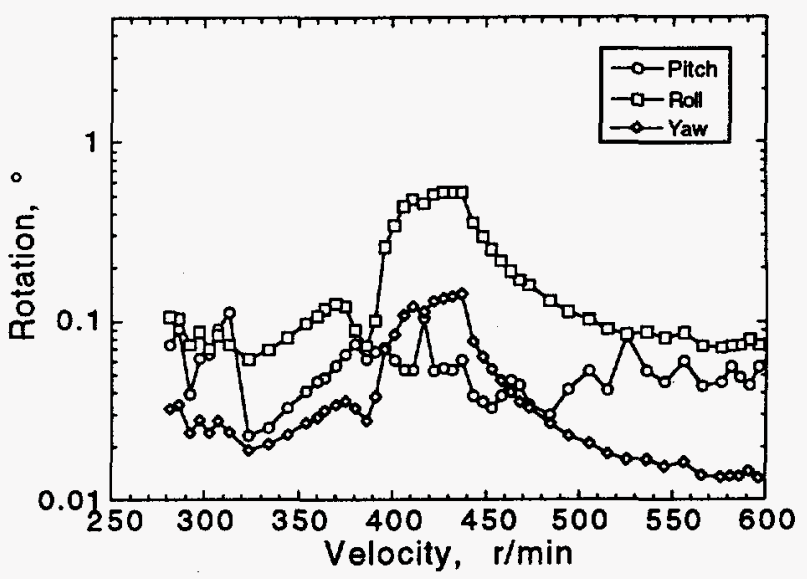

(c)

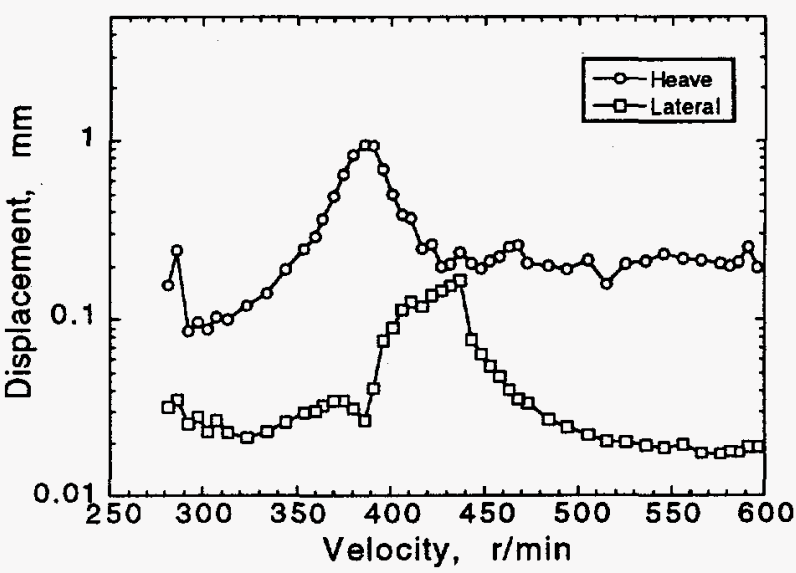

(d)

Fig. 34. Experimental results from Test B. (a) RMS force; (b) RMS displacement; (c) degree of pitch, roll, and yaw; and (d) heave and lateral displacement, all as a function of velocity

magnets (see Fig. 32). Figure 34a shows RMS longitudinal force as a function of the rotating speed of the wheel; Fig. 34b shows RMS displacements at six measurement positions as a function of speed; pitch, roll, yaw, heave, and slide motions, calculated from displacements are given in Figs. 34c and 34d. Note the logarithmic scales in Figs. 34c and 34d. The motion of the vehicle at various rotating speeds from $\approx 600$ to $290 \mathrm{r} / \mathrm{min}$ was recorded on a video tape. At each of the following speeds, the motions were recorded for $\approx 30$ s: $596,455,440,390,380$, $370,330,320,310$, and $290 \mathrm{r} / \mathrm{min}$.

From Fig. 34 and recorded video tape playback, we observe that dynamic instability does indeed exist in this vehicle model, and large motion occurs 
between 350 and $450 \mathrm{r} / \mathrm{min}$. From the video, it was noted that the vehicle touched the guideway intermittently at speeds from 380 to $440 \mathrm{r} / \mathrm{min}$; while at 370 and $455 \mathrm{r} / \mathrm{min}$, no impact was noted. The response characteristics depend on the rotating speed of the flywheel. At $440 \mathrm{r} / \mathrm{min}$, the motion was fairly steady with regular and sometimes intermittent impacts. At $390 \mathrm{r} / \mathrm{min}$, the motion was more irregular; it appeared to be chaotic vibration. At $380 \mathrm{r} / \mathrm{min}$, the motion was fairly steady but, in each cycle, several impacts occurred.

Significantly, it was noted that slide motion was much smaller in Test B than in Test $A$ because the guidance magnets in Test B provided sufficient guidance force. From experimental data and observation, oscillations of the vehicle were dominated by heave and roll motions in Test $B$.

Based on the experimental data, precise identification of the cause of largeamplitude oscillations is difficult. Several mechanisms may be involved: periodic excitation, because of imperfections in the flywheel; motion-dependent magnetic forces; and aerodynamic forces. The results from the experiment indicate future research needs in the area of vehicle dynamics of maglev systems. To predict vehicle response confidently, magnetic and aerodynamic forces, and guideway characteristics must be quantified. The most critical elements in predicting vehicle response are magnetic forces, including steady and unsteady magnetic forces. At this time, only limited steady magnetic forces are available. Future research should be extended to the prediction and measurement of unsteady magnetic forces. The effects of dynamic mode coupling seem to be important and should be investigated in detail.

\section{Numerical Simulation of Maglev Vehicles with Five DOF}

A computer code for simulating the dynamic response of maglev systems has been developed (Coffey et al. 1991; Cai and Chen 1995). The code, which incorporates all of the quasistatic magnetic forces that were measured experimentally and can simulate the nonlinear dynamic response of maglev systems with six DOF when the user inputs vehicle and track configurations, it was employed in this study to calculate dynamic response and the onset of instability in a maglev vehicle model with five DOF. The simulations and predictions were compared with results obtained from the dynamic stability experiments. 


\subsection{Theoretical Aspects}

Consider a maglev vehicle system with six DOF, i.e., three translations, $u_{x}$, $\mathrm{u}_{\mathrm{y}}$, and $\mathrm{u}_{\mathrm{z}}$, and three rotations, $\omega_{\mathrm{x}}, \omega_{\mathrm{y}}$, and $\omega_{\mathrm{z}}$, as illustrated in Fig. 35.

Governing equations of motion of this six-DOF maglev system are derived from Newton's and Euler's equations, and the transform between the vehicle and guideway coordinate systems is based on Euler angles (Cai and Chen 1993a, 1995; Coffey et al. 1972, 1991).

Consider a rigid body vehicle with six DOF (three translations, $\mathbf{u}_{\mathbf{x}}, \mathrm{u}_{\mathrm{y}}$, and $\mathrm{u}_{\mathrm{z}}$, and three rotations, $\omega_{\mathrm{x}}, \omega_{\mathrm{y}}$, and $\omega_{\mathrm{z}}$. Let $U$ be the translation vector and $\Omega$ the rotation vector, i.e.,

$$
\mathrm{U}=\left\{\begin{array}{l}
\mathrm{u}_{\mathrm{x}} \\
\mathrm{u}_{\mathrm{y}} \\
\mathrm{u}_{\mathrm{z}}
\end{array}\right\}, \quad \Omega=\left\{\begin{array}{c}
\omega_{\mathrm{x}} \\
\omega_{\mathrm{y}} \\
\omega_{\mathrm{z}}
\end{array}\right\} .
$$
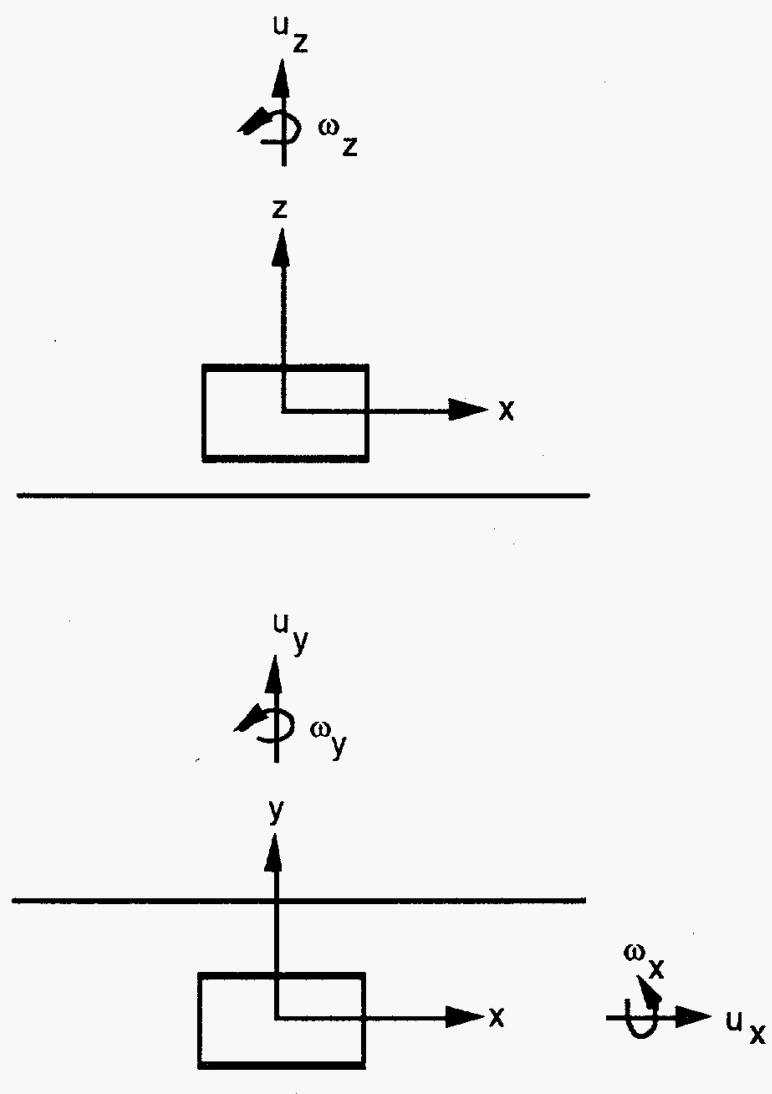

Fig. 35. Displacement components of a maglev system 
To transform from the vehicle to the guideway coordinate system, the Euler angles $\psi$ (heading), $\theta$ (attack), and $\phi$ (roll) are introduced (Coffey et al. 1972, 1974a, 1991). A vector $\bar{R}_{g}$ in the guideway coordinates transforms from a vector $\bar{R}_{v}$ in the vehicle coordinates as

$$
\overline{\mathbf{R}}_{\mathrm{g}}=[\ell] \overline{\mathrm{R}}_{\mathrm{v}}
$$

with the transformation matrix given by

$$
[\ell]=\left[\begin{array}{ccc}
\cos \theta \cos \psi & -\sin \psi \cos \phi+\cos \psi \sin \theta \sin \phi & \sin \psi \sin \phi+\cos \psi \sin \theta \cos \phi \\
\cos \theta \sin \psi & \cos \psi \cos \phi+\sin \psi \sin \theta \sin \phi & -\cos \psi \sin \phi+\sin \psi \sin \theta \cos \phi \\
-\sin \theta & \cos \theta \sin \phi & \cos \theta \cos \phi
\end{array}\right] .
$$

Equations of motion expressed in the vehicle coordinate system can be written as

$$
\left.\begin{array}{l}
M \vec{U}+C \bar{U}=M \vec{G}+M(\bar{U} \times \dot{\Omega})+\vec{F}_{m} \\
I \bar{U}+D \vec{U}=I \bar{\Gamma}+R \cdot \vec{F}_{m}
\end{array}\right\},
$$

where $M$ and I are the mass of the vehicle and the moment of inertia about the center of the mass of the vehicle, and are defined by

$$
\mathrm{M}=\left[\begin{array}{ccc}
\mathrm{m} & 0 & 0 \\
0 & \mathrm{~m} & 0 \\
0 & 0 & \mathrm{~m}
\end{array}\right], \quad \mathrm{I}=\left[\begin{array}{ccc}
\mathrm{I}_{\mathrm{x}} & 0 & 0 \\
0 & \mathrm{I}_{\mathrm{y}} & 0 \\
0 & 0 & \mathrm{I}_{\mathrm{z}}
\end{array}\right]
$$

and $\mathrm{C}$ and $\mathrm{D}$ are damping coefficient matrices

$$
\mathrm{C}=\left[\begin{array}{lll}
\mathrm{c}_{11} & \mathrm{c}_{12} & \mathrm{c}_{13} \\
\mathrm{c}_{21} & \mathrm{c}_{22} & \mathrm{c}_{23} \\
\mathrm{c}_{31} & \mathrm{c}_{32} & \mathrm{c}_{33}
\end{array}\right], \quad \mathrm{D}=\left[\begin{array}{lll}
\mathrm{d}_{11} & \mathrm{~d}_{12} & \mathrm{~d}_{13} \\
\mathrm{~d}_{21} & \mathrm{~d}_{22} & \mathrm{~d}_{23} \\
\mathrm{~d}_{31} & \mathrm{~d}_{32} & \mathrm{~d}_{33}
\end{array}\right]
$$

The damping coefficient in Eq. 6 should be determined from experimental data. Before these experimental data are available, assumed damping ratios can be utilized in the simulations $\left(C_{i i}=0.025, C_{i j}[i \neq j]=0, D_{i j}=0\right)$. The elements of $\bar{G}$ and $\bar{r}$ are defined by 


$$
\overline{\mathrm{G}}=\left\{\begin{array}{c}
-\mathrm{g} \sin \theta \\
\mathrm{g} \cos \theta \sin \phi \\
\mathrm{g} \cos \theta \cos \phi
\end{array}\right\}
$$

and

$$
\vec{\Gamma}=\left\{\begin{array}{l}
\frac{I_{y}-I_{z}}{I_{x}} \dot{\omega}_{y} \dot{\omega}_{z} \\
\frac{I_{z}-I_{x}}{I_{y}} \dot{\omega}_{z} \dot{\omega}_{x} \\
\frac{I_{x}-I_{y}}{I_{z}} \dot{\omega}_{x} \dot{\omega}_{y}
\end{array}\right\}
$$

$\overrightarrow{\mathrm{F}}_{\mathrm{m}}$ is the magnetic force applied on the center of the mass, and $\mathrm{R}$ is the moment arm matrix. Because the applied forces depend on the distances between the vehicle and the guideway surfaces, but all components of the forces and moments in the equations of motion are to be expressed along the axes of the vehicle, the transformation must convert forces from one coordinate to the other.

Because the time derivatives of the Euler angles $\psi, \theta$, and $\phi$ are related to the rotational velocities,

$$
\left.\begin{array}{l}
\dot{\psi}=\sec \theta\left(\dot{\omega}_{\mathrm{z}} \cos \phi+\dot{\omega}_{\mathrm{y}} \sin \phi\right) \\
\dot{\theta}=\dot{\omega}_{\mathrm{y}} \cos \phi-\dot{\omega}_{\mathrm{z}} \sin \phi \\
\dot{\phi}=\dot{\omega}_{\mathrm{x}}+\tan \theta\left(\dot{\omega}_{\mathrm{z}} \cos \phi+\dot{\omega}_{\mathrm{y}} \sin \phi\right)
\end{array}\right\}
$$

Because only a five-DOF vehicle model is considered in the dynamic simulation and in experiments performed with the ANL rotating-wheel facility, the longitudinal motion $u_{x}$ of the vehicle is restricted and can be assumed to be zero in the equations of motion. 


\subsection{Computer Code for Maglev Systems}

A computer code, based on governing Eqs. 4-9, was developed for nonlineardynamic simulation of maglev systems (Cai and Chen 1993a, 1995; Coffey et al. 1972, 1974a, 1991). The program uses the fourth-order Runge-Kutta method to numerically integrate nonlinear differential equations that characterize the dynamics of maglev vehicles.

The objective of the computer code is to predict the dynamic behavior of the five-DOF maglev systems described in Section 3, even though the code can be extended to cover a wider range of vehicle and guideway designs. The differing system descriptions in Test $A$ and Test $B$, such as design of vehicle and track geometry, number and size of magnets, and vehicle traveling speed, can easily be included in a user-friendly input package of the code. Then, a specific subroutine of the code will automatically calculate essential parameters of vehicle/track systems for later numerical simulation.

Magnetic-force data from experimental measurements are incorporated in force subroutines of the code. Once the distances between the magnets and the sheet guideway are calculated during each time step, lift, guidance, and drag forces on each magnet are determined from prestored magnetic-force data curves by a multidimensional interpolation method. Then, total magnetic forces and moments acting on the vehicle body are calculated and inserted into differential equations. The coordinate transformation (Eq. 2) is required to convert forces from one coordinate to the other, because the applied forces are dependent on the distance between the vehicle and the guideway surfaces, but all components of the forces and moments in the equations of motion are to be expressed along the axes of the vehicle body.

One difficulty with describing the system is how to express system damping in the differential equation. The system damping is very important in the dynamic and stability analysis. However, so far, an actual system damping ratio cannot be obtained by either experimental or analytical methods. Therefore, we assumed the reasonable value of $+2.5 \%$ for the damping ratio in most of the simulations and that this ratio is vehicle-speed-independent. Here, the reasonable value means that with this value, simulation results would be closest to those obtained from experiments. Also, differing damping values are considered in the simulation. Usually, if the damping ratio is increased to a certain value, the vehicle motion would be stable in the whole speed range; if less damping is assumed, the instability region broadens. The system damping affects motions in all directions. 


\subsection{Numerical Simulation of Test $A$ and Comparison with Experimental Results}

Typical experimental results from Case 1 of Test A (see Fig. 31) are replotted in Fig. 36, with RMS force and displacements as a function of wheel surface velocity $(\mathrm{m} / \mathrm{s})$. Several speed regions were found by measurement and observation. (1) When the wheel speed was $<6 \mathrm{~m} / \mathrm{s}$, the vehicle was unstable, with high-frequency (flutter) due to a large drag force. (2) When the speed was between 6 and $13 \mathrm{~m} / \mathrm{s}$, the vehicle was stable and amplitudes of displacement and force were relatively small. (3) When the speed was between 13 and $30 \mathrm{~m} / \mathrm{s}$, the vehicle was unstable and dominated by vertical, slide, and yaw (not shown in Fig. 36) instabilities. (4) When the speed was $>30 \mathrm{~m} / \mathrm{s}$, the vehicle was unstable in almost every direction and the oscillation amplitudes in five directions increased significantly.

Numerical simulation of the dynamic response of a five-DOF maglev vehicle was carried out by using vehicle dimension input as described in Fig. 30 and Section 3. Figure 37 shows the simulation results of lateral and vertical displacements of vehicle mass center for various wheel speeds, with initial perturbations of $\mathrm{z}_{0}$ and $\mathrm{y}_{0}$ equal to $0.1 \mathrm{~mm}$. The system damping ratio in the simulation was assumed to be $2.5 \%$. For vertical displacement, a positive value means the vehicle is moving toward the guideway. The following conclusions can be drawn. (1) When vehicle velocity is $15 \mathrm{~m} / \mathrm{s}$, the vehicle is stable. Its amplitudes of vertical and lateral motion decrease as time increases. (2) For vehicle velocities of 20,25 , and $30 \mathrm{~m} / \mathrm{s}$, both lateral and vertical oscillation amplitudes increase until the vehicle hits the guideway. (3) With defined vehicle parameters, vehicle motion is dominated by slide and yaw instabilities, even though heave instability, caused by weak guidance force, is still present. (4) Oscillation frequency varies

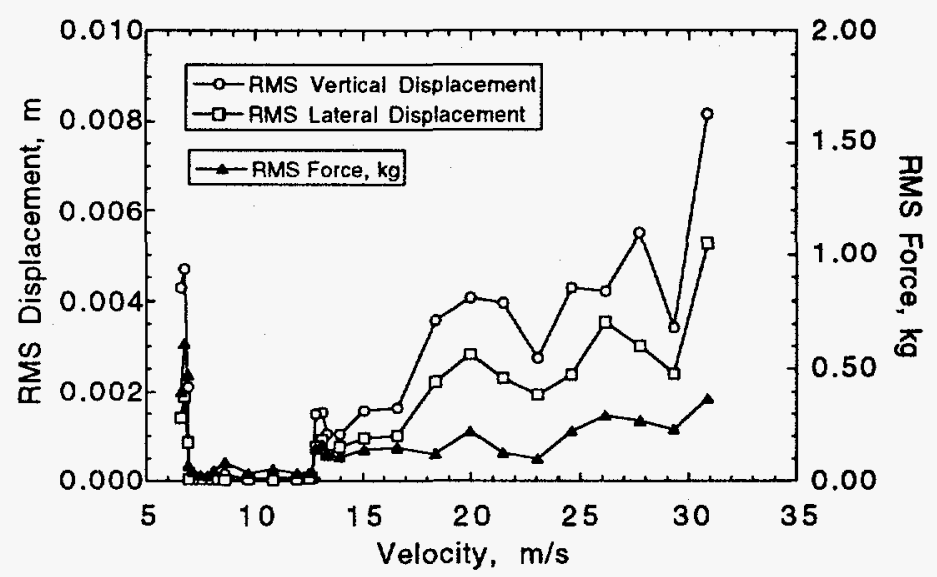

Fig. 36. Experimental results from Case 1 in Test A 


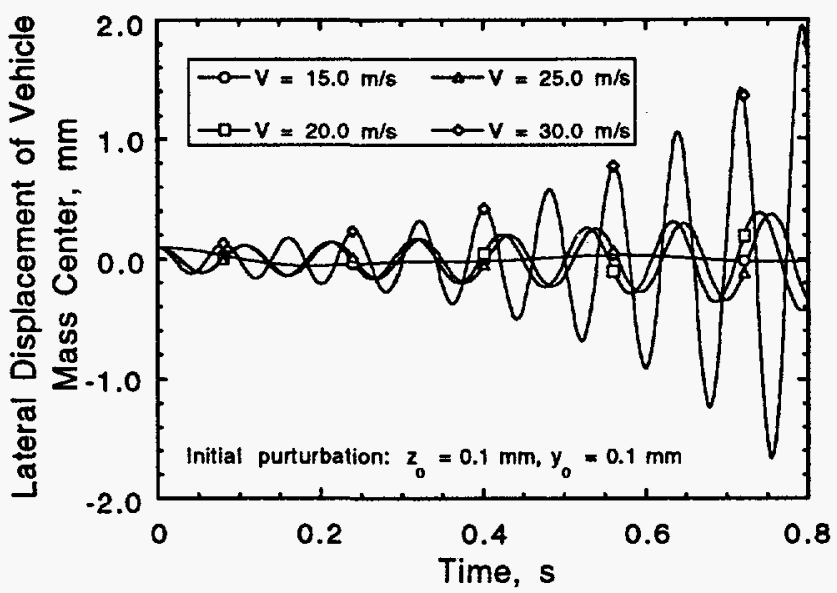

(a)

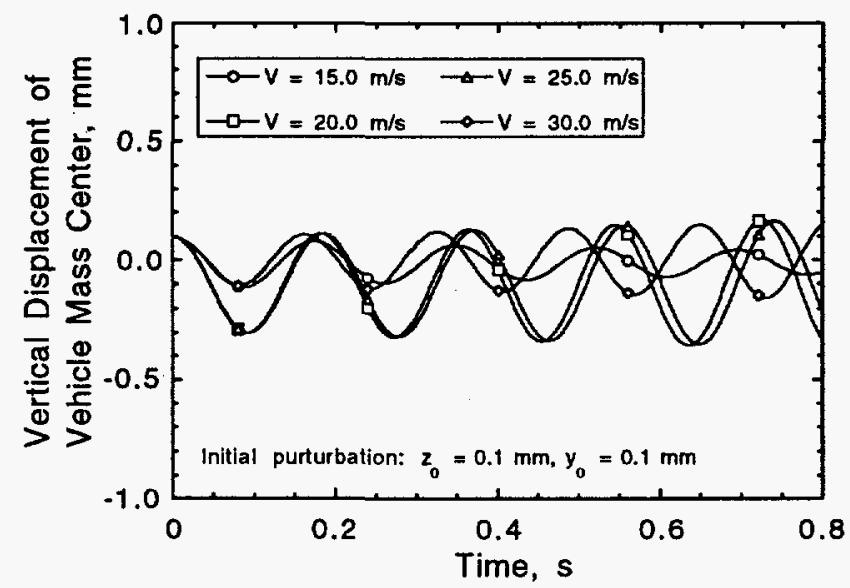

(b)

Fig. 37. Simulation results of (a) lateral and (b) vertical mass center displacement in Test A at various vehicle speeds

with the vehicle velocity because of lift and drag force stiffness. In stable regions, frequency is quite low. (5) The current computer program is unable to deal with nonlinearity when the vehicle hits the guideway. For all calculations of time history, the program automatically stops once any side of a vehicle hits the guideway; therefore, it cannot be used to calculate RMS values of displacement and power spectral density (PSD) for comparison with the experimental data shown in Fig. 36. Consequently, because the simulated lateral instability grows much more rapidly than the vertical instability, the simulation is stopped by lateral motion that strikes the guideway wall long before the vertical motion has time to build up. Hence, an apparent discrepancy exists between the experimentally observed large lateral and vertical motions, and the simulated large lateral motions. 
Figure 38 shows time histories of both lateral and vertical motion of a vehicle with a velocity of $30.0 \mathrm{~m} / \mathrm{s}$. Lateral motion is rapidly developed and, finally, the vehicle hits the guideway. Notice that the oscillation period changes when the amplitude of lateral motion increases. After the vehicle contacts the side wall of the L-shaped guideway ( $\mathrm{t}>1.0 \mathrm{~s}$ ), the lateral motion of vehicle mass center increases significantly and period is reduced.

Figure 39 shows five vehicle motions, slip, heave, yaw, pitch, and roll, when vehicle velocity $=20.0 \mathrm{~m} / \mathrm{s}$ and initial perturbation is $0.1 \mathrm{~mm}$ in slip and heave motion and $0.1^{\circ}$ in pitch and roll motion. In this particular case, pitch and roll motion is stable, whereas slip, heave, and yaw motion is unstable. The frequency and phase of the five motions differ, which may be attributed to weak coupling of motion in various directions. The slip and yaw motions are strongly coupled, but only weakly coupled to the vertical modes. This finding is consistent with the force characteristics presented in Section 2.2.

\subsection{Numerical Simulation of Test B and Comparison with Experimental Results}

Typical results from Test B (see Fig. 34) are replotted in Fig. 40, with RMS values of heave, slide, yaw, pitch, and roll motion of the vehicle as a function of wheel surface velocity ranging from 15 to $31 \mathrm{~m} / \mathrm{s}$, with the lateral gap between guidance magnets and the vertical part of the guideway $\mathrm{L}$ equal to $13.5 \mathrm{~mm}$. Large motion occurs between 19 and $23 \mathrm{~m} / \mathrm{s}$. When the velocity is $<18 \mathrm{~m} / \mathrm{s}$ or $>24 \mathrm{~m} / \mathrm{s}$, the vehicle was very stable (Fig. 40 ).

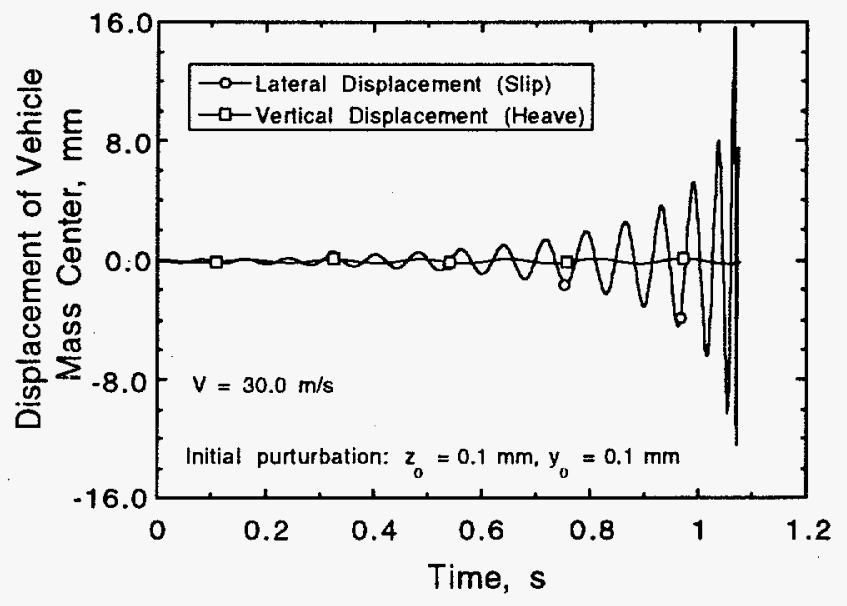

Fig. 38. Simulated time histories of lateral and vertical displacement of vehicle that contacts side wall of guideway 


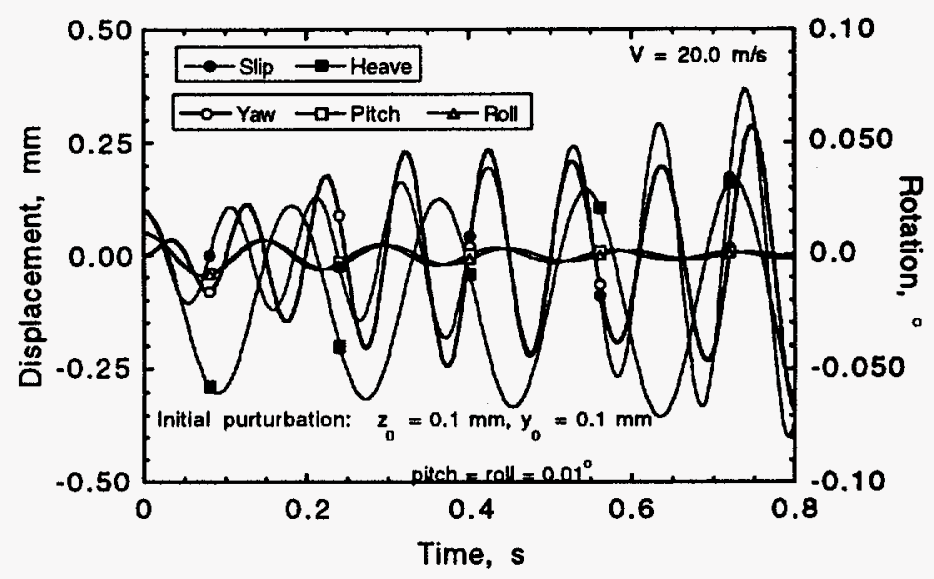

Fig. 39. Simulation results of displacement and rotation in Test $A$ when vehicle speed $=20 \mathrm{~m} / \mathrm{s}$
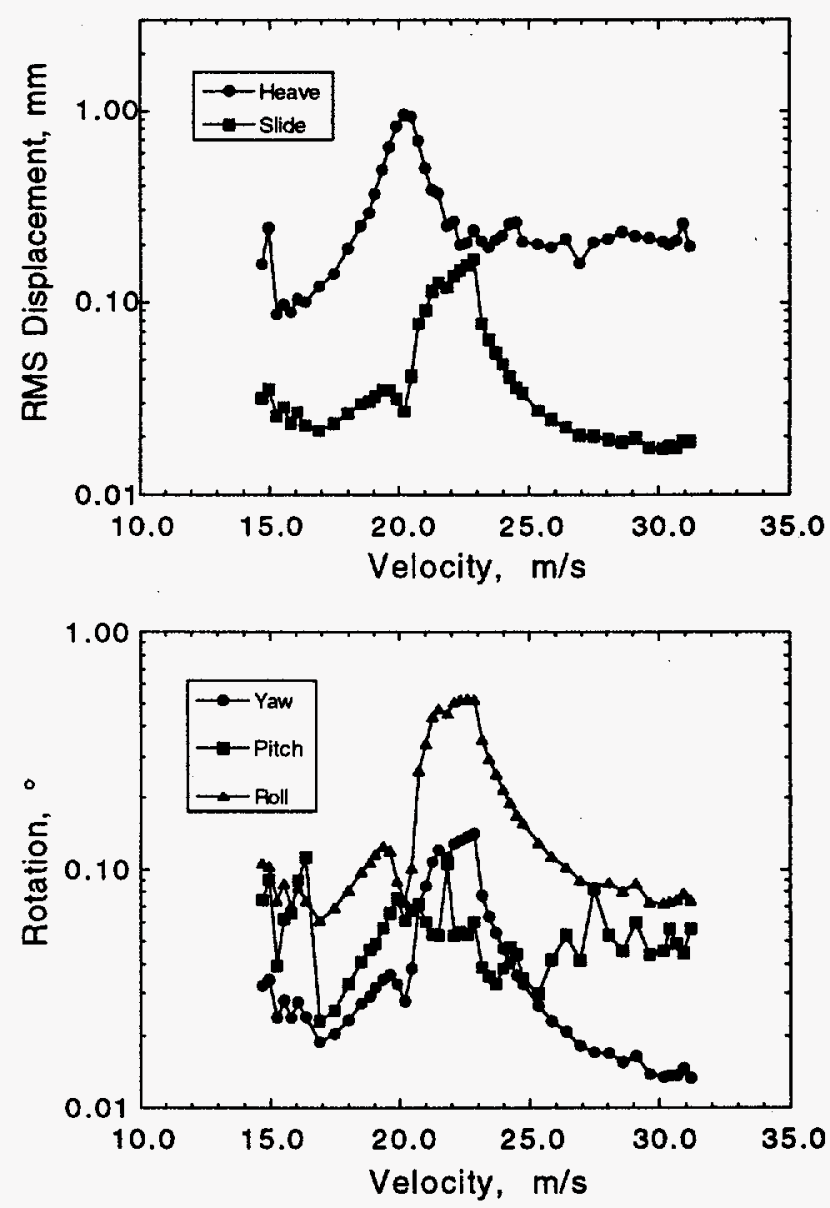

Fig. 40. Experimental results when guidance magnet gap $=13.5 \mathrm{~mm}$ in Test $B$ 
Numerical simulation was carried out for the vehicle in Test $B$. The vehicle configuration and position of the magnets were measured and input into the program. Detailed vehicle dimensions and other parameters have been described in Section 3.2. In the simulation, the initial gaps between magnets and the guideway $\mathrm{L}$ were set as follows: lateral gap, $13.5 \mathrm{~mm}$; vertical gap, equal to the value at which the lift forces of four lift magnets were sufficient to balance the vehicle weight at given wheel speeds; initial perturbations $\mathrm{z}_{0}$ and $\mathrm{y}_{0}$ at vertical and lateral directions, $0.1 \mathrm{~mm}$; and system damping ratio, $2.5 \%$. Note that, for vertical displacement, a positive value means the vehicle is moving toward the guideway.

Figures 41-44 show the time histories of simulation results at vehicle velocities of $15,20,25$, and $30 \mathrm{~m} / \mathrm{s}$, respectively. The following conclusions can be drawn. (1) With strong guidance forces provided by four guidance magnets, slide motion decays very quickly ( $<4 \mathrm{~s}$, which seems to agree well with experimental observations), and no slide or yaw instabilities are present in the whole speed range. When the vehicle velocity increases, the period for slide motion to die out decreases because guidance forces and stiffness of guidance forces increase with wheel velocity. This conclusion can also be applied to all of the rotation motions. (2) Pitch oscillations are quite small because, in the calculation, drag force moments are balanced mostly by the moment of the tether. However, because of the rest of the unbalanced drag moment, some pitch angle offset is still present when oscillation disappears. (3) Oscillating frequencies of various motions differ significantly for this configuration. (4) The vehicle motion is dominated by heave motion, and heave instability occurs when vehicle velocity is $20 \mathrm{~m} / \mathrm{s}$, which is in good agreement with the experimental result shown in Fig. 40.

The drag force produced by the four lift magnets may play an important role in these experiments. Figure 45 shows the guidance force (actually, lift force to the magnet, see Section 2.3, but guidance force to the vehicle) and drag force of the guidance magnet as a function of vehicle speed. Drag force is small and remains almost constant in the test speed region. Thus, the influence of the drag force of the guidance magnet on vehicle motion could be ignored. Figure 46 gives the initial vertical gap at which magnets support the vehicle and the drag force that is produced by the lift magnet at various speeds. As the velocity increases, the vertical gap between the magnet and sheet guideway increases because the lift force needed to balance the vehicle weight remains the same; whereas, in this same situation, the drag force decreases. 

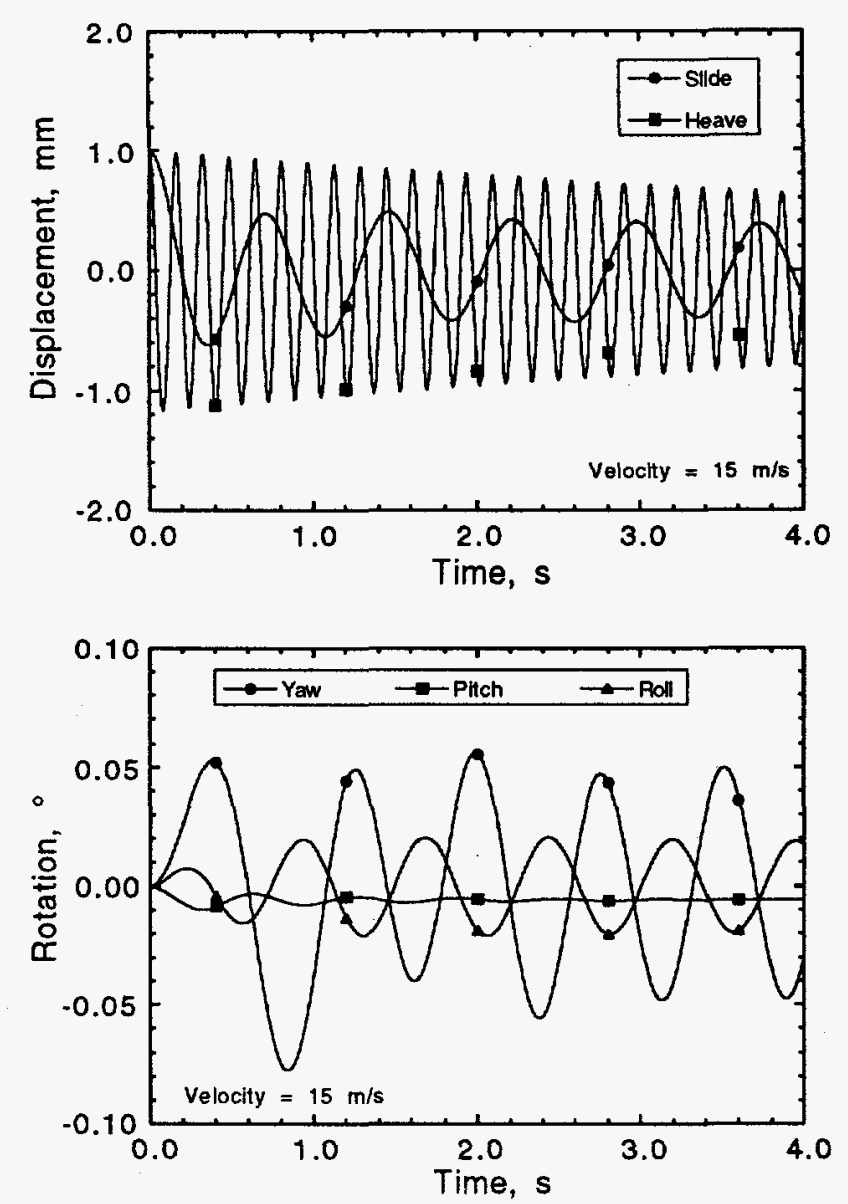

Fig. 41. Simulation results of displacement and rotation in Test $B$ when vehicle speed $=15 \mathrm{~m} / \mathrm{s}$

\section{Conclusions}

Measurement of magnetic forces is critically important to the analysis of any vehicle dynamics, design of guideway structures and fastening, and prediction of ride quality. In this report, force components are considered from the standpoint of vehicle stability. The report documents magnetic-force data obtained from both experiments and calculations for a permanent magnet moving over a sheet guideway. All of the experimental data have been incorporated into an existing computer program for simulation of nonlinear dynamics of maglev vehicles. The magnetic-force data, which have never been published, will provide potential references for future maglev programs. 

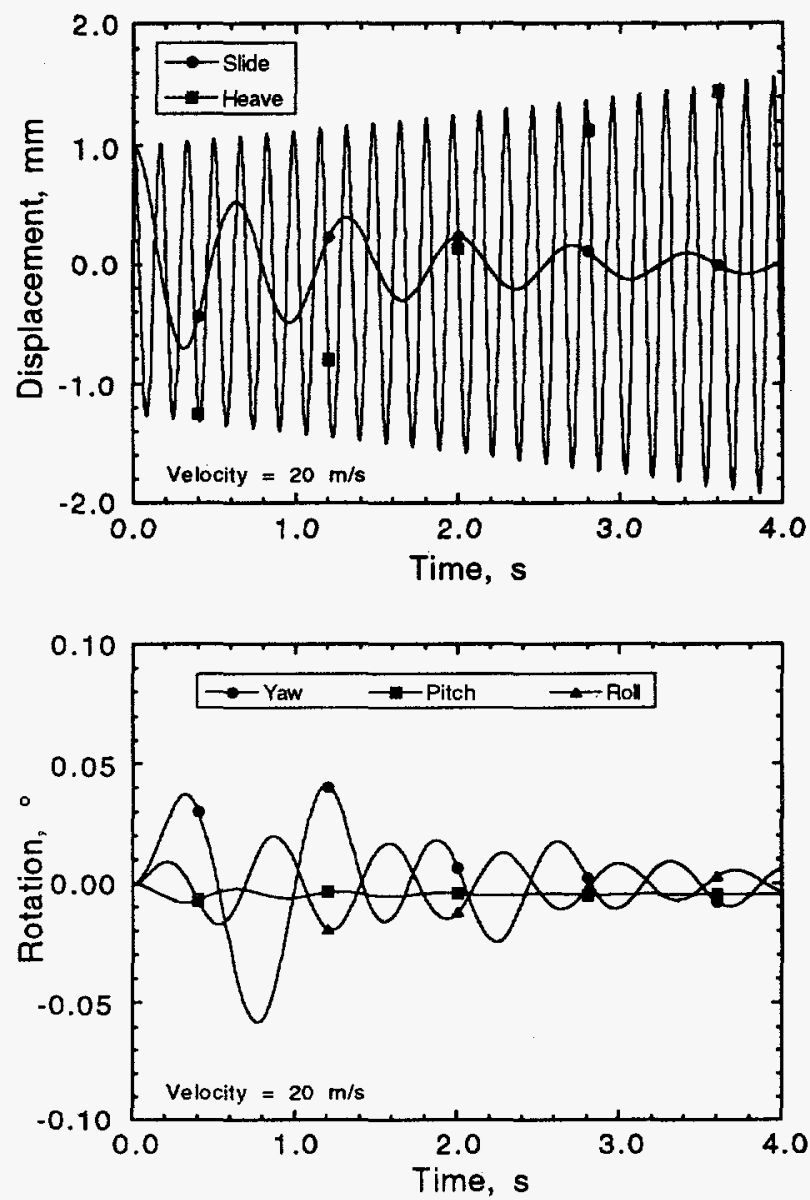

Fig. 42. Simulation results of displacement and rotation in Test $B$ when vehicle speed $=20 \mathrm{~m} / \mathrm{s}$

Motion-dependent magnetic forces, as well as other forms of damping forces, are the key elements in modeling and understanding dynamic instabilities of maglev systems. At this time, it appears that very limited data are available for motion-dependent magnetic forces. Efforts shall be made to compile analytical results and experimental data for motion-dependent magnetic forces. Only when this work is completed can recommendations be fully presented on the needs of research on magnetic forces.

Two series of extensive experimental investigations on dynamic stability of maglev systems were conducted with a free vehicle moving on a double L-shaped aluminum guideway mounted on the top of a rotating wheel. Five modes (vertical heave, lateral slip, pitch, yaw, and roll) of the vehicle motion were measured during experiments in which the rotating speed of the wheel was varied. 

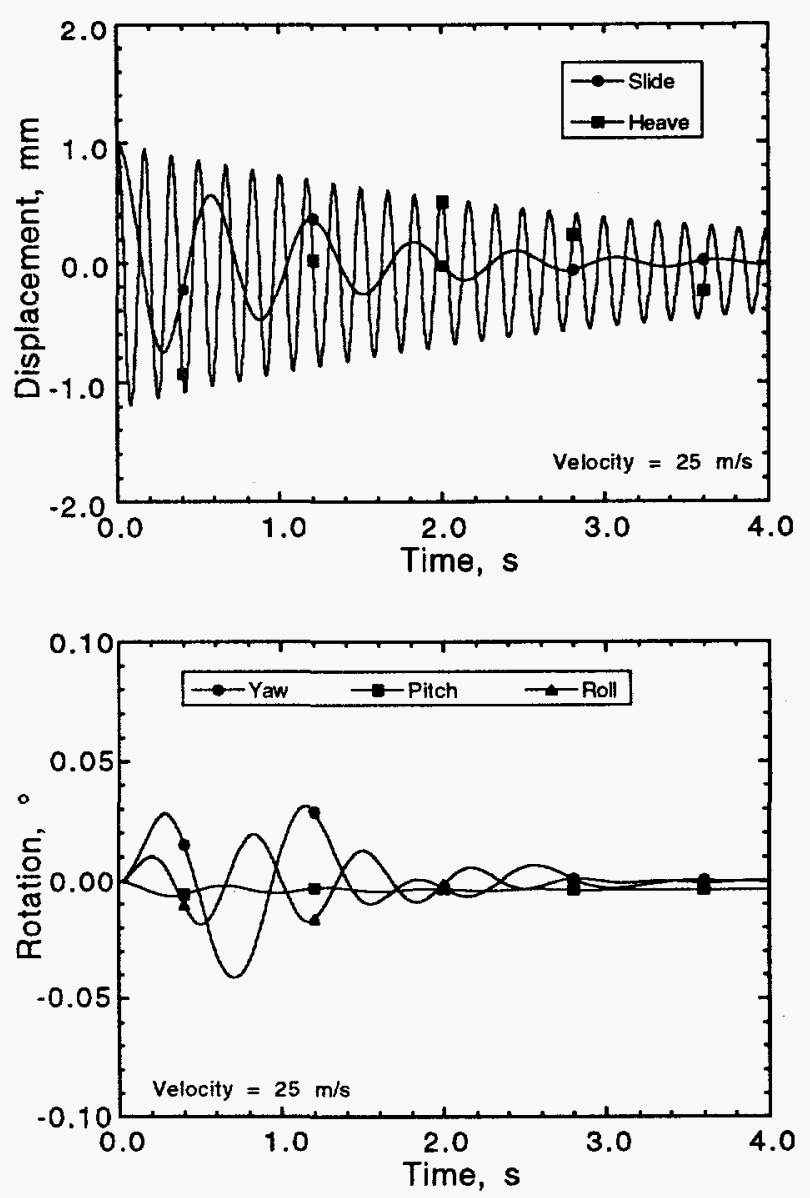

Fig. 43. Simulation results of displacement and rotation in Test $B$ when vehicle speed $=25 \mathrm{~m} / \mathrm{s}$

Instabilities of an EDS-type maglev system have been observed through the experiments. Stable and unstable motion of a maglev vehicle was observed and recorded. An integrated experimental/analytical study of stability characteristics is definitely an important aspect of maglev research and must be considered in the development of all maglev systems.

Various methods can be used to stabilize a maglev system: passive electrodynamic primary suspension damping, active electrodynamic primary suspension damping, passive mechanical secondary suspension, and active mechanical secondary suspension. With a better understanding of vehicle stability characteristics, a better control law can be adopted to ensure a high level of ride comfort and safety. 

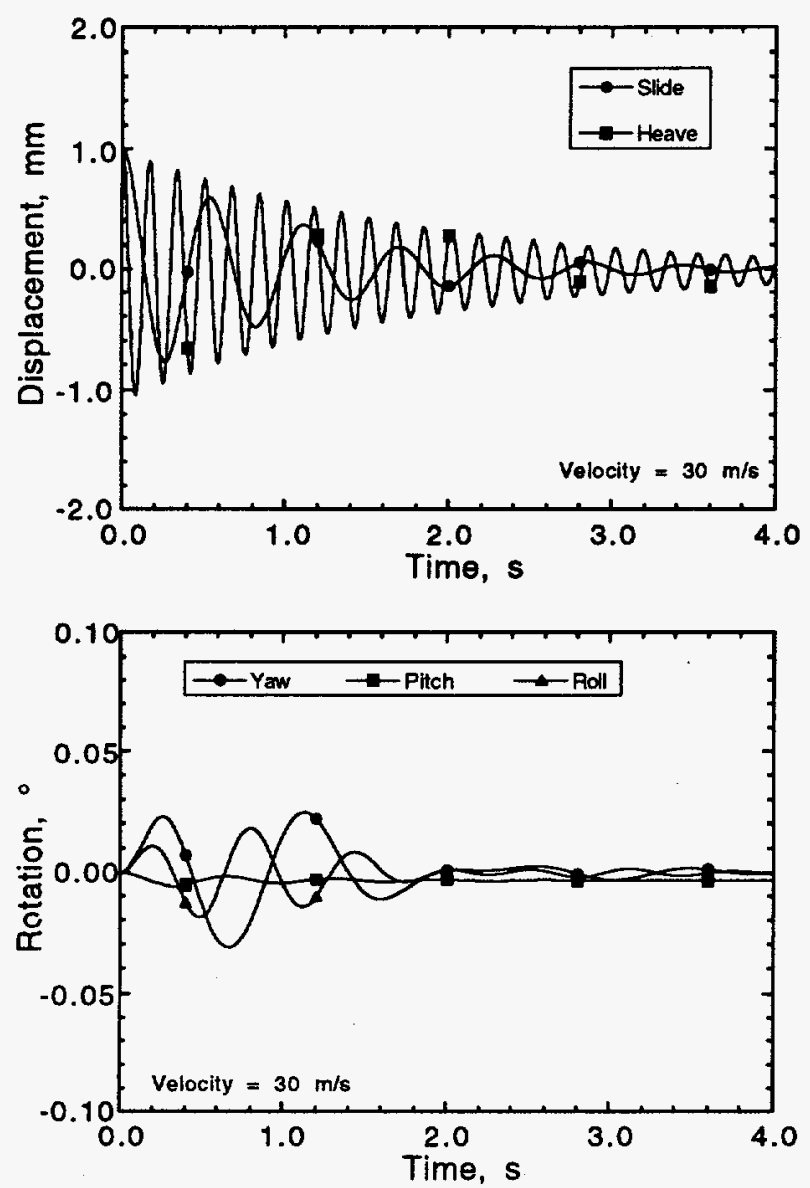

Fig. 44. Simulation results of displacement and rotation in Test $B$ when vehicle speed $=30 \mathrm{~m} / \mathrm{s}$

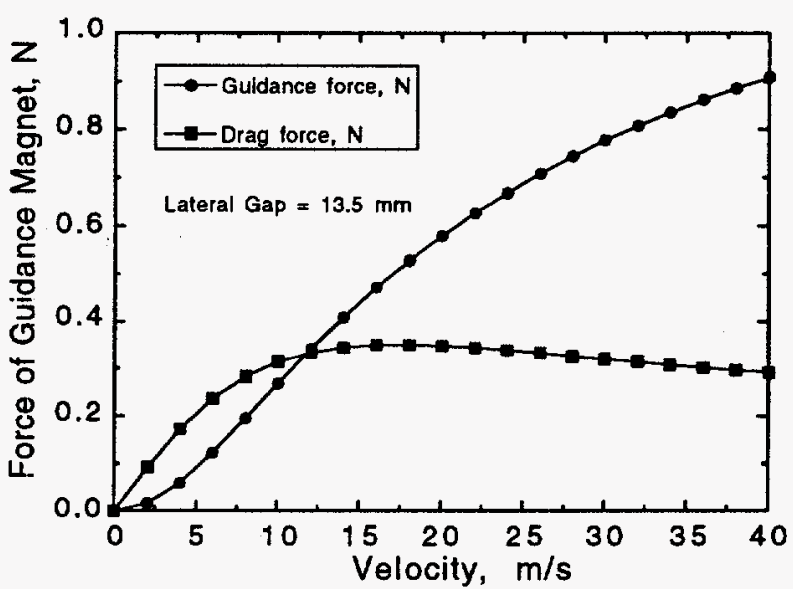

Fig. 45. Comparison of vehicle guidance and drag forces as a function of velocity 


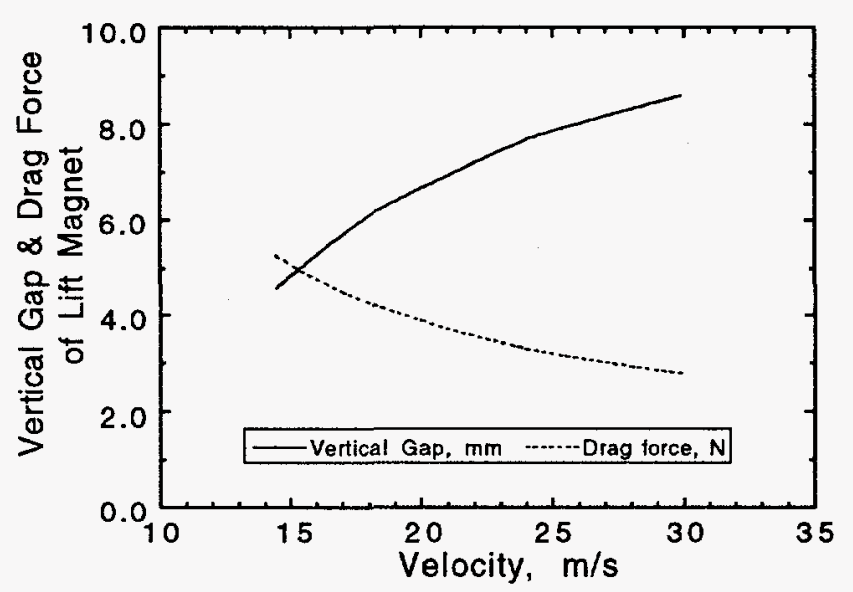

Fig. 46. Comparison of vertical gap and drag force as a function of velocity when vehicle is at equilibrium

Computer programs are needed to screen new system concepts, evaluate various designs, and predict vehicle response. A computer code for nonlineardynamic simulation of maglev systems was extensively used in this study. It can simulate nonlinear dynamic response of maglev systems with six DOF when the user inputs vehicle and track configurations. It provides more functionality for broad vehicle/guideway designs than previous codes. Numerical simulations presented in this study for a five-DOF maglev system are in good agreement with experimental results. However, some results remain partially unexplained. Part of the difficulty arises from the fact that we do not know all of the sources of damping that were present in the experiments. On the simulation side, some of the difficulty arises from the simplified manner in which damping is incorporated into the present simulation model. A single damping coefficient is used for all modes and for all coupling between those modes. The damping force is proportional to the vehicle velocity, but otherwise does not depend on vehicle motion. Complete treatment of the damping force would require solution of the coupled electromagnetic and mechanical equations of motion. At present, this cannot be done for a continuous-sheet guideway except for very simple cases. The problem is more tractable in the case of discrete-coil guideways, but small-scale laboratory experiments are quite difficult for several practical reasons. Another limitation of the simulation that needs to be rectified is the inability of the code to properly continue the time history through guideway strikes.

A more precise set of simulations and experiments is called for but is beyond the scope of the present project. In particular, greater attention must be given to the properties of intrinsic magnetic damping and how it behaves in the case of 
L-shaped guideways. Only very limited experiments with a continuous-sheet guideway conductor were performed involving the damping force present in the same direction as the perturbing motion. Coupling to other modes was not investigated. In addition, the influences of the elastic tether and the irregularities in the guideway require more detailed attention.

The experimental and theoretical analyses developed in this study identify basic stability characteristics and future research needs of maglev systems.

\section{Acknowledgments}

This work was performed under the sponsorship of the U.S. Army Corps of Engineers and the Federal Railroad Administration through interagency agreements with the U.S. Department of Energy. The authors thank Drs. Jianliang He, Howard T. Coffey, and John Hull for their help in extensive discussions and constructive comments on this study.

\section{References}

Andriollo, M., Martinelli, G., Morini, A., and Scuttari, A. (1995a), Transient Stability in EDS-MAGLEV Vehicles: Analytical Approach, Proc. 14th Int. Conf. on Magnetically-Levitated Systems, Bremen, Germany, Nov. 26-29, 1995, pp. 449-454.

Andriollo, M., Martinelli, G., Morini, A., and Scuttari, A. (1995b), Transient Stability in EDS-MAGLEV Vehicles: Numerical Simulation, Proc. 14th Int. Conf. on Magnetically-Levitated Systems, Bremen, Germany, Nov. 26-29, 1995, pp. 455-459.

Borcherts, R. H. (1982), Maglev Dynamics and Ride Quality: Past, Present and Future, Proc. 2nd Int. Seminar on Superconductive Magnetic Levitated Train, Miyazaki, Japan, Nov. 4-5, 1982, pp. 133-135. Eds. T. Ohtsuka and M. Iguchi.

Cai, Y., Chen, S. S., Mulcahy, T. M., and Rote, D. M. (1992a), Dynamic Stability of Maglev Systems, Proc. 63rd Shock and Vibration Symp., Oct. 27-29, 1992, Las Cruces, NM, pp. 533-543. 
Cai, Y., Chen, S. S., Mulcahy, T. M., and Rote, D. M. (1992b), Dynamic Stability of Maglev Systems, Argonne National Laboratory Report ANL-92/21.

Cai, Y., Chen, S. S., and Rote, D. M. (1992c), Dynamic and Controls in Maglev Systems, Argonne National Laboratory Report ANL-92/43.

Cai, Y. and Chen, S. S. (1993a), Instability of Electrodynamic Maglev Systems, Proc. 64th Shock and Vibration Symp., Ft. Walton Beach, FL, Oct. 26-28, 1993, pp. 319-326.

Cai, Y., Chen, S. S., Zhu, S., Mulcahy, T. M., Rote, D. M., and Coffey, H. T. (1993b), Dynamics, Stability, and Control of Maglev Systems, Proc. Maglev '93, 13th Int. Conf. on Magnetically Levitated Systems and Linear Drives, May 19-21, 1993, Argonne, IL, pp. 265-270.

Cai, Y., Zhu, S., Chen, S. S., and Rote, D. M. (1993c), Control of Maglev Suspension Systems, 1993 ASME Pressure Vessels and Piping Conf., ASME, New York, PVP-Vol. 256-2, pp. 57-67.

Cai, Y., and Chen, S. S. (1995), Numerical Analysis for Dynamic Instability of Electrodynamic Maglev Systems, Shock Vibration J., 2(4), pp. 339-349.

Cai, Y., and Chen, S. S. (1996), Control of Maglev Suspension Systems, J. Vibration and Control, 2, pp. 349-368.

Chen, S. S., Rote, D. M., and Coffey, H. T. (1992), A Review of Vehicle/Guideway Interactions in Maglev Systems, Fluid-Structure Interaction, Transient ThermalHydraulics, and Structural Mechanics, ASME, New York, Vol. 231, pp. 81-95.

Chen, S. S., Zhu, S., and Cai, Y. (1993), On the Unsteady-Motion Theory of Magnetic Forces for Maglev, Argonne National Laboratory Report ANL-93/39.

Chu, D., and Moon, F. C. (1983), Dynamic Instabilities in Magnetically Levitated Models, J. Appl. Phys., 54(3), pp. 1619-1625.

Coffey, H. T., Chilton, F., and Hoppie, L. O. (1972), The Feasibility of Magnetically Levitating High Speed Ground Vehicle, Final Report, Task 1, to the Federal Railroad Administration, Feb. 1972, National Technical Information Service Publication 210505. 
Coffey, H. T., Colton, J. D., Mahrer, K. D. (1973), Study of A Magnetically Levitated Vehicle, Final Report, Task 2, to the Federal Railroad Administration, Feb. 1973, National Technical Information Service Publication PB 221696.

Coffey, H. T., Colton, J. D., Solinsky, J. C., and Woodbury, J. R. (1974a), An Evaluation of The Dynamics of a Magnetically Levitated Vehicle, Final Report, Task 3, to the Federal Railroad Administration, Mar. 1974, National Technical Information Service Publication PB 236671.

Coffey, H. T. (1974b), SRI Magnetic Suspension Studies for High-Speed Vehicles, Adv. Cryo. Eng., 19, pp. 137-152.

Coffey, H. T., et al. (1974c), Dynamic Performance of the SRI Maglev Vehicle, IEEE Trans. Mag., 3, pp. 451-457. (Pages as published are not in correct sequence).

Coffey, H. T., et al. (1991), Preliminary Design for a Maglev Development Facility, Report ANL/ESD-14, Argonne National Laboratory, Argonne, IL.

Coltman, M. (1992), Summary of December 16th Ride Quality Workshop, Memorandum from Michael Coltman, Volpe National Transportation System Center, to John Harding, National Maglev Initiative Office, Federal Railroad Administration, Washington, DC, Feb. 4, 1992.

Davis, L. C., and Wilkie, D. F. (1971), Analysis of Motion of Magnetic Levitation Systems: Implications, J. Appl. Phys., 42(12), pp. 4779-4793.

Davis, L. C., Reitz, J. R., Wilkie, D. F., and Borcherts, R. H. (1972), Technical Feasibility of Magnetic Levitation as a Suspension System for High-Speed Ground Transportation Vehicles, Report FRA-RT-72-40, Federal Railroad Administration, Washington, DC.

Fink, H. J., and Hobrecht, C. E. (1971), Instability of Vehicles Levitated by Eddy Current Repulsion - Case of an Infinitely Long Current Loop, J. Appl. Phys., 42(9), pp. 3446-3450.

Fujie, J. (1989), Current Status of EDS System in Japan, Proc. 11th Int. Conf. on Magnetically-Levitated Systems and Linear Drives, Yokohama, Japan, July 7-11, 1989. 
Fujiwara, S. (1980), Damping Characteristics of the Repulsive Magnetic Levitation Vehicle, Japanese Railway Technical Research Institute, Quarterly Reports, 21(1), pp. 49-52.

Fujiwara, S., and Hariyama, T. (1983), Damping Characteristics and AC Magnetic Field of Repulsive Magnetic Levitation, Japanese Railway Technical Research Institute, Quarterly Reports, 24(2), p. 93.

He, J. L., Rote, D. M., and Chen, S. S. (1994), Characteristics and Computer Model Simulation of Magnetic Damping Forces in Maglev System, Argonne National Laboratory Report ANL/ESD/TM-66.

Iwahana, T., Iketani, T., and Fujimoto, T. (1980), Characteristics of a Maglev Running on Aluminum Sheet Guideways, Quarterly Reports of the Railway Technical Research Institute, 21(4).

Iwamoto, M., Yamada, T., and Ohno, E. (1974), Magnetic Damping Force in Electrodynamically Suspended Trains, IEEE Trans. Mag, MAG-10(3), pp. 458-461.

Kolm, H., and Thornton, R. (1973), Electromagnetic Flight, Scientific American, 229(4), pp. 17-25.

Kolm, H. (1993), Why Magneplane is the Only Stable EDS, Memorandum from H. Kolm, Magneplane International Inc., Jet Aviation Terminal, Hanscom Field, Bedford, MA, to John Harding, National Maglev Initiative Office, Federal Railroad Administration, Washington, DC, July 7, 1993.

Masada, E. (1993), Development of Maglev Transportation in Japan: Present State and Future Prospects, Proc. Maglev '93, 13th Int. Conf. on Magnetically Levitated Systems and Linear Drives, May 19-21, 1993, Argonne, IL, pp. 1-6.

Masada, E. (1995), Development of Maglev and Linear Drive Technology for Transportation in Japan, Proc. 14th Int. Conf. on Magnetically-Levitated Systems, Bremen, Germany, Nov. 26-29, 1995, pp. 11-16.

Moon, F. C. (1974), Laboratory Studies of Magnetic Levitation in the Thin Track Limit, IEEE Trans. Mag., MAG-10(3), pp. 439-442. 
Moon, F. C. (1977), Vibration Problems in Magnetic Levitation and Propulsion, Transport Without Wheels, Ed. E. R. Laithwaite, Elek Science, London, pp. 122-161.

Moon, F. C. (1978), Nonconservative Instabilities in Electrodynamic Magnetic Levitation of Vehicles, Proc. Int. Seminar on Superconductive Magnetic Levitated Train, Miyazaki, Japan, Nov. 9-10, 1978. Eds. T. Ohtsuka and M. Iguchi.

Nakashima, H., et al. (1993), Superconducting Magnet and Refrigeration System for Maglev Vehicle, Proc. 13th Int. Conf. on Magnetically-Levitated Systems and Linear Drives, Argonne National Laboratory, May 19-21, 1993, pp. 160-164.

Ohno, E., Iwamoto, M., and Yamada, T. (1973), Characteristic of Superconductive Magnetic Suspension and Propulsion for High-Speed Trains, Proc. IEEE, 61(5), pp. 579-586.

Philco-Ford Corporation (1975), Conceptual Design and Analysis of the Tracked Magnetically Levitated Vehicle Technology Program (TMLV), Repulsion Scheme, Volume 1, Report FRA-OR\&D-75-21, Federal Railroad Administration, Washington, DC.

Reitz, J. R., Borcherts, R. H., Davis, L. C., Hunt, T. K., and Wilkie, D. F. (1973), Preliminary Design Studies of Magnetic Suspensions for High-Speed Ground Transportation, Report FRA-RT-73-27, Federal Railroad Administration, Washington, DC.

Rote, D. M. (1989), personal observations during test ride on MLU-002 vehicle.

Rote, D. M. (1993), personal communications with staff at Miyazaki Test Track and at Japanese Railway Technical Research Institute during visit, Nov. 1993.

Sato, Y., Matsuura, A., Miura, S., and Satoh, Y. (1985), Development of Guideway for Maglev, Proc. Int. Conf. on Maglev Transport '85, Tokyo, Sept. 17-19, 1985, pp. 243-250.

Tanaka, H. (1982), Outline of the Test on Miyazaki Test Track, Proc. 2nd Int. Seminar on Superconductive Magnetic Levitated Train, Miyazaki, Japan, Nov. 4-5, 1982, pp. 117-126. Eds. T. Ohtsuka and M. Iguchi. 
Tanaka, H. (1991), Change in the Coil Configuration of Electrodynamic Suspension System, Proc. Int. Symp. on Magnetic Suspension Technology, Langley Research Center, Hampton, VA, Aug. 19-23, 1991, NASA Conf. Pub. 3152, Part 2.

Yamada, T., Iwamoto, M., and Ito, T. (1974), Magnetic Damping Force in Inductive Magnetic Levitation System for High-Speed Trains, Elec. Eng. Jap., 94(1), pp. 80-84.

Yamaguchi, H., and Fujiwara, S. (1993), Influence of Current Mode on Electromagnetic Damping of EDS Type Maglev, Proc. Int. Conf. on Speedup Technology For Railway and Maglev Vehicles, The Japan Society of Mechanical Engineers, Yokohama, Japan, Nov. 22-23, 1993, pp. 192-195.

Yamashita, H. (1978), Present Status of the Miyazaki Test Experiment, Proc. Int. Seminar on Superconductive Magnetic Levitated Train, Miyazaki, Japan, Nov. 9-10, 1978, pp. 85-97. Eds. T. Ohtsuka and M. Iguchi.

Zhu, S., Chen, S. S., Cai, Y., and Rote, D. M. (1994), Magnetic Damping for Maglev, 1994 Winter Annual Meeting, Nov. 6-11, 1994, Chicago, ASME, New York, PVP-Vol. 289, pp. 1-10. 


\section{Appendix: Magnetic Force Data from Experimental} Measurements

In Tables A.1-A.13, we list measured quasistatic magnetic-force data for the $25.4 \times 50.8 \times 6.35 \mathrm{~mm}$ magnet that corresponds to Figs. 4-9, and the $12.7 \times 50.8 \times$ $6.35-\mathrm{mm}$ magnet that corresponds to Fig. 28. 
Table A.1. Measured lift magnetic force $(N)$ when $Y=5.0 \mathrm{~mm}$

\begin{tabular}{ccccccccc}
\hline $\begin{array}{c}\text { Height, } \\
\mathrm{m} \mathrm{m}\end{array}$ & $\begin{array}{c}\mathrm{V}=4.55 \\
\mathrm{~m} / \mathrm{s}\end{array}$ & $\begin{array}{c}\mathrm{V}=7.89 \\
\mathrm{~m} / \mathrm{s}\end{array}$ & $\begin{array}{c}\mathrm{V}=10.62 \\
\mathrm{~m} / \mathrm{s}\end{array}$ & $\begin{array}{c}\mathrm{V}=13.32 \\
\mathrm{~m} / \mathrm{s}\end{array}$ & $\begin{array}{c}\mathrm{V}=18.20 \\
\mathrm{~m} / \mathrm{s}\end{array}$ & $\begin{array}{c}\mathrm{V}=24.15 \\
\mathrm{~m} / \mathrm{s}\end{array}$ & $\begin{array}{c}\mathrm{V}=30.10 \\
\mathrm{~m} / \mathrm{s}\end{array}$ & $\begin{array}{c}\mathrm{V}=36.10 \\
\mathrm{~m} / \mathrm{s}\end{array}$ \\
\hline 5.000 & 1.0451 & 2.5957 & 3.9378 & 5.2324 & 7.2951 & 9.2438 & 10.562 & 11.651 \\
6.000 & 0.91766 & 2.2373 & 3.3923 & 4.5002 & 6.2764 & 7.9298 & 9.0468 & 9.9822 \\
7.000 & 0.79077 & 1.9308 & 2.9271 & 3.8891 & 5.4203 & 6.8365 & 7.7943 & 8.5869 \\
8.000 & 0.69039 & 1.6812 & 2.5420 & 3.3842 & 4.7035 & 5.9278 & 6.7518 & 7.4294 \\
9.000 & 0.61040 & 1.4675 & 2.2207 & 2.9615 & 4.1118 & 5.1641 & 5.8795 & 6.4625 \\
10.000 & 0.53812 & 1.2908 & 1.9460 & 2.5938 & 3.6103 & 4.5277 & 5.1504 & 5.6501 \\
12.700 & 0.38141 & 0.91256 & 1.3865 & 1.8570 & 2.5750 & 3.2354 & 3.6788 & 4.0371 \\
13.000 & 0.37110 & 0.88029 & 1.3383 & 1.7943 & 2.4931 & 3.1303 & 3.5554 & 3.9008 \\
15.000 & 0.28903 & 0.69668 & 1.0637 & 1.4284 & 1.9862 & 2.4957 & 2.8386 & 3.1147 \\
20.000 & - & - & - & - & - & - & - & 1.8988 \\
25.000 & - & - & - & - & - & - & - & 1.2636 \\
30.000 & - & - & - & - & - & - & - & 0.90294 \\
35.000 & - & - & - & - & - & - & - & 0.69926 \\
40.000 & - & - & - & - & - & - & - & 0.57776 \\
45.000 & - & - & - & - & - & - & - & 0.48013 \\
50.000 & - & - & - & - & - & - & - & 0.36727 \\
\hline
\end{tabular}


Table A.2. Measured lift magnetic force $(N)$ when $Y=12.7 \mathrm{~mm}$

\begin{tabular}{ccccccccc}
\hline $\begin{array}{c}\text { Height, } \\
\mathrm{m} \mathrm{m}\end{array}$ & $\begin{array}{c}\mathrm{V}=4.55 \\
\mathrm{~m} / \mathrm{s}\end{array}$ & $\begin{array}{c}\mathrm{V}=7.89 \\
\mathrm{~m} / \mathrm{s}\end{array}$ & $\begin{array}{c}\mathrm{V}=10.62 \\
\mathrm{~m} / \mathrm{s}\end{array}$ & $\begin{array}{c}\mathrm{V}=13.32 \\
\mathrm{~m} / \mathrm{s}\end{array}$ & $\begin{array}{c}\mathrm{V}=18.20 \\
\mathrm{~m} / \mathrm{s}\end{array}$ & $\begin{array}{c}\mathrm{V}=24.15 \\
\mathrm{~m} / \mathrm{s}\end{array}$ & $\begin{array}{c}\mathrm{V}=30.10 \\
\mathrm{~m} / \mathrm{s}\end{array}$ & $\begin{array}{c}\mathrm{V}=36.10 \\
\mathrm{~m} / \mathrm{s}\end{array}$ \\
\hline 5.000 & 1.0955 & 2.6161 & 3.9605 & 5.2814 & 7.3515 & 9.3087 & 10.676 & 11.805 \\
6.000 & 0.94664 & 2.2545 & 3.3970 & 4.5139 & 6.3151 & 7.9683 & 9.1351 & 10.080 \\
7.000 & 0.81583 & 1.9367 & 2.9226 & 3.8977 & 5.4191 & 6.8397 & 7.8049 & 8.6117 \\
8.000 & 0.70712 & 1.6686 & 2.5221 & 3.3668 & 4.6907 & 5.8954 & 6.7165 & 7.3991 \\
9.000 & 0.61203 & 1.4513 & 2.1937 & 2.9296 & 4.0759 & 5.1076 & 5.8145 & 6.3945 \\
10.000 & 0.53374 & 1.2658 & 1.9114 & 2.5579 & 3.5538 & 4.4472 & 5.0512 & 5.5470 \\
12.700 & 0.36982 & 0.88409 & 1.3357 & 1.7984 & 2.4904 & 3.1052 & 3.5267 & 3.8584 \\
13.000 & 0.35219 & 0.84933 & 1.2875 & 1.7361 & 2.4037 & 2.9957 & 3.4014 & 3.7259 \\
15.000 & 0.27539 & 0.66572 & 1.0054 & 1.3636 & 1.8837 & 2.3421 & 2.6608 & 2.9041 \\
20.000 & - & - & - & - & - & - & - & 1.6615 \\
25.000 & - & - & - & - & - & - & - & 1.0252 \\
30.000 & - & - & - & - & - & - & - & 0.66869 \\
35.000 & - & - & - & - & - & - & - & 0.45884 \\
40.000 & - & - & - & - & - & - & - & 0.32739 \\
45.000 & - & - & - & - & - & - & - & 0.23401 \\
50.000 & - & - & - & - & - & - & - & 0.16809 \\
\hline
\end{tabular}


Table A.3. Measured lift magnetic force (N) when $h=7.0 \mathrm{~mm}$

\begin{tabular}{rcccccccc}
\hline Gap, & $\mathrm{V}=4.55$ & $\mathrm{~V}=7.89$ & $\mathrm{~V}=10.62$ & $\mathrm{~V}=13.32$ & $\mathrm{~V}=18.20$ & $\mathrm{~V}=24.15$ & $\mathrm{~V}=30.10$ & $\mathrm{~V}=36.10$ \\
$\mathrm{~m} \mathrm{~m}$ & $\mathrm{~m} / \mathrm{s}$ & $\mathrm{m} / \mathrm{s}$ & $\mathrm{m} / \mathrm{s}$ & $\mathrm{m} / \mathrm{s}$ & $\mathrm{m} / \mathrm{s}$ & $\mathrm{m} / \mathrm{s}$ & $\mathrm{m} / \mathrm{s}$ & $\mathrm{m} / \mathrm{s}$ \\
\hline 5.000 & 0.80121 & 1.9141 & 2.9061 & 3.8765 & 5.4086 & 6.8017 & 7.7810 & 8.5608 \\
6.000 & 0.80485 & 1.9186 & 2.9103 & 3.8865 & 5.4090 & 6.7890 & 7.7679 & 8.5471 \\
7.000 & 0.80143 & 1.9207 & 2.9116 & 3.8811 & 5.4047 & 6.7887 & 7.7602 & 8.5383 \\
8.000 & 0.80612 & 1.9224 & 2.9143 & 3.8877 & 5.4072 & 6.7844 & 7.7642 & 8.5411 \\
9.000 & 0.80847 & 1.9266 & 2.9177 & 3.8896 & 5.4110 & 6.7777 & 7.7583 & 8.5448 \\
10.000 & 0.81084 & 1.9339 & 2.9212 & 3.8907 & 5.4181 & 6.7858 & 7.7670 & 8.5598 \\
12.700 & 0.80694 & 1.9314 & 2.9187 & 3.8878 & 5.4097 & 6.8048 & 7.7962 & 8.5949 \\
13.000 & 0.80654 & 1.9298 & 2.9218 & 3.8918 & 5.4166 & 6.8056 & 7.7969 & 8.6008 \\
15.000 & 0.80960 & 1.9306 & 2.9161 & 3.8883 & 5.4222 & 6.8127 & 7.8057 & 8.6321 \\
17.000 & - & - & - & - & - & - & 7.8208 & 8.6663 \\
20.000 & - & - & - & - & - & - & - & 8.7054 \\
22.000 & - & - & - & - & - & - & - & 8.7193 \\
25.000 & - & - & - & - & - & - & - & 8.7220 \\
26.000 & - & - & - & - & - & - & - & 8.7130 \\
27.000 & - & - & - & - & - & - & - & 8.7019 \\
28.000 & - & - & - & - & - & - & - & 8.6783 \\
29.000 & - & - & - & - & - & - & - & 8.6503 \\
30.000 & - & - & - & - & - & - & - & 8.6122 \\
31.000 & - & - & - & - & - & - & - & 8.5553 \\
32.000 & - & - & - & - & - & - & - & 8.4845 \\
35.000 & - & - & - & - & - & - & - & 8.1381 \\
40.000 & - & - & - & - & - & - & - & 6.9166 \\
45.000 & - & - & - & - & - & - & - & 4.9871 \\
50.000 & - & - & - & - & - & - & - & 2.7338 \\
\hline
\end{tabular}


Table A.4. Measured lift magnetic force $(N)$ when $h=12.7 \mathrm{~mm}$

\begin{tabular}{rcccccccc}
\hline $\begin{array}{c}\text { Gap, } \\
\mathrm{m} \mathrm{m}\end{array}$ & $\begin{array}{c}\mathrm{V}=4.55 \\
\mathrm{~m} / \mathrm{s}\end{array}$ & $\begin{array}{c}\mathrm{V}=7.89 \\
\mathrm{~m} / \mathrm{s}\end{array}$ & $\begin{array}{c}\mathrm{V}=10.62 \\
\mathrm{~m} / \mathrm{s}\end{array}$ & $\begin{array}{c}\mathrm{V}=13.32 \\
\mathrm{~m} / \mathrm{s}\end{array}$ & $\begin{array}{c}\mathrm{V}=18.20 \\
\mathrm{~m} / \mathrm{s}\end{array}$ & $\begin{array}{c}\mathrm{V}=24.15 \\
\mathrm{~m} / \mathrm{s}\end{array}$ & $\begin{array}{c}\mathrm{V}=30.10 \\
\mathrm{~m} / \mathrm{s}\end{array}$ & $\begin{array}{c}\mathrm{V}=36.10 \\
\mathrm{~m} / \mathrm{s}\end{array}$ \\
\hline 5.000 & 0.37788 & 0.90238 & 1.3718 & 1.8505 & 2.5732 & 3.2065 & 3.6706 & 4.0127 \\
6.000 & 0.37967 & 0.90227 & 1.3676 & 1.8437 & 2.5494 & 3.1774 & 3.6340 & 3.9705 \\
7.000 & 0.37603 & 0.90000 & 1.3620 & 1.8343 & 2.5468 & 3.1599 & 3.6043 & 3.9352 \\
8.000 & 0.37182 & 0.89802 & 1.3575 & 1.8266 & 2.5321 & 3.1395 & 3.5848 & 3.9074 \\
9.000 & 0.37459 & 0.89189 & 1.3531 & 1.8208 & 2.5151 & 3.1268 & 3.5595 & 3.8855 \\
10.000 & 0.37172 & 0.88857 & 1.3477 & 1.8163 & 2.5118 & 3.1097 & 3.5498 & 3.8729 \\
12.700 & 0.36636 & 0.88496 & 1.3382 & 1.7973 & 2.4896 & 3.0842 & 3.5213 & 3.8490 \\
13.000 & 0.36895 & 0.88526 & 1.3369 & 1.7979 & 2.4892 & 3.0826 & 3.5163 & 3.8488 \\
15.000 & 0.36174 & 0.87754 & 1.3247 & 1.7828 & 2.4769 & 3.0673 & 3.5092 & 3.8402 \\
20.000 & - & - & - & - & - & - & - & 3.8250 \\
25.000 & - & - & - & - & - & - & - & 3.7733 \\
30.000 & - & - & - & - & - & - & - & 3.6226 \\
35.000 & - & - & - & - & - & - & - & 3.2929 \\
40.000 & - & - & - & - & - & - & - & 2.7036 \\
45.000 & - & - & - & - & - & - & - & 1.8991 \\
50.000 & - & - & - & - & - & - & - & 1.0999 \\
\hline
\end{tabular}


Table A.5. Measured guidance magnetic force $(N)$ when $Y=5.0 \mathrm{~mm}$

\begin{tabular}{ccccccccc}
\hline $\begin{array}{c}\text { Height, } \\
\mathrm{m} \mathrm{m}\end{array}$ & $\begin{array}{c}\mathrm{V}=4.55 \\
\mathrm{~m} / \mathrm{s}\end{array}$ & $\begin{array}{c}\mathrm{V}=7.89 \\
\mathrm{~m} / \mathrm{s}\end{array}$ & $\begin{array}{c}\mathrm{V}=10.62 \\
\mathrm{~m} / \mathrm{s}\end{array}$ & $\begin{array}{c}\mathrm{V}=13.32 \\
\mathrm{~m} / \mathrm{s}\end{array}$ & $\begin{array}{c}\mathrm{V}=18.20 \\
\mathrm{~m} / \mathrm{s}\end{array}$ & $\begin{array}{c}\mathrm{V}=24.15 \\
\mathrm{~m} / \mathrm{s}\end{array}$ & $\begin{array}{c}\mathrm{V}=30.10 \\
\mathrm{~m} / \mathrm{s}\end{array}$ & $\begin{array}{c}\mathrm{V}=36.10 \\
\mathrm{~m} / \mathrm{s}\end{array}$ \\
\hline 5.000 & 0.18065 & 0.44393 & 0.71410 & 0.98960 & 1.5682 & 2.2220 & 2.7983 & 3.3500 \\
6.000 & 0.18417 & 0.45186 & 0.72744 & 1.0170 & 1.6034 & 2.2619 & 2.8586 & 3.4133 \\
7.000 & 0.18068 & 0.46084 & 0.74301 & 1.0289 & 1.6325 & 2.2890 & 2.8935 & 3.4652 \\
8.000 & 0.18766 & 0.46147 & 0.74814 & 1.0445 & 1.6458 & 2.3130 & 2.9141 & 3.4866 \\
9.000 & 0.18833 & 0.47170 & 0.75691 & 1.0496 & 1.6620 & 2.3285 & 2.9345 & 3.5110 \\
10.000 & 0.18729 & 0.47215 & 0.75790 & 1.0510 & 1.6666 & 2.3385 & 2.9420 & 3.5156 \\
13.000 & 0.19191 & 0.47090 & 0.76569 & 1.0615 & 1.6699 & 2.3323 & 2.9421 & 3.5116 \\
15.000 & 0.18777 & 0.47444 & 0.76355 & 1.0576 & 1.6677 & 2.3194 & 2.9147 & 3.4810 \\
20.000 & - & - & - & - & - & - & - & 3.3748 \\
25.000 & - & - & - & - & - & - & - & 3.2648 \\
30.000 & - & - & - & - & - & - & - & 3.1568 \\
35.000 & - & - & - & - & - & - & - & 3.0531 \\
40.000 & - & - & - & - & - & - & - & 2.9309 \\
\hline
\end{tabular}


Table A.6. Measured guidance magnetic force $(N)$ when $Y=12.7 \mathrm{~mm}$

\begin{tabular}{rcccccccc}
\hline $\begin{array}{c}\text { Height, } \\
\mathrm{m} \mathrm{m}\end{array}$ & $\begin{array}{c}\mathrm{V}=4.55 \\
\mathrm{~m} / \mathrm{s}\end{array}$ & $\begin{array}{c}\mathrm{V}=7.89 \\
\mathrm{~m} / \mathrm{s}\end{array}$ & $\begin{array}{c}\mathrm{V}=10.62 \\
\mathrm{~m} / \mathrm{s}\end{array}$ & $\begin{array}{c}\mathrm{V}=13.32 \\
\mathrm{~m} / \mathrm{s}\end{array}$ & $\begin{array}{c}\mathrm{V}=18.20 \\
\mathrm{~m} / \mathrm{s}\end{array}$ & $\begin{array}{c}\mathrm{V}=24.15 \\
\mathrm{~m} / \mathrm{s}\end{array}$ & $\begin{array}{c}\mathrm{V}=30.10 \\
\mathrm{~m} / \mathrm{s}\end{array}$ & $\begin{array}{c}\mathrm{V}=36.10 \\
\mathrm{~m} / \mathrm{s}\end{array}$ \\
\hline 5.000 & 0.097706 & 0.20690 & 0.30712 & 0.38804 & 0.53884 & 0.65595 & 0.74890 & 0.82918 \\
6.000 & 0.094964 & 0.20529 & 0.30992 & 0.39729 & 0.56286 & 0.69580 & 0.80601 & 0.90144 \\
7.000 & 0.091036 & 0.20977 & 0.31310 & 0.40684 & 0.57802 & 0.73006 & 0.84524 & 0.95586 \\
8.000 & 0.090508 & 0.204 .02 & 0.31586 & 0.41019 & 0.59173 & 0.75649 & 0.88238 & 0.99907 \\
9.000 & 0.093734 & 0.20588 & 0.31544 & 0.41667 & 0.60427 & 0.77338 & 0.91097 & 1.0331 \\
10.000 & 0.087470 & 0.20646 & 0.31930 & 0.42212 & 0.61046 & 0.78828 & 0.93361 & 1.0681 \\
12.700 & 0.083869 & 0.19930 & 0.30894 & 0.41791 & 0.61670 & 0.80983 & 0.96883 & 1.1137 \\
13.000 & 0.081553 & 0.19838 & 0.31017 & 0.41911 & 0.61545 & 0.81066 & 0.97017 & 1.1160 \\
15.000 & 0.079007 & 0.19274 & 0.30440 & 0.41200 & 0.61152 & 0.81318 & 0.97188 & 1.1252 \\
20.000 & - & - & - & - & - & - & - & 1.1000 \\
25.000 & - & - & - & - & - & - & - & 1.0424 \\
30.000 & - & - & - & - & - & - & - & 0.96882 \\
35.000 & - & - & - & - & - & - & - & 0.89044 \\
40.000 & - & - & - & - & - & - & - & 0.82608 \\
45.000 & - & - & - & - & - & - & - & 0.76790 \\
50.000 & - & - & - & - & - & - & - & 0.72454 \\
\hline
\end{tabular}


Table A.7. Measured guidance magnetic force $(N)$ when $h=7.0 \mathrm{~mm}$

\begin{tabular}{|c|c|c|c|c|c|c|c|c|}
\hline $\begin{array}{l}\text { Gap, } \\
\mathrm{m} \mathrm{m}\end{array}$ & $\begin{array}{c}\mathrm{V}=4.55 \\
\mathrm{~m} / \mathrm{s}\end{array}$ & $\begin{array}{c}\mathrm{V}=7.89 \\
\mathrm{~m} / \mathrm{s}\end{array}$ & $\begin{array}{c}\mathrm{V}=10.62 \\
\mathrm{~m} / \mathrm{s}\end{array}$ & $\begin{array}{c}\mathrm{V}=13.32 \\
\mathrm{~m} / \mathrm{s}\end{array}$ & $\begin{array}{c}\mathrm{V}=18.20 \\
\mathrm{~m} / \mathrm{s}\end{array}$ & $\begin{array}{c}\mathrm{V}=24.15 \\
\mathrm{~m} / \mathrm{s}\end{array}$ & $\begin{array}{c}\mathrm{V}=30.10 \\
\mathrm{~m} / \mathrm{s}\end{array}$ & $\begin{array}{c}\mathrm{V}=36.10 \\
\mathrm{~m} / \mathrm{s}\end{array}$ \\
\hline 5.000 & 0.19122 & 0.45731 & 0.73137 & 1.0322 & 1.6304 & 2.2933 & 2.8992 & 3.4594 \\
\hline 6.000 & 0.16639 & 0.39968 & 0.63375 & 0.88455 & 1.3820 & 1.9332 & 2.4178 & 2.8615 \\
\hline 7.000 & 0.15097 & 0.34776 & 0.55057 & 0.76025 & 1.1773 & 1.6356 & 2.0328 & 2.3895 \\
\hline 8.000 & 0.13917 & 0.31218 & 0.48647 & 0.66585 & 1.0152 & 1.3904 & 1.7220 & 2.0064 \\
\hline 9.000 & 0.13029 & 0.28606 & 0.43460 & 0.58761 & 0.88464 & 1.1986 & 1.4675 & 1.6938 \\
\hline 10.000 & 0.12170 & 0.26143 & 0.39458 & 0.52755 & 0.77599 & 1.0376 & 1.2542 & 1.4431 \\
\hline 13.000 & 0.11148 & 0.22066 & 0.32044 & 0.41785 & 0.56402 & 0.71816 & 0.83196 & 0.92319 \\
\hline 15.000 & 0.10777 & 0.21193 & 0.30006 & 0.37833 & 0.48031 & 0.59664 & 0.66109 & 0.71464 \\
\hline 16.000 & - & - & - & - & - & - & - & 0.62420 \\
\hline 17.000 & - & - & - & - & - & - & - & 0.56259 \\
\hline 18.000 & - & - & - & - & - & - & - & 0.51805 \\
\hline 20.000 & - & - & - & - & - & - & - & 0.47121 \\
\hline 22.000 & - & - & - & - & - & - & - & 0.45942 \\
\hline 25.000 & - & - & - & - & - & - & - & 0.53118 \\
\hline 23.000 & - & - & - & - & - & - & - & 0.47426 \\
\hline 22.000 & - & - & - & - & - & - & - & 0.46136 \\
\hline 24.000 & - & - & - & - & - & - & - & 0.50279 \\
\hline 25.000 & - & - & - & - & - & - & - & 0.54166 \\
\hline 26.000 & - & - & - & - & - & - & - & 0.57850 \\
\hline 27.000 & - & - & - & - & - & - & - & 0.63566 \\
\hline 28.000 & - & - & - & - & - & - & - & 0.70825 \\
\hline 29.000 & - & - & - & - & - & - & - & 0.78758 \\
\hline 30.000 & - & - & - & - & - & - & - & 0.87856 \\
\hline 31.000 & - & - & - & - & - & - & - & 0.97932 \\
\hline 32.000 & - & - & - & - & - & - & - & 1.1058 \\
\hline 33.000 & - & - & - & - & - & - & - & 1.2436 \\
\hline 34.000 & - & - & - & - & - & - & - & 1.3905 \\
\hline 35.000 & - & - & - & - & - & - & - & 1.5497 \\
\hline 36.000 & - & - & - & - & - & - & - & 1.7205 \\
\hline 37.000 & - & - & - & - & - & - & - & 1.8941 \\
\hline 38.000 & - & - & - & - & - & - & - & 2.0679 \\
\hline 39.000 & - & - & - & - & - & - & - & 2.2402 \\
\hline 40.000 & - & - & - & - & - & - & - & 2.3956 \\
\hline 41.000 & - & - & - & - & - & - & - & 2.5338 \\
\hline 42.000 & - & - & - & - & - & - & - & 2.6490 \\
\hline 43.000 & - & - & - & - & - & - & - & 2.7376 \\
\hline
\end{tabular}


Table A.7. Cont'd

\begin{tabular}{rcccccccc}
\hline $\begin{array}{l}\mathrm{Gap}, \\
\mathrm{m} \mathrm{m}\end{array}$ & $\begin{array}{c}\mathrm{V}=4.55 \\
\mathrm{~m} / \mathrm{s}\end{array}$ & $\begin{array}{c}\mathrm{V}=7.89 \\
\mathrm{~m} / \mathrm{s}\end{array}$ & $\begin{array}{c}\mathrm{V}=10.62 \\
\mathrm{~m} / \mathrm{s}\end{array}$ & $\begin{array}{c}\mathrm{V}=13.32 \\
\mathrm{~m} / \mathrm{s}\end{array}$ & $\begin{array}{c}\mathrm{V}=18.20 \\
\mathrm{~m} / \mathrm{s}\end{array}$ & $\begin{array}{c}\mathrm{V}=24.15 \\
\mathrm{~m} / \mathrm{s}\end{array}$ & $\begin{array}{c}\mathrm{V}=30.10 \\
\mathrm{~m} / \mathrm{s}\end{array}$ & $\begin{array}{c}\mathrm{V}=36.10 \\
\mathrm{~m} / \mathrm{s}\end{array}$ \\
\hline 44.000 & - & - & - & - & - & - & - & 2.7861 \\
45.000 & - & - & - & - & - & - & - & 2.8098 \\
46.000 & - & - & - & - & - & - & - & 2.7861 \\
46.000 & - & - & - & - & - & - & - & 2.7877 \\
47.000 & - & - & - & - & - & - & - & 2.7349 \\
48.000 & - & - & - & - & - & - & - & 2.6488 \\
49.000 & - & - & - & - & - & - & - & 2.5441 \\
50.000 & - & - & - & - & - & - & - & 2.4179 \\
51.000 & - & - & - & - & - & - & - & 2.2653 \\
52.000 & - & - & - & - & - & - & - & 2.1055 \\
53.000 & - & - & - & - & - & - & - & 1.9357 \\
\hline
\end{tabular}


Table A.8. Measured guidance magnetic force $(N)$ when $h=12.7 \mathrm{~mm}$

\begin{tabular}{|c|c|c|c|c|c|c|c|c|}
\hline $\begin{array}{l}\text { Gap, } \\
\mathrm{m} \mathrm{m}\end{array}$ & $\begin{array}{c}\mathrm{V}=4.55 \\
\mathrm{~m} / \mathrm{s}\end{array}$ & $\begin{array}{c}\mathrm{V}=7.89 \\
\mathrm{~m} / \mathrm{s}\end{array}$ & $\begin{array}{c}\mathrm{V}=10.62 \\
\mathrm{~m} / \mathrm{s}\end{array}$ & $\begin{array}{c}\mathrm{V}=13.32 \\
\mathrm{~m} / \mathrm{s}\end{array}$ & $\begin{array}{c}\mathrm{V}=18.20 \\
\mathrm{~m} / \mathrm{s}\end{array}$ & $\begin{array}{c}\mathrm{V}=24.15 \\
\mathrm{~m} / \mathrm{s}\end{array}$ & $\begin{array}{c}\mathrm{V}=30.10 \\
\mathrm{~m} / \mathrm{s}\end{array}$ & $\begin{array}{c}\mathrm{V}=36.10 \\
\mathrm{~m} / \mathrm{s}\end{array}$ \\
\hline 5.000 & 0.16979 & 0.45445 & 0.74629 & 1.0482 & 1.6583 & 2.3402 & 2.9856 & 3.5008 \\
\hline 6.000 & 0.15160 & 0.38587 & 0.64142 & 0.89846 & 1.4110 & 1.9835 & 2.5116 & 2.9385 \\
\hline 7.000 & 0.13681 & 0.33966 & 0.56009 & 0.77435 & 1.2130 & 1.6944 & 2.1361 & 2.4894 \\
\hline 8.000 & 0.11769 & 0.30203 & 0.49382 & 0.67819 & 1.0556 & 1.4616 & 1.8246 & 2.1221 \\
\hline 9.000 & 0.10520 & 0.26779 & 0.43972 & 0.60001 & 0.92745 & 1.2662 & 1.5761 & 1.8277 \\
\hline 10.000 & 0.094461 & 0.24160 & 0.38845 & 0.53316 & 0.81830 & 1.1116 & 1.3697 & 1.5795 \\
\hline 12.700 & 0.078118 & 0.19241 & 0.31376 & 0.41773 & 0.61378 & 0.81021 & 0.97368 & 1.1036 \\
\hline 13.000 & 0.078038 & 0.18856 & 0.30458 & 0.40892 & 0.59571 & 0.78456 & 0.94053 & 1.0712 \\
\hline 15.000 & 0.074923 & 0.17032 & 0.27774 & 0.36331 & 0.51582 & 0.65495 & 0.76163 & 0.85348 \\
\hline 20.000 & - & - & - & - & - & - & - & 0.59110 \\
\hline 25.000 & - & - & - & - & - & - & - & 0.56213 \\
\hline 26.000 & - & - & - & - & - & - & - & 0.58183 \\
\hline 27.000 & - & - & - & - & - & - & - & 0.60261 \\
\hline 28.000 & - & - & - & - & - & - & - & 0.62805 \\
\hline 29.000 & - & - & - & - & - & - & - & 0.65752 \\
\hline 30.000 & - & - & - & - & - & - & - & 0.69215 \\
\hline 31.000 & - & - & - & - & - & - & - & 0.73462 \\
\hline 32.000 & $\because$ & - & - & - & - & - & - & 0.77862 \\
\hline 33.000 & - & - & - & - & - & - & - & 0.82802 \\
\hline 34.000 & - & - & - & - & - & - & - & 0.87711 \\
\hline 35.000 & - & - & - & - & - & - & - & 0.92915 \\
\hline 38.000 & - & - & - & - & - & - & - & 1.0834 \\
\hline 40.000 & - & - & - & - & - & - & - & 1.1639 \\
\hline 42.000 & - & - & - & - & - & - & - & 1.2147 \\
\hline 44.000 & - & - & - & - & - & - & - & 1.2380 \\
\hline 45.000 & - & - & - & - & - & - & - & 1.2343 \\
\hline 46.000 & - & - & - & - & - & - & - & 1.2158 \\
\hline 47.000 & - & - & - & - & - & - & - & 1.1890 \\
\hline 48.000 & - & - & - & - & - & - & - & 1.1532 \\
\hline 49.000 & - & - & - & - & - & - & - & 1.1144 \\
\hline 50.000 & - & - & - & - & - & - & - & 1.0627 \\
\hline
\end{tabular}


Table A.9. Measured drag magnetic force $(N)$ when $Y=5.0 \mathrm{~mm}$

\begin{tabular}{rcccccccc}
\hline $\begin{array}{c}\text { Height, } \\
\mathrm{m} \mathrm{m}\end{array}$ & $\begin{array}{c}\mathrm{V}=4.55 \\
\mathrm{~m} / \mathrm{s}\end{array}$ & $\begin{array}{c}\mathrm{V}=7.89 \\
\mathrm{~m} / \mathrm{s}\end{array}$ & $\begin{array}{c}\mathrm{V}=10.62 \\
\mathrm{~m} / \mathrm{s}\end{array}$ & $\begin{array}{c}\mathrm{V}=13.32 \\
\mathrm{~m} / \mathrm{s}\end{array}$ & $\begin{array}{c}\mathrm{V}=18.20 \\
\mathrm{~m} / \mathrm{s}\end{array}$ & $\begin{array}{c}\mathrm{V}=24.15 \\
\mathrm{~m} / \mathrm{s}\end{array}$ & $\begin{array}{c}\mathrm{V}=30.10 \\
\mathrm{~m} / \mathrm{s}\end{array}$ & $\begin{array}{c}\mathrm{V}=36.10 \\
\mathrm{~m} / \mathrm{s}\end{array}$ \\
\hline 5.000 & 3.0899 & 4.5607 & 5.2778 & 5.6976 & 5.9508 & 5.8713 & 5.6439 & 5.4027 \\
6.000 & 2.7156 & 4.0115 & 4.6392 & 5.0186 & 5.2514 & 5.1931 & 5.0020 & 4.7839 \\
7.000 & 2.4139 & 3.5401 & 4.1140 & 4.4653 & 4.6733 & 4.6290 & 4.4703 & 4.2780 \\
8.000 & 2.1504 & 3.1631 & 3.6723 & 3.9933 & 4.1989 & 4.1691 & 4.0321 & 3.8626 \\
9.000 & 1.9392 & 2.8430 & 3.3110 & 3.6114 & 3.8042 & 3.7907 & 3.6719 & 3.5230 \\
10.000 & 1.7548 & 2.5734 & 3.0068 & 3.2859 & 3.4736 & 3.4708 & 3.3689 & 3.2403 \\
12.700 & 1.3775 & 2.0225 & 2.3846 & 2.6338 & 2.7998 & 2.8228 & 2.7617 & 2.6715 \\
13.000 & 1.3439 & 1.9703 & 2.3329 & 2.5755 & 2.7420 & 2.7733 & 2.7178 & 2.6260 \\
15.000 & 1.1535 & 1.7049 & 2.0209 & 2.2399 & 2.4076 & 2.4519 & 2.4191 & 2.3380 \\
20.000 & - & - & - & - & - & - & - & 1.8856 \\
25.000 & - & - & - & - & - & - & - & 1.6287 \\
30.000 & - & - & - & - & - & - & - & 1.4599 \\
35.000 & - & - & - & - & - & - & - & 1.3414 \\
40.000 & - & - & - & - & - & - & - & 1.2395 \\
45.000 & - & - & - & - & - & - & - & 1.1352 \\
50.000 & - & - & - & - & - & - & - & 1.0074 \\
\hline
\end{tabular}


Table A.10. Measured drag magnetic force $(N)$ when $Y=12.7 \mathrm{~mm}$

\begin{tabular}{ccccccccc}
\hline $\begin{array}{c}\text { Height, } \\
\mathrm{m} \mathrm{m}\end{array}$ & $\begin{array}{c}\mathrm{V}=4.55 \\
\mathrm{~m} / \mathrm{s}\end{array}$ & $\begin{array}{c}\mathrm{V}=7.89 \\
\mathrm{~m} / \mathrm{s}\end{array}$ & $\begin{array}{c}\mathrm{V}=10.62 \\
\mathrm{~m} / \mathrm{s}\end{array}$ & $\begin{array}{c}\mathrm{V}=13.32 \\
\mathrm{~m} / \mathrm{s}\end{array}$ & $\begin{array}{c}\mathrm{V}=18.20 \\
\mathrm{~m} / \mathrm{s}\end{array}$ & $\begin{array}{c}\mathrm{V}=24.15 \\
\mathrm{~m} / \mathrm{s}\end{array}$ & $\begin{array}{c}\mathrm{V}=30.10 \\
\mathrm{~m} / \mathrm{s}\end{array}$ & $\begin{array}{c}\mathrm{V}=36.10 \\
\mathrm{~m} / \mathrm{s}\end{array}$ \\
\hline 5.000 & 2.7672 & 3.9798 & 4.5695 & 4.9081 & 5.0506 & 4.9185 & 4.7044 & 4.4699 \\
6.000 & 2.3707 & 3.4231 & 3.9263 & 4.2150 & 4.3393 & 4.2126 & 4.0277 & 3.8128 \\
7.000 & 2.0555 & 2.9609 & 3.3931 & 3.6459 & 3.7496 & 3.6363 & 3.4675 & 3.2863 \\
8.000 & 1.7866 & 2.5791 & 2.9554 & 3.1830 & 3.2622 & 3.1675 & 3.0208 & 2.8608 \\
9.000 & 1.5689 & 2.2634 & 2.5962 & 2.7984 & 2.8714 & 2.7839 & 2.6552 & 2.5075 \\
10.000 & 1.3802 & 1.9988 & 2.2902 & 2.4781 & 2.5396 & 2.4621 & 2.3552 & 2.2176 \\
12.700 & 1.0130 & 1.4573 & 1.6869 & 1.8307 & 1.8816 & 1.8267 & 1.7532 & 1.6606 \\
13.000 & 0.98104 & 1.4158 & 1.6327 & 1.7756 & 1.8265 & 1.7807 & 1.7090 & 1.6166 \\
15.000 & 0.79730 & 1.1534 & 1.3391 & 1.4644 & 1.5105 & 1.4749 & 1.4251 & 1.3461 \\
20.000 & - & - & - & - & - & - & - & 0.93444 \\
25.000 & - & - & - & - & - & - & - & 0.71183 \\
30.000 & - & - & - & - & - & - & - & 0.57532 \\
35.000 & - & - & - & - & - & - & - & 0.47564 \\
40.000 & - & - & - & - & - & - & - & 0.40846 \\
45.000 & - & - & - & - & - & - & - & 0.34486 \\
50.000 & - & - & - & - & - & - & - & 0.29709 \\
\hline
\end{tabular}


Table A.11. Measured drag magnetic force $(N)$ when $h=7.0 \mathrm{~mm}$

\begin{tabular}{|c|c|c|c|c|c|c|c|c|}
\hline $\begin{array}{l}\text { Gap, } \\
\text { m m }\end{array}$ & $\begin{array}{c}\mathrm{V}=4.55 \\
\mathrm{~m} / \mathrm{s}\end{array}$ & $\begin{array}{c}\mathrm{V}=7.89 \\
\mathrm{~m} / \mathrm{s}\end{array}$ & $\begin{array}{c}\mathrm{V}=10.62 \\
\mathrm{~m} / \mathrm{s}\end{array}$ & $\begin{array}{c}\mathrm{V}=13.32 \\
\mathrm{~m} / \mathrm{s}\end{array}$ & $\begin{array}{c}\mathrm{V}=18.20 \\
\mathrm{~m} / \mathrm{s}\end{array}$ & $\begin{array}{c}\mathrm{V}=24.15 \\
\mathrm{~m} / \mathrm{s}\end{array}$ & $\begin{array}{c}\mathrm{V}=30.10 \\
\mathrm{~m} / \mathrm{s}\end{array}$ & $\begin{array}{c}\mathrm{V}=36.10 \\
\mathrm{~m} / \mathrm{s}\end{array}$ \\
\hline 5.000 & 2.4131 & 3.5329 & 4.0949 & 4.4551 & 4.6617 & 4.6124 & 4.4564 & 4.2658 \\
\hline 6.000 & 2.3374 & 3.4004 & 3.9352 & 4.2630 & 4.4429 & 4.3721 & 4.2004 & 4.0160 \\
\hline 7.000 & 2.2673 & 3.2988 & 3.8024 & 4.1042 & 4.2653 & 4.1765 & 4.0084 & 3.8195 \\
\hline 8.000 & 2.2186 & 3.2060 & 3.6976 & 3.9909 & 4.1253 & 4.0257 & 3.8568 & 3.6667 \\
\hline 9.000 & 2.1715 & 3.1380 & 3.6068 & 3.8878 & 4.0121 & 3.9046 & 3.7416 & 3.5404 \\
\hline 10.000 & 2.1342 & 3.0766 & 3.5359 & 3.8045 & 3.9206 & 3.8075 & 3.6456 & 3.4514 \\
\hline 12.700 & 2.0487 & 2.9530 & 3.3947 & 3.6450 & 3.7452 & 3.6279 & 3.4661 & 3.2807 \\
\hline 13.000 & 2.0465 & 2.9492 & 3.3866 & 3.6339 & 3.7346 & 3.6174 & 3.4529 & 3.2693 \\
\hline 15.000 & 2.0084 & 2.8832 & 3.3136 & 3.5574 & 3.6574 & 3.5421 & 3.3874 & 3.1996 \\
\hline 17.000 & - & - & - & - & - & - & - & 3.1612 \\
\hline 20.000 & - & - & - & - & - & - & - & 3.1324 \\
\hline 22.000 & - & - & - & - & - & - & - & 3.1280 \\
\hline 25.000 & - & - & - & - & - & - & - & 3.1244 \\
\hline 26.000 & - & - & - & - & - & - & - & 3.1268 \\
\hline 27.000 & - & - & - & - & - & - & - & 3.1356 \\
\hline 28.000 & - & - & - & - & - & - & - & 3.1439 \\
\hline 29.000 & - & - & - & - & - & - & - & 3.1416 \\
\hline 30.000 & - & - & - & - & - & - & - & 3.1497 \\
\hline 31.000 & - & - & - & - & - & - & - & 3.1568 \\
\hline 32.000 & - & - & - & - & - & - & - & 3.1568 \\
\hline 35.000 & - & - & - & - & - & - & - & 3.1518 \\
\hline 40.000 & - & - & - & - & - & - & - & 2.9977 \\
\hline 45.000 & - & - & - & - & - & - & - & 2.5574 \\
\hline 50.000 & - & - & - & - & - & - & - & 1.8590 \\
\hline
\end{tabular}


Table A.12. Measured drag magnetic force (N) when $h=12.7 \mathrm{~mm}$

\begin{tabular}{rcccccccc}
\hline Gap, & $\mathrm{V}=4.55$ & $\mathrm{~V}=7.89$ & $\mathrm{~V}=10.62$ & $\mathrm{~V}=13.32$ & $\mathrm{~V}=18.20$ & $\mathrm{~V}=24.15$ & $\mathrm{~V}=30.10$ & $\mathrm{~V}=36.10$ \\
$\mathrm{~m} \mathrm{~m}$ & $\mathrm{~m} / \mathrm{s}$ & $\mathrm{m} / \mathrm{s}$ & $\mathrm{m} / \mathrm{s}$ & $\mathrm{m} / \mathrm{s}$ & $\mathrm{m} / \mathrm{s}$ & $\mathrm{m} / \mathrm{s}$ & $\mathrm{m} / \mathrm{s}$ & $\mathrm{m} / \mathrm{s}$ \\
\hline 5.000 & 1.3715 & 2.0218 & 2.3827 & 2.6163 & 2.7915 & 2.8030 & 2.7596 & 2.6502 \\
6.000 & 1.2988 & 1.9054 & 2.2245 & 2.4369 & 2.5863 & 2.5708 & 2.5234 & 2.4080 \\
7.000 & 1.2261 & 1.7999 & 2.0951 & 2.2932 & 2.4162 & 2.3824 & 2.3231 & 2.2141 \\
8.000 & 1.1730 & 1.7116 & 1.9946 & 2.1750 & 2.2757 & 2.2347 & 2.1749 & 2.0624 \\
9.000 & 1.1283 & 1.6430 & 1.9075 & 2.0744 & 2.1626 & 2.1101 & 2.0519 & 1.9459 \\
10.000 & 1.0857 & 1.5840 & 1.8357 & 1.9908 & 2.0695 & 2.0165 & 1.9469 & 1.8411 \\
12.700 & 1.0074 & 1.4657 & 1.6939 & 1.8303 & 1.8864 & 1.8246 & 1.7553 & 1.6566 \\
13.000 & 1.0024 & 1.4542 & 1.6756 & 1.8171 & 1.8685 & 1.8045 & 1.7324 & 1.6420 \\
15.000 & 0.96331 & 1.3938 & 1.6080 & 1.7374 & 1.7872 & 1.7157 & 1.6522 & 1.5528 \\
20.000 & - & - & - & - & - & - & - & 1.4401 \\
25.000 & - & - & - & - & - & - & - & 1.3995 \\
30.000 & - & - & - & - & - & - & - & 1.3726 \\
35.000 & - & - & - & - & - & - & - & 1.3360 \\
40.000 & - & - & - & - & - & - & - & 1.2283 \\
45.000 & - & - & - & - & - & - & - & 1.0341 \\
50.000 & - & - & - & - & - & - & - & 0.77217 \\
\hline
\end{tabular}


Table A.13. Measured lift and drag magnetic force (N) for guidance magnet

\begin{tabular}{cllllll}
\hline $\begin{array}{c}\text { Velocity, } \\
\mathrm{m} / \mathrm{s}\end{array}$ & $\begin{array}{l}\text { Lift, } \mathrm{h}= \\
8.5 \mathrm{~mm}\end{array}$ & $\begin{array}{l}\text { Lift, } \mathrm{h}= \\
13.5 \mathrm{~mm}\end{array}$ & $\begin{array}{l}\text { Lift, } \mathrm{h}= \\
18.5 \mathrm{~mm}\end{array}$ & $\begin{array}{l}\text { Drag, } \mathrm{h}= \\
8.5 \mathrm{~mm}\end{array}$ & $\begin{array}{l}\text { Drag, } \mathrm{h}= \\
13.5 \mathrm{~mm}\end{array}$ & $\begin{array}{l}\text { Drag, } \mathrm{h}= \\
18.5 \mathrm{~mm}\end{array}$ \\
\hline 0.000 & 0.0000 & 0.0000 & 0.0000 & 0.0000 & 0.0000 & 0.0000 \\
2.000 & 0.030830 & 0.015949 & 0.0090586 & 0.18331 & 0.091968 & 0.051258 \\
4.000 & 0.11647 & 0.059970 & 0.033941 & 0.34709 & 0.17321 & 0.096164 \\
6.000 & 0.24052 & 0.12299 & 0.069256 & 0.47963 & 0.23748 & 0.13110 \\
8.000 & 0.38513 & 0.19534 & 0.10934 & 0.57870 & 0.28387 & 0.15566 \\
10.000 & 0.53638 & 0.26971 & 0.15002 & 0.64827 & 0.31484 & 0.17142 \\
12.000 & 0.68549 & 0.34172 & 0.18889 & 0.69452 & 0.33391 & 0.18051 \\
14.000 & 0.82778 & 0.40921 & 0.22484 & 0.72344 & 0.34439 & 0.18489 \\
16.000 & 0.96118 & 0.47138 & 0.25753 & 0.73993 & 0.34890 & 0.18607 \\
18.000 & 1.0852 & 0.52820 & 0.28704 & 0.74769 & 0.34938 & 0.18516 \\
20.000 & 1.1999 & 0.57995 & 0.31361 & 0.74940 & 0.34718 & 0.18290 \\
22.000 & 1.3061 & 0.62709 & 0.33755 & 0.74696 & 0.34325 & 0.17982 \\
24.000 & 1.4043 & 0.67010 & 0.35916 & 0.74172 & 0.33823 & 0.17626 \\
26.000 & 1.4953 & 0.70943 & 0.37873 & 0.73462 & 0.33256 & 0.17245 \\
28.000 & 1.5799 & 0.74551 & 0.39652 & 0.72633 & 0.32656 & 0.16854 \\
30.000 & 1.6587 & 0.77871 & 0.41274 & 0.71731 & 0.32041 & 0.16464 \\
32.000 & 1.7323 & 0.80935 & 0.42760 & 0.70789 & 0.31426 & 0.16080 \\
34.000 & 1.8011 & 0.83773 & 0.44124 & 0.69831 & 0.30820 & 0.15708 \\
36.000 & 1.8657 & 0.86408 & 0.45383 & 0.68872 & 0.30229 & 0.15348 \\
38.000 & 1.9265 & 0.88863 & 0.46547 & 0.67923 & 0.29656 & 0.15004 \\
40.000 & 1.9837 & 0.91156 & 0.47628 & 0.66993 & 0.29104 & 0.14675 \\
\hline
\end{tabular}




\section{Distribution for ANL-96/18}

\section{Internal}

Y. Cai (20)

R. D. Carlson

S. S. Chen (20)

H. T. Coffey

H. Drucker

J. L. $\mathrm{He}$

J. R. Hull

L. R. Johnson

C. A. Malefyt
T. M. Mulcahy

R. B. Poeppel

D. M. Rote (50)

W. J. Shack

R. A. Valentin

M. W. Wambsganss (3)

Z. Wang

R. W. Weeks

TIS Files

\section{External}

DOE-OSTI for distribution per UC-1500 (355)

ANL Libraries

ANL-E

ANL-W

Manager, Chicago Field Office, DOE

Director, Technology Management Div., DOE-CH

D. L. Bray, DOE-CH

T. Crawford, DOE-CH

Energy Technology Division Review Committee:

H. K. Birnbaum, University of Illinois, Urbana

R. C. Buchanan, University of Cincinnati, Cincinnati, $\mathrm{OH}$

S.-N. Liu, Fremont, CA

H. S. Rosenbaum, Fremont, CA

R. K. Shah, University of Kentucky, Lexington

S. Smialowska, Ohio State University, Columbus

R. E. Smith, Altran Corp., Huntersville, NC

J. S. Coleman, DOE, Washington, DC

D. Frederick, DOE, Washington, DC

J. T. Harding, DOT, Washington, DC

O. P. Manley, DOE, Washington, DC

F. C. Moon, Cornell University, Ithaca, NY

R. D. Thornton, Massachusetts Institute of Technology, Cambridge, MA

D. N. Wormley, Pennsylvania State University, University Park, PA 